\author{
UNIVERSIDADE DE SÃO PAULO \\ FACULDADE DE CIÊNCIAS FARMACÊUTICAS \\ Programa de Pós-Graduação em Fármaco e Medicamentos \\ Área de Insumos Farmacêuticos
}

\title{
Planejamento, síntese e avaliação biológica de derivados pirrólicos com potencial atividade antiinflamatória
}

\section{Camila Garcel Pancote}

Tese para obtenção do grau de Doutor

Orientador: Prof. Dr. Carlos Alberto Brandt

São Paulo

2009 


\section{Camila Garcel Pancote}

\section{Planejamento, síntese e avaliação biológica de derivados pirrólicos com potencial atividade antiinflamatória}

Tese apresentada a Faculdade de Ciências Farmacêuticas da Universidade de São Paulo (FCFUSP) para obtenção do grau de Doutor em Fármaco e Medicamentos

São Paulo 2009 


\section{Camila Garcel Pancote}

\section{Planejamento, síntese e avaliação biológica de derivados pirrólicos com potencial atividade antiinflamatória}

Comissão Julgadora

da

Tese para obtenção do grau de Doutor

Prof. Dr. Carlos Alberto Brandt orientador/presidente

\begin{tabular}{l}
\hline $1^{\circ} \cdot$ examinador \\
\hline $2^{\circ} \cdot$ examinador \\
\hline $3^{\circ} \cdot$ examinador \\
\hline $4^{\circ} \cdot$ examinador
\end{tabular}

São Paulo, fevereiro, 2009 
“Os ventos que às vezes tiram algo que amamos, são os mesmos que trazem algo que aprendemos a amar. Por isso não devemos chorar pelo que nos foi tirado e sim, aprender a amar o que nos foi dado. Pois tudo aquilo que é realmente nosso, nunca se vai para sempre” 
Agradeço a Deus pela vida e oportunidades concedidas, sem Ele não teria conseguido!

Agradeço à minha mãe Malena, que amo muito e dedico este trabalho a ela, por nunca ter medido esforços para me ajudar a alcançar os meus sonhos. Meus sinceros agradecimentos pelo exemplo de vitória e perseverança...

Ao meu pai José Pancote e à minha querida avó, Bia (in memorian) que contribuíram significativamente para essa conquista. Obrigada por tudo que fizeram por mim... Nunca me esquecerei de vocês!...

Agradeço também ao meu noivo Matheus pela compreensão, companheirismo, amizade e amor nos momentos dificeis dessa caminhada e por fazer dos momentos bons, melhores ainda... Você me faz muito feliz, te amo!!! 
Ao meu orientador Brandt, agradeço pelo apoio, confiança, paciência, amizade e à alegria durante todos esses anos de convívio. Sou inteiramente grata por essa orientação, bem como o imenso carinho nos momentos de dificuldade... 
Talvez esta Tese seja o resultado mais visível desse processo de construção em meio a uma conjuração de afetos e amizades. Dessa forma, dando continuidade à história, dedico algumas palavras àqueles que dela fazem parte direta ou indiretamente ou, ainda, pelo fato de simplesmente existirem:

- Mané, Be e Matheusinho, agradeço à atenção e à compreensão pela distância e ausência em alguns momentos... Vocês são muito importantes na minha vida!

- A essa família maravilhosa que Deus colocou em minha vida, meu sogro Mariano, minha sogra Maria Helena, minha cunhada Érika, Dri e Rafa, pela força e amizade...Muito obrigada!!!

- Às minhas amigas Carol, Déia, Lili, Fê, Raquel, Cris, pelo carinho. Com certeza, amigas, sem essa cumplicidade e companheirismo teria sido mais difícil. Meu muitíssimo obrigado pelas múltiplas e inestimáveis contribuições;

- Ao Professor "Xuds", um grande amigo... Agradeço a oportunidade e atenção prestada durante todos esses anos, sem sua força teria sido impossível;

- À Vanessa, sou eternamente grata pela solicitude na realização dos ensaios biológicos, bem como pelo cuidado e zelo com que lidou com meu trabalho;

- À Kerly, agradeço as ricas sugestões a esse trabalho, assim como sua dedicação e paciência quando precisei;

- À Profa Dayse, agradeço pelo espaço cedido em seu Laboratório!

- Agradeço imensamente ao Prof. Mauricio pela gentileza e simpatia, por ter tornado os obstáculos menores...

- Não poderia deixar de mencionar minhas estagiárias e amigas Cibele e Valéria, que tornou meu cotidiano mais leve, graças ao entusiasmo e boa vontade; 
- Aos colegas de trabalho Bruno, Bigui, Mimi, Lucas, Décio, Kátia Bee, Dani, Charles, Gustavo, Roberto, Geanine, Vanessa, Carol, obrigada pelo convívio e companheirismo, em especial agradeço ao meu amigo Jõao Paulo pela prestimosa e indispensável colaboração;

- Gostaria de agradecer, em especial a Profa Elizabeth Igne, referência profissional, sou imensamente grata pelo incentivo, contribuindo para esta concretização. Você foi indispensável;

- Aos amigos que tornaram meus dias mais agradáveis e com toda certeza muito mais alegres: Tião, Alonso, Tostão;

- À Prof. Elfi, sempre tão simpática e doce, meus sinceros agradecimentos;

-Não posso deixar de dedicar esse trabalho a uma pessoa muito especial: a sempre Profa Maria Amélia, exemplo de garra e determinação;

Finalmente agradeço a todas as pessoas que fizeram parte dessa conquista... 
Planejamento, síntese e avaliação biológica de derivados pirrólicos com potencial atividade antiinflamatória

Resumo

Os antiinflamatórios não-esteróides (AINEs) estão entre os fármacos mais prescritos e utilizados do mundo. Estes fármacos inibem as ciclooxigenases, enzimas responsáveis pela transformação do ácido araquidônico em prostaglandinas flogísticas, pela ação da fosfolipase $\mathrm{A}_{2}$. A síntese de compostos antiinflamatórios contendo núcleo pirrólico em suas estruturas vem sendo um tópico muito atrativo e bastante estudado, que somado ao conhecimento do sítio de interação do fármaco ao receptor possibilita o planejamento de estruturas de novas substâncias candidatas a protótipos de novos fármacos, por meio da modificação molecular. Nesse contexto, o presente trabalho teve como objetivo o planejamento, síntese e avaliação biológica de derivados pirrólicos com potencial atividade antiinflamatória, com base nas estruturas da indometacina, protótipo da classe dos derivados de ácido arilalcanóico e dos diarilheterociclos (COXIBES). Sendo assim, foram obtidos cinco compostos em rendimentos satisfatórios, a partir de acetoacetato de etila, via metodologia de Hantzsch e ciclofuncionalização, utilizando ultrassom, que resultou na redução do tempo de reação e do consumo de solvente, seguindo os princípios da Química Verde. Os compostos 5a e 5b mostraram-se promissores, a partir de ensaios "in vitro".

Palavras-chave: Pirrol. Betaenaminoéster. Ciclofuncionalização. Ultrassom 
Design, synthesis and evaluation of biological derivatives pyrroles potentially antiinflamatory activity

\section{Abstract}

The nonsteroidal antiinflammatory drugs (NSAIDs) are among the most prescribed and used drugs in the world. These drugs inhibit the cyclooxygenases, enzymes responsible for conversion of arachidonic acid into phlogistic prostaglandins, by the action of phospholipase $\mathrm{A}_{2}$. The synthesis of compounds containing pyrrole nucleus in their structures has been a topic very attractive and well studied, that knowledge added to the site of interaction of the drug to the receptor enables the planning of new structures of substances candidates for prototypes of new drugs through of molecular modification. In this context, this work aimed at the design, synthesis and biological evaluation of pyrrole derivatives with potential antiinflammatory activity, based on the structures of indomethacin, the prototype of arylalkanoic acid class and diarylheterocycles (coxibs). Thus, five compounds were obtained in good yields from ethyl acetoacetate, route of Hantzsch and cyclofunctionalization methods, using ultrasound, which resulted in the reduction of the reaction time and consumption of solvent, following the principles of Green Chemistry. The $5 \mathrm{a}$ and $5 \mathrm{~b}$ compounds were shown to be promising, from tests in vitro.

Key-words: Pyrrol. Betaenaminoester. Cyclofuncionalization. Ultrasound. 
SUMÁRIO

CAPÍTULO 1 - APRESENTAÇÃO

Pág.

1.1. INTRODUÇÃO 14

1.2. OBJETIVOS E JUSTIFICATIVA 16

CAPÍTULO 2 - REVISÃO BIBLIOGRÁFICA 21

2.1. REVISÃO BIBLIOGRÁFICA 22

2.1.1. Processo Inflamatório 22

2.1.1.2. COX: alvo biológico dos AINEs 24

2.1.1.3. Influência da $\mathrm{PGE}_{2}$ no Processo Inflamatório 27

2.1.2. Antiinflamatórios não-esteróides (AINEs) 29

2.1.3. Planejamento de Fármacos $\quad 34$

2.1.3.1. Análogos da indometacina potencialmente antiinflamatórios 36

2.1.3.2. Planejamento sintético de derivados pirrólicos 41

2.1.3.3. Síntese de enaminas 45

2.1.4. Uso do ultrassom no contexto da Química Verde 50

CAPÍTULO 3 - PARTE EXPERIMENTAL 52

3.1. MATERIAL 53

3.2. METODOLOGIA SINTÉTICA 55

3.3. MÉTODOS ANALÍTICOS 61

3.4. AVALIAÇÃO BIOLÓGICA 62

CAPÍTULO 4 - RESULTADOS E DISCUSS ÃO 65

4.1. RESULTADOS E DISCUSSÃO 66

4.1.1. Parte Experimental: Síntese Orgânica 66

4.1.1.1. Obtenção do 2-acetil-pent-4-enoato de etila (2) 66

4.1.1.2. -enaminoésteres (3a, 3b, 4a, $\mathbf{4 b}, \mathbf{e} \mathbf{4 c})$ 
4.1.1.3. Derivados pirrólicos obtidos via metodologia de Hantzsch (5a-b) 75

4.1.1.3.1. 1-benzil-2-metil-5-fenil-1H-pirrol-3-carboxilato de etila (5a) 76

4.1.1.3.2. 1-hexil-2-metil-5-fenil-1Hpirrol-3-carboxilato de etila (5b) 80

4.1.1.4. Derivados pirrólicos obtidos via Ciclofuncionalização (7a, 7b e 7c) 91

4.1.1.4.1. 1-benzil-2,5-dimetil-1H-pirrol-3-carboxilato de elila (7a) 92

4.1.1.4.2. 1-fenil-2,5-dimetil-1H-pirrol-3-carboxilato de elila (7b) 96

4.1.1.4.3. 1-hexil-2,5-dimetil-1H-pirrol-3-carboxilato de elila (7c) 98

$\begin{array}{ll}\text { 4.1.2. Parte Experimental Biológica } & 100\end{array}$

CAPÍTULO 5 - CONCLUSÃO 109

5.1. CONCLUSÃO 110

CAPÍTULO 6 - REFERÊNCIAS BIBLIOGRÁFICAS

6.1. REFERÊNCIAS BIBLIOGRÁFICAS 113 
CAPÍTULO 1

APRESENTAÇÃO

$\overline{=}$




\subsection{INTRODUÇÃO}

A resposta inflamatória foi descrita a cerca de 2 mil anos atrás e ainda é objeto de grande interesse em pesquisas, umas vez que serve como base para o conhecimento do mecanismo de inúmeras doenças, dentre elas asma brônquica, artrite reumatóide, aterosclerose, Alzheimer e câncer (PORTH, 2007; YAQUB et al., 2008).

Inúmeros estímulos químicos ou mecânicos nos tecidos tais como invasão por microorganismos, traumas cirúrgicos ou injúria do tecido, podem desencadear a liberação de mediadores químicos endógenos, que levam ao surgimento dos sinais característicos do processo inflamatório, tais como dor, calor, tumor e rubor (BURKE et al., 2006; SERHAN et al., 2008).

A inflamação pode ser dividida em aguda ou crônica. A inflamação aguda é, relativamente, de curta duração, se estendendo por minutos ou dias, caracterizando-se pela exsudação de fluidos e componentes do plasma e migração leucocitária. Já a inflamação crônica possui duração mais longa, persistindo por dias ou até anos e é associada com a presença de linfócitos e macrófagos, proliferação de vasos sanguíneos, fibrose e necrose tissular. A forma comumente apresentada é uma associação das duas, porém inúmeros fatores podem influenciar este curso (GORDON, 2007; PORTH, 2007; SERHAN et al., 2008).

Ainda assim, o processo inflamatório é considerado mecanismo de defesa do organismo, frente a estímulos nocivos, entretanto pode se tornar exagerado e persistente sem qualquer benefício aparente, sendo necessária a utilização dos fármacos antiinflamatórios a fim de controlar os sintomas (BUSCARIOLO, 2004; BURKE et al., 2006).

Os fármacos antiinflamatórios diferenciam-se em duas classes distintas: os esteróides (corticosteróides) e os não-esteróides (AINEs), que serão abordados nesse trabalho.

Os antiinflamatórios não esteróides (AINEs) suprimem o processo inflamatório pela inibição das ciclooxigenases, impedindo a síntese de prostaglandinas. Estes constituem um grupo heterogêneo de fármacos, sendo a maioria, ácidos orgânicos com ação analgésica, antipirética e antiinflamatória. São os medicamentos mais vendidos em todo o mundo, prescritos ou não por médicos e, em conjunto com os analgésicos e antitérmicos, correspondem a aproximadamente 30\% dos medicamentos utilizados (HILÁRIO et al., 2006, BORNE et al., 2008). 
Segundo a Associação Americana de Reumatologia, dentre todas as doenças crônicas existentes, as doenças reumáticas são as que mais afetam os indivíduos, principalmente mulheres e os AINEs são os fármacos de escolha no alívio dos sintomas dessas doenças, a fim de assegurar a qualidade de vida dos pacientes (BURKE et al., 2006; BORNE, 2008).

A indometacina, fármaco derivado de ácido arilalcanóico, foi introduzida no mercado em 1965, para o tratamento da artrite reumatóide e doenças similares. Apesar de possuir efeitos indesejáveis, principalmente ao nível gastrintestinal, este AINE é considerado muito eficaz. Sua atividade farmacológica se dá pelo bloqueio das enzimas ciclooxigenases, impedindo a biossíntese das prostaglandinas (KOROLKOVAS. 1988; BURKE et al., 2006; BORNE, 2008).

A atividade farmacológica dos AINEs se dá pelo bloqueio das enzimas ciclooxigenases 1 e 2 em diferentes graus de seletividade. Essas enzimas diferenciam-se por apenas dois resíduos de aminoácidos, mais especificamente, a substituição do aminoácido isoleucina (Ile), nas posições 434 e 523, presentes na COX-1, pelo aminoácido valina (Val), na COX-2. O reconhecimento das diferenças morfológicas entre as duas isoformas da enzima ciclooxigenase (COX-1 e COX-2), permitiu prever a possibilidade de se desenvolver inibidores seletivos da COX-2, conhecidos como coxibes, como estratégia para obter-se efeito antiinflamatório desprovido de efeitos colaterais ao nível gatrintestinal, além da ocorrência de efeitos adversos ao nível renal e cardiovascular (BORNE, et al., 2008; MARNETT, KALGUTKAR, 1998; SIMON, 1999; SALTER et al., 2001; PDB, 2003). Segundo Khan e colaboradores (2002), a COX-2 é também uma enzima constitutiva, expressa em regiões glomerulares e pequenos vasos sanguíneos nos rins dos primatas, incluindo os humanos.

A modificação molecular no planejamento de antiinflamatórios tem sido largamente aplicada a fim de obterem-se novos fármacos com maior potência e principalmente desprovidos de efeitos colaterais, tais como efeitos gastrintestinais e hematológicos, característicos dos antiinflamatórios clássicos empregados na terapêutica. A obtenção desses fármacos tornou-se mais eficiente graças à síntese orgânica, que atualmente representa um autêntico desafio para aqueles que possuem a arte de sintetizar moléculas e contribui para a descoberta de novas metodologias (BLACK et al., 1996; BARREIRO et al., 2002; MARTIC et al., 2004; SHIN et al., 2004; BORNE, 2008). 
A síntese de compostos antiinflamatórios contendo núcleo pirrólico em suas estruturas é considerada um tópico muito atrativo e bastante estudado. Inúmeros derivados pirrólicos, seja de origem natural ou sintética, foram testados com sucesso em determinadas doenças, incluindo a inflamação (LEHUÉDÉ et al., 1999; DEMIR et al., 2002; RANU E DEY, 2003; MINETTO et al., 2004; BIAVA et al., 2005; DEMIR, EMRULLAHOGLU, 2005; BIAVA et al., 2007; ATTANASI et. al., 2008; DAVIS, et. al., 2008; FAN, et. al., 2008).

Preconizam-se, então, modificações na estrutura de fármacos já existentes visando à melhora de propriedades físico-químicas, eficácia e redução no custo de sua produção. Frente ao exposto e movido pela polêmica em relação aos efeitos colaterais em torno dos AINEs, este trabalho engloba o planejamento, inspirado na elevada potência antiinflamatória da indometacina, somado à vantajosa seletividade dos diarilheterociclos (COXIBES), a síntese e avaliação biológica de novos protótipos, candidatos a fármacos antiinflamatórios, contendo núcleo pirrólico em suas estruturas. Para tal, o processo de modificação molecular foi utilizado visando melhorias no perfil farmacológico dos análogos, utilizando metodologias sintéticas simples e de baixo custo, seguindo conceitos de química verde ("green chemistry"), também denominada "Química Limpa" (SILVA et al., 2005; ESCOLA DE QUÍMICA VERDE). Nesse contexto, o ultra-som tem sido bastante utilizado em reações de síntese orgânica e apresenta inúmeras vantagens, tais como: redução do tempo de reação e da quantidade de reagentes e aumento de rendimento e de seletividade, favorecendo reações que normalmente não ocorreriam em condições normais (MARTINES et al., 2000).

\subsection{OBJETIVOS E JUSTIFICATIVA}

Em virtude do grande interesse farmacológico por derivados pirrólicos e sabendo-se que estes podem desempenhar potente atividade antiinflamatória, o principal objetivo desse trabalho foi o planejamento, síntese e avaliação biológica de novos candidatos a protótipos de fármacos potencialmente antiinflamatórios. Processos de modificação molecular, tais como simplificação molecular e modificação de sistemas anelares, foram aplicados às estruturas dos protótipos indometacina, AINE pertencente à classe dos arilalcanóicos e celecoxibe (Celebra®), representado pelo AINE diarilheterociclo seletivo para COX-2 (figura 1). 


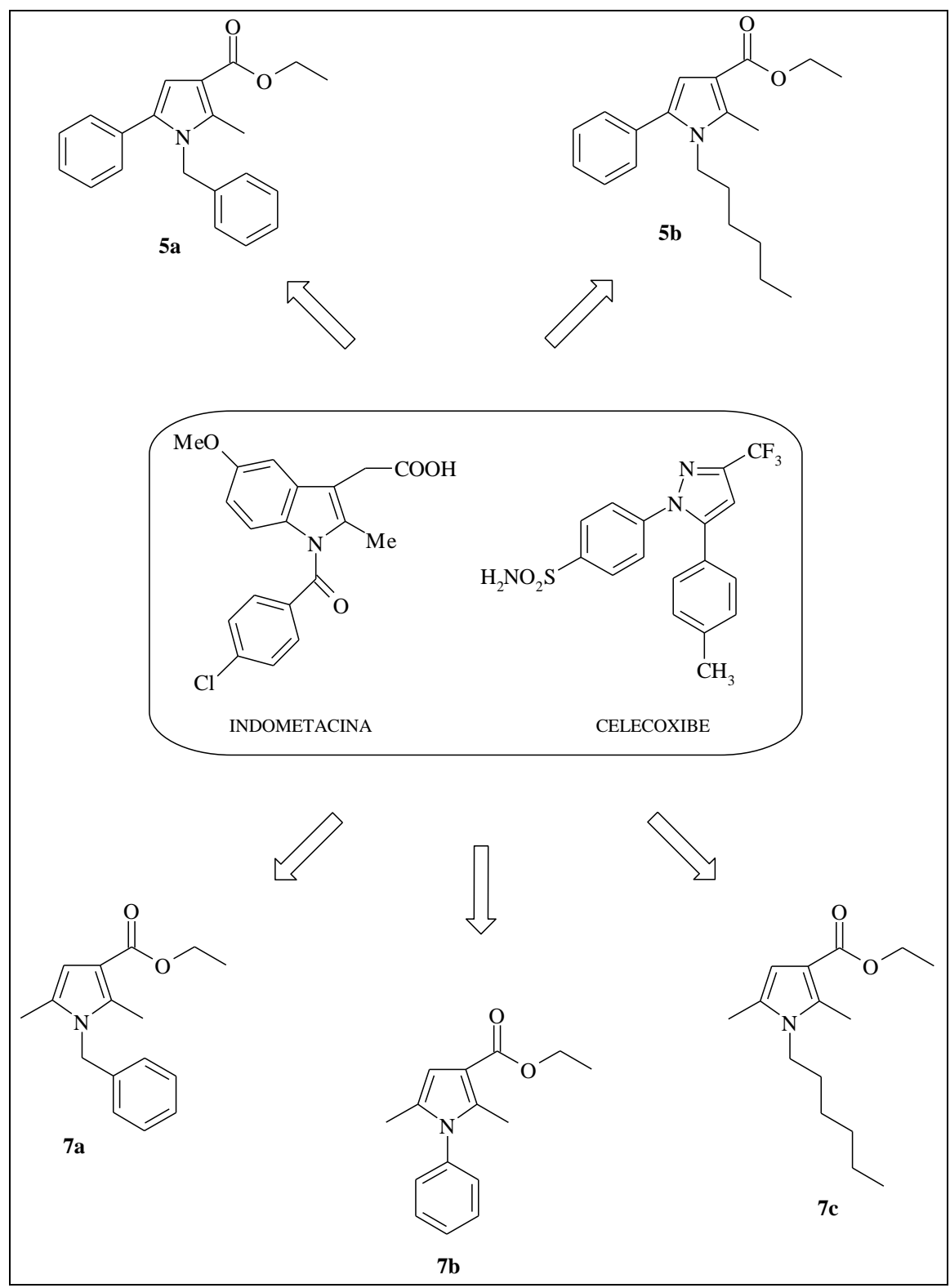

Figura1: Planejamento dos compostos potencialmente antiinflamatórios com base nas estruturas da indometacina e de derivados diarilheterociclos, representados pelo celecoxibe.

No trabalho desenvolvido anteriormente (PANCOTE, 2004), foi realizada a síntese total dos compostos contendo núcleo pirrólico, utilizando a metodologia de Hantzsch (A), descrita por ROOMI e MAcDONALD (1970) para síntese de pirróis. Desse modo, foi possível obter 
derivados de maneira eficiente e direta, partindo de $\beta$-enaminoésteres e $\alpha$-bromocetonas, em apenas uma etapa.

A fim de se obter novos análogos, optou-se também por utilizar uma segunda metodologia (B) descrita por BRANDT e colaboradores (1991), que consiste na iodociclização, seguida de eliminação de derivados de enaminonas, preparadas a partir do acetoacetato de etila, mantendo assim o emprego de reagente de baixo custo, facilmente acessível.

As enaminas de partida, utilizadas nas metodologias A e B foram sintetizadas anteriormente em nosso Laboratório em excelentes rendimentos (BRANDT et al., 2004).

De acordo com o esquema 1, duas metodologias diferentes (A e B) foram utilizadas para síntese dos derivados pirrólicos planejados, a fim de obter compostos de forma eficiente, com rendimento satisfatório e baixo custo.

\section{ESQUEMA 1}

METODOLOGIA A

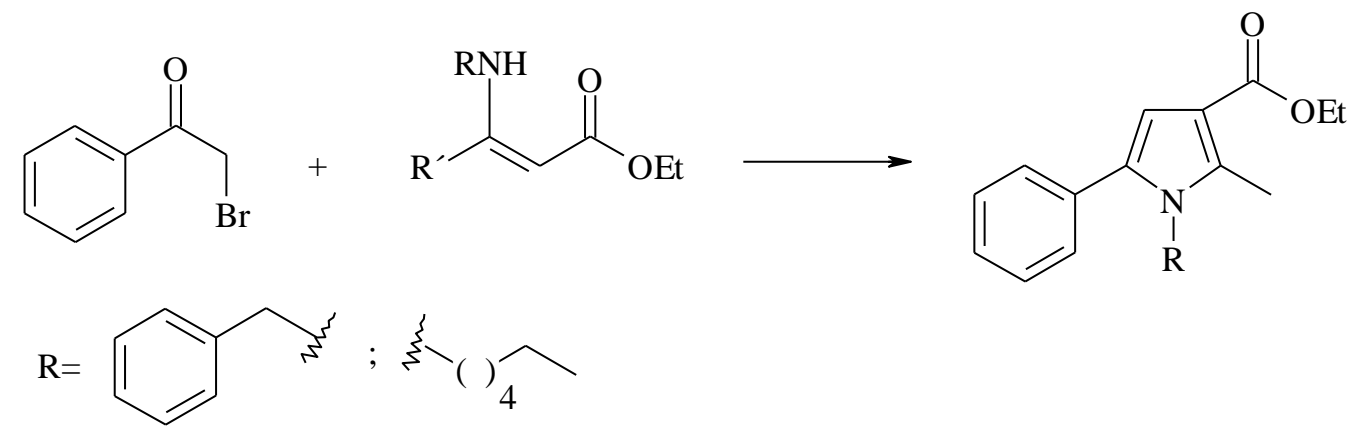

\section{METODOLOGIA B}<smiles></smiles><smiles>[R]=C=C(C)Cc1ccccc1</smiles> 
Para obtenção dos compostos optou-se por utilizar as duas metodologias (Esquema 1) pelo fato da metodologia B, apesar de ser considerada eficiente na obtenção dos derivados pirrólicos, não permite substituintes na posição 5. Já no esquema 2, há a formação de regioisômeros, em que o regioisômero I é o minoritário e o II o majoritário, não se obtendo o núcleo pirrólico desejado.

\section{ESQUEMA 2}

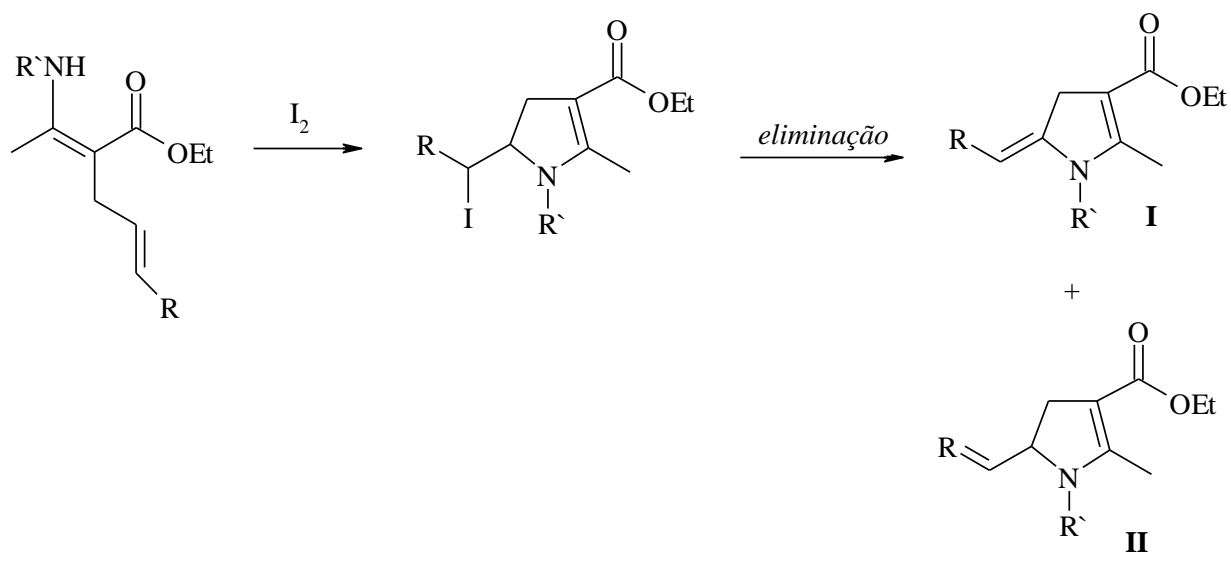

Sendo assim, o esquema 1 mostrou-se promissor por meio da metodologia de Hantzsch (A). Foi possível modificar o substituinte da posição 5, além de apresentar como vantagem o fato da enamina ser facilmente obtida a partir do acetoacetato de etila.

Diante do planejamento exposto, foi possível obter análogos mais simples e promissores no contexto dos AINEs, fato este constatado após a realização de ensaios biológicos "in vivo" e “in vitro". De acordo com literaturas recentes (BIAVA et al., 2005; BIAVA et al., 2007; BIAVA et al. 2008), derivados de éster da indometacina mostraram-se potencialmente antiinflamatórios, em inúmeros ensaios “in vitro”. Sendo assim, os compostos planejados realmente poderiam desempenhar potente atividade antiinflamatória, uma vez que estão de acordo com requisitos de relação estrutura química-atividade biológica (REA) da classe de fármacos arilalcanóicos, que relata a importância da presença de um centro aromático ou heteroaromático ligado a um grupo de alta densidade eletrônica, representado na maioria dos AINEs por ácido carboxílico. Pelo fato dos compostos sintetizados não possuírem grupos ácidos livres, que, anteriormente acreditava-se ser essencial para a ação antiinflamatória, estes novos análogos de ésteres podem ser menos tóxicos à mucosa gástrica (LÚCIO et al., 2008). Este grupamento pode ainda sofrer hidrolise “in 
vivo”, e desempenhar atividade antiinflamatória também nessa forma. Seria então denominado: híbrido análogo pró-fármaco.

Espera-se que compostos sintetizados nesse trabalho sejam candidatos a fármacos potencialmente antiinflamatórios, sendo úteis como modelos para o estudo das relações entre estrutura química-atividade biológica, ferramenta essencial para o entendimento do mecanismo de ação dos fármacos e sua interação com os respectivos receptores. 
CAPÍTULO 2

REVISÃO BIBLIOGRÁFICA 


\subsection{REVISÃO BIBLIOGRÁFICA}

\subsubsection{Processo Inflamatório}

O processo inflamatório é bastante complexo e envolve grande número de células e mediadores químicos e biológicos. Esses mediadores são produzidos tanto no plasma quanto nas células e eles modificam ou regulam reações vasculares e celulares (BURKE et al., 2006; BORNE et al., 2008).

A inflamação é uma resposta essencial frente a determinados estímulos nocivos, podendo ser localizada ou sistêmica. Ocorre em três fases distintas, mediadas por diferentes mecanismos, que incluem uma fase aguda, caracterizada por vasodilatação local e aumento da permeabilidade capilar, uma fase subaguda, que consiste na infiltração de leucócitos e células fagocitárias e uma fase proliferativa crônica, na qual ocorre degeneração tissular e fibrose (BURKE et al., 2006; BORNE et al., 2008).

Após lesão inicial do tecido ou outro estímulo nocivo ocorre liberação de mediadores pró-inflamatórios, tais como histamina, serotonina, prostaglandinas, bradicinina, entre outros. Também merecem grande importância as citocinas pró-inflamatórias, a interleucina-1 (IL-1) e as interleucinas inflamatórias IL-2, IL-6, IL-8, o fator de necrose tumoral (tumoral necrosis factor TNF), as proteínas de fase aguda (acute phase response - APR), o fator ativador de plaquetas (platelet-activating factor - PAF), o fator complemento C5a e inúmeros outros (BURKE et al., 2006; BORNE et al., 2008; SERHAN et al., 2008).

Uma das causas mais importante da inflamação é o aumento na produção de prostaglandinas (PGs), sintetizadas pelas enzimas ciclooxigenases (COX) após estímulo inflamatório no tecido (SOMVANSHI et al., 2007; SERHAN et al., 2008).

De acordo com a figura 2 este processo se inicia por meio da liberação do ácido araquidônico para célula via hidrólise dos fosfolipídeos de membrana, quando ocorre aumento na concentração intracelular de cálcio que, então, desencadeia uma série de eventos determinantes na ativação da fosfolipase $\mathrm{A}_{2}$. A partir da formação do ácido araquidônico, este sofre metabolização por sistemas enzimáticos distintos: prostaglandina $\mathrm{G}_{2}\left(\mathrm{PGG}_{2}\right)$ e $\mathrm{H}_{2}\left(\mathrm{PGH}_{2}\right)$ sintases. Estas sistemas enzimáticos possuem ciclooxigenases (COX) e hidroperoxidases (HOX) ativas, que catalisam a formação sequiencial de PGs endoperóxidos. Estas, por sua vez, são 
derivadas de ácidos graxos $\left(\mathrm{C}_{20}\right)$ e metabolizadas por isomerases e sintases (ex: PGE sintase), que são expressas em tecidos específicos e originam diferentes PGs capazes de ativar receptores acoplados à proteína $\mathrm{G}$ distintos ( $G$ protein-coupled receptor - GPCR) (MARNETT, KALGUTAR, 1998; SIMON, 1999; GERALD, 2003; SOMVANSHI et al., 2007).

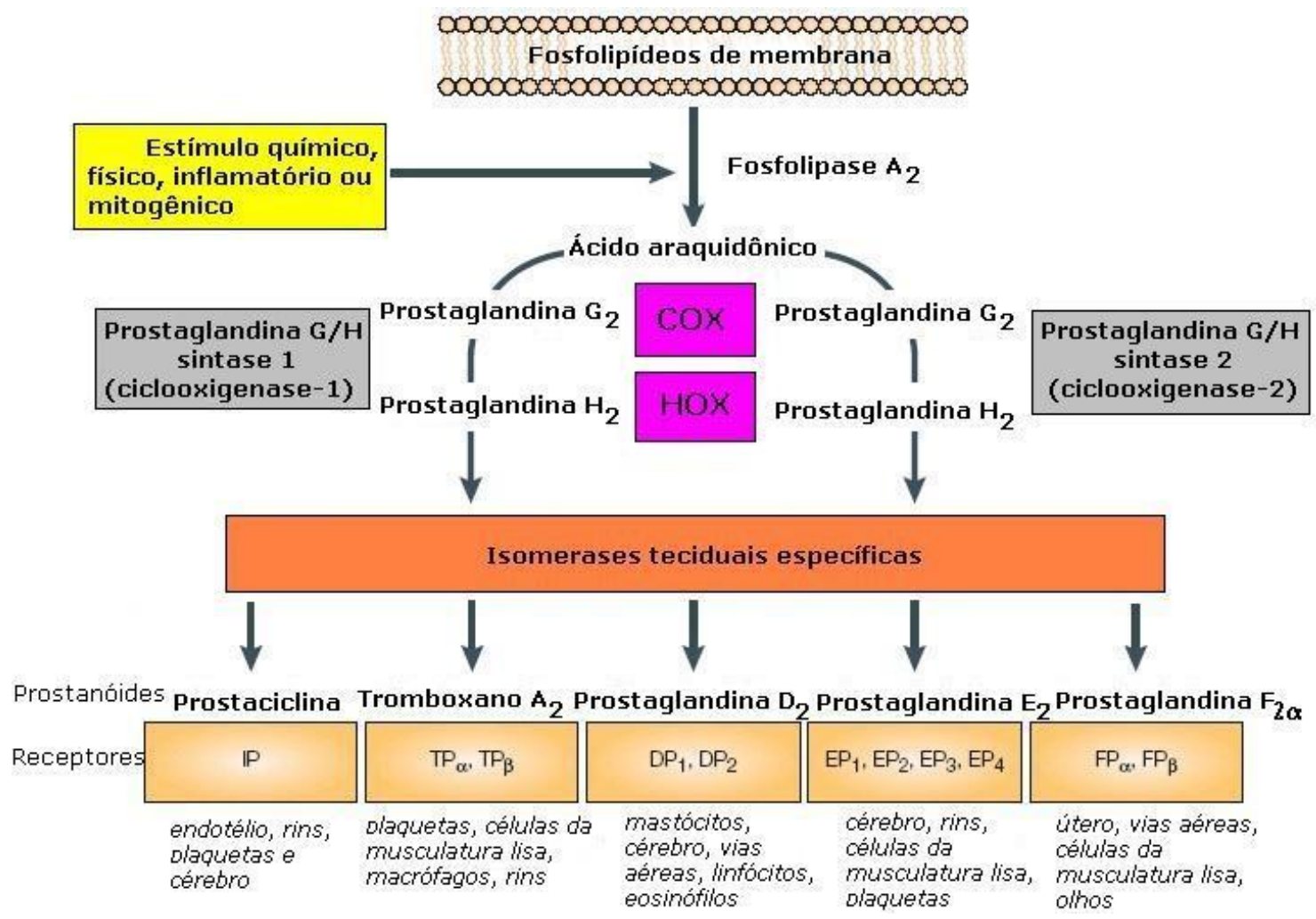

Figura 2: Cascata da biossíntese de PGs. O ácido araquidônico é produzido diante de estímulo físico ou químico não específico por meio da enzima fosfolipase $\mathrm{A}_{2}$, que posteriormente será metabolizado pelas PGG/H sintases diferenciando em inúmeras PGs. Essas ativam receptores acoplados a proteína G derivados de receptores E prostanóides (EP) (Fonte: FITZGERALD, 2003).

Os sinais da inflamação são: dor, tumor, calor e rubor e envolve uma fase vascular e outra celular marcada pelo movimento de células brancas sanguíneas ou leucócitos. Vale ressaltar a importância dos macrófagos, que constituem um dos grupos mais importantes de células fagocitárias de vida longa e compreendem a linhagem fagocítica mononuclear, que inclui os monócitos sanguíneos, os fagócitos residentes nos tecidos ou fixados à camada endotelial de capilares sanguíneos e os fagócitos perambulantes - pulmonares e peritoneais. Os macrófagos exercem funções de defesa no organismo contra infecções e injúrias e possuem papel importante 
na resposta inflamatória. O controle da ativação dessas células é mediado por citocinas, tais como IL-10 e TGF- $\beta$ e metabólitos do ácido araquidônico, como exemplo PGE $_{2}$ (GORDON, 2007; E-SCIENCE, 2008).

\subsubsection{COX: alvo biológico dos AINEs}

Existem dois principais tipos de ciclooxigenases, a ciclooxigenase-1 (COX-1) e a cicooxigenase-2 (COX-2), embora, tenha sido identificada uma terceira isoforma, a ciclooxigenase-3 (COX-3). Esta, por sua vez, é uma variante da COX-1, expressa no cérebro e coração e apresenta a mesma seqüência de aminoácidos da COX-1, porém com trinta aminoácidos extras, codificado pelo intron-1 (CHANDRASEKHARAN et al., 2002; BOTTING, 2003; RAMSAY et al., 2003; SCHWAB et al., 2003; LÚCIO et al., 2008). Segundo Simmons (2003), a COX-3 é enzimaticamente ativa na biossíntese de PGs a partir do ácido araquidônico e apresenta $20 \%$ da atividade da COX-1, quando expressa em células recombinantes de inseto. Atualmente é possível explicar a atividade biológica exercida por determinados fármacos, via inibição da biossíntese de PGs por meio do bloqueio da COX-3 no SNC, tal como o efeito analgésico e antipirético promovido pelo paracetamol (BORNE et al., 2008).

A COX-1 é uma enzima constitutiva, expressa em muitos tecidos e, sob condições fisiológicas, produz PGs necessárias à modulação das funções gastrintestinais, renais e a homeostase vascular. A COX-2, descrita em 1992, está presente, principalmente, no cérebro e medula espinhal. É induzida, em células inflamatórias, tais como fibroblastos, macrófagos,

monócitos e células sinoviais, quando elas são ativadas. É considerada enzima que produz os mediadores da inflamação da classe dos prostanóides. O gene da COX-2 é expresso em resposta a vários agentes pró-inflamatórios, citocinas, endotoxinas, fatores de crescimento e promotores de tumor (CHANDRASEKHARAN et al., 2002; TANIURA et al., 2002; BOTTING, 2003; RAMSAY et al., 2003; SCHWAB et al., 2003; SIMMONS, 2003; SOMVANSHI et al., 2007; YAQUB et. al., 2008).

Segundo Khan e colaboradores (2002), a COX-2 é também uma enzima constitutiva, expressa em regiões glomerulares e pequenos vasos sanguíneos nos rins, confirmando assim sua importância na manutenção das funções fisiológicas cardiovasculares e renovasculares. Sugeriu- 
se, então, que a inibição da COX-2 por AINEs acarretaria efeitos colaterais renais e cardiovasculares (FURBERG et al., 2005; KROTZ et al., 2005; SOMVANSHI et al., 2007). Mais tarde esses efeitos foram comprovados por meio de estudos utilizando roedores tratados com inibidores seletivos de COX-1 e COX-2, resultando em redução da pressão arterial, mediada pela Angiotensina II, com o primeiro grupo e, em contrapartida, o tratamento com inibidores seletivos de COX-2 gerou aumento do efeito pressor da Angiotensina II. Este estudo comprova a hipótese de que as PGs derivadas da COX-2 contribuem para redução da pressão arterial, enquanto que as PGs derivadas da COX-1 contribuem para elevação da pressão arterial (GUAN et al., 2007).

A COX-1 e COX-2 são similares quanto à estrutura tridimensional e atividade enzimática. São proteínas hemodiméricas, contendo grupo heme e apresentam massa molecular de $71 \mathrm{KDa}$. A COX é composta de três domínios independentes: domínio do fator de crescimento epidérmico (epidermal growth factor - EGF) e dois domínios funcionais, o de ligação à membrana (membrane binding domain - MBD) e o catalítico. Este último, o maior deles contém os sítios peroxidase e ciclooxigenase (CHANG, JAHNG, 1998; VANE et al., 1998; SOMVANSHI et al., 2007).

A homologia entre a COX-1 e COX-2 aproxima-se de 90\%. A estrutura tridimensional da COX-2 humana pode ser sobreposta a da COX-1 (figura 3). 


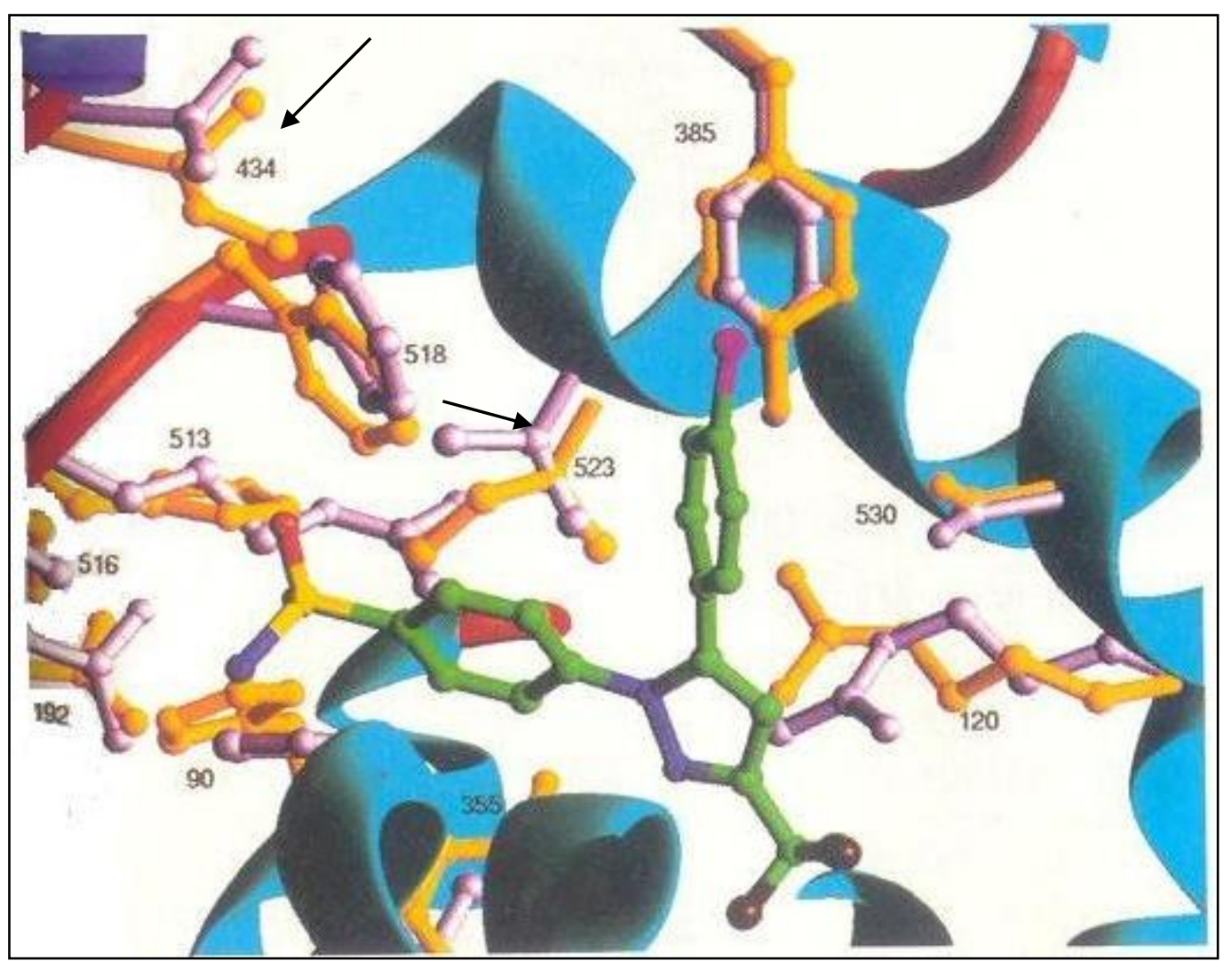

Figura 3. Sítios ativos das enzimas COX-1 e COX-2 sobrepostos. Sobreposição da COX-1 (amarelo) e COX-2 (rosa) e SC-558 (diarilheterociclo - inibidor das ciclooxigenases, com maior seletividade para COX-2).

Acesso restrito na COX-1 devido ao resíduo de isoleucina 523 (Fonte: KURUMBAIL et al., 1996)

Comparando o sítio ativo da COX-1 ao da COX-2, mais especificamente onde ocorre interação com ácido araquidônico ou os respectivos AINEs, foi observado que todos os resíduos de aminoácidos (aa) estão presentes em ambas as enzimas, exceto pela substituição do aminoácido isoleucina (Ile ou I), nas posições 434 e 523, presentes na COX-1, pelo aminoácido valina (Val ou V), na COX-2. Essa diferença poderia levar a alteração no tamanho da cavidade em que se ligariam os fármacos. Diante dessa hipótese, tornou-se possível o planejamento de novas classes de antiinflamatórios não esteróides (AINEs), mais especificamente os derivados diarilheterociclos (COXIBEs) (SIMON, 1999; SALTER et al., 2001; PDB, 2003).

O sítio ativo da COX é formado, principalmente, por resíduos hidrofóbicos e se conecta com a membrana por meio de um extenso canal apolar, que possibilita o acesso dos substratos/inibidores (SOMVANSHI et al., 2007).

Na estrutura co-cristalizada da COX-1, o aminoácido arginina 120 (Arg120), localizado próximo ao canal de entrada da enzima, participa da interação (ligação covalente) com o íon 
carboxilato, presente nos AINEs convencionais. Em contrapartida, este mesmo resíduo não interage com inibidores seletivos da COX-2, permitindo, assim, o avanço na descoberta de novos agentes antiinflamatórios, buscando redução da toxicidade e aumento da seletividade (BHATTACHARYA et al., 1996; LÚCIO et al., 2008).

O reconhecimento das diferenças morfológicas entre as duas isoformas da enzima ciclooxigenase (COX-1 e COX-2) permitiu o desenvolvimento de inibidores seletivos da COX-2, como estratégia para obter-se efeito antiinflamatório desprovido de efeitos colaterais ao nível gatrintestinal (MARNETT, KALGUTKAR, 1998; SALTER et al., 2001; BORNE et al., 2008; LÚCIO et al., 2008).

\subsubsection{Influência da $\mathrm{PGE}_{2}$ no Processo Inflamatório}

Prostaglandinas são metabólitos de ácidos graxos e incluem quatro compostos bioativos, que são: prostaglandina $\mathrm{E}_{2}\left(\mathrm{PGE}_{2}\right)$, prostaglandina $\mathrm{F}_{2 \alpha}\left(\mathrm{PG} \mathrm{F}_{2 \alpha}\right)$, prostaglandina $\mathrm{D}_{2}\left(\mathrm{PGD}_{2}\right) \mathrm{e}$ prostaciclina $\left(\mathrm{PGI}_{2}\right)$. Exercem seus efeitos via receptores acoplados à proteína $\mathrm{G}$ e atuam como potentes mediadores da inflamação, dor e febre e, recentemente foi descoberto seu papel na modulação da pressão arterial e excreção renal de sal (FITZGERALD, 2003; GUAN et al., 2007; HARRAK et al., 2007).

A $\mathrm{PGE}_{2}$ é produzida por células imunes, tais como macrófagos e possui importante papel em inúmeros processos fisiopatológicos, em particular na inflamação. Esta, por sua vez pode ser biossintetizada por meio das enzimas ciclooxigenase-1 (COX-1) e ciclooxigenase -2 (COX-2) a partir do ácido araquidônico. $\mathrm{A} \mathrm{PGE}_{2}$ derivada da COX-2 participa de doenças inflamatórias, incluindo a artrite reumatóide. Estudos têm demonstrado a influência da $\mathrm{PGE}_{2}$ no surgimento e progressão de tumores por meio de estímulo de seus respectivos receptores EP, promovendo assim angiogênese, inibição do apoptose, estímulo da invasão tumoral e supressão das respostas imunes. Estudos epidemiológicos indicaram que a utilização de aspirina® ou outro AINE pode reduzir a incidência de câncer de cólon e reto em, aproximadamente, 50\%. Este efeito é relacionado à redução dos níveis de $\mathrm{PGE}_{2}$ (GEORGE et al., 2007; SHU-JUNG HU et al., 2008; YAQUB et al., 2008). 
Diante da hipótese de que a $\mathrm{PGE}_{2}$ teria influência significativa no mecanismo de resistência a quimioterapia contra o câncer, seria uma excelente estratégia planejar e desenvolver inibidores de $\mathrm{PGE}_{2}$ visando aumentar a eficácia dos agentes quimioterápicos (GEORGE et al., 2007).

Foi observada também sua participação no processo da dor e ativação do fator nuclear NFkB (nuclear factor-kappa B) controlador de inúmeros genes envolvidos na inflamação, assim como seu efeito supressor na liberação de interleucinas (ILs), mais especificamente a IL-5, produzidas pelas células-T e mastócitos e possui funções importantes, tais como estimular o crescimento de determinadas células e promover ativação de eosinófilos (ELSAS et al., 2008; SHU-JUNG HU et al., 2008).

$\mathrm{A} \mathrm{PGE}_{2}$ pode ativar quatro subtipos diferentes de receptores específicos pertencentes à família de receptores acoplados à proteína-G, constituídos de sete domínios transmembrana, designados receptores prostanóides $\mathrm{EP}_{1}, \mathrm{EP}_{2}, \mathrm{EP}_{3}$ e $\mathrm{EP}_{4}$, codificados por diferentes genes, distribuídos em tecidos variados e conseqüentemente exercem ações diferenciadas. Dentre elas, destacam-se a interferência de receptores $\mathrm{EP}_{1}$ no aumento da concentração intracelular de cálcio. Estudos sugerem a participação dos receptores $\mathrm{EP}_{1}$ na manutenção da pressão arterial, uma vez que antagonista desses receptores acarretou na redução da pressão arterial em ratos (GUAN et al., 2007). Os receptores $\mathrm{EP}_{2}$ e $\mathrm{EP}_{4}$ podem promover aumento na concentração de AMP cíclico e $\mathrm{EP}_{3}$ sinaliza a redução na atividade do hormônio que estimula a formação de AMP cíclico. Outras isoformas de receptores $\mathrm{EP}_{3}$ têm sido descritas na literatura (GEORGE et al., 2007; SHUJUNG HU et al., 2008; YAQUB et al., 2008).

$\mathrm{PGE}_{2}$ pode ser produzida em células macrófagicas quando estimuladas por reagentes fisiológicos ou fisiopatológicos, em especial o lipopolissacarídeo (LPS). Nesse contexto, BEZUGLA e colaboradores (2006) relataram que a expressão da COX-2 era significativamente aumentada com adição de LPS ao meio de cultura, principalmente no período superior a 24 horas, o que não ocorreu com a COX-1, já que sua produção foi constante, tanto no período de 8 ou 24 horas, independente da indução com LPS. A concentração de $\mathrm{PGE}_{2}$ foi maior em 24 horas que em 8 horas após acréscimo de LPS ao meio, entretanto a expressão da COX-2 relacionada à produção de $\mathrm{PGE}_{2}$ não está totalmente elucidada. 


\subsubsection{Antiinflamatórios não-esteróides (AINEs)}

Os AINEs constituem a classe de fármacos mais prescritos e utilizados no mundo e consistem no tratamento de primeira escolha em inúmeras patologias como artrite reumatóide, osteoartrite e outras doenças inflamatórias. Esses fármacos apresentam também atividade analgésica e antipirética em sua grande maioria. Sua atividade antiinflamatória ocorre, principalmente, devido ao bloqueio da COX (MARNETT, KALGUTKAR, 1998; SALTER et al., 2001; BIAVA et al., 2007; HARRAK et al., 2007; BORNE et al., 2008; LÚCIO et al., 2008).

Atualmente existem mais de 50 tipos de AINEs disponíveis no mercado, com características individuais, entretanto, em sua grande maioria se ligam às enzimas COX-1 e COX-2, com pequena especificidade, inibindo assim a produção de PGs. Tal inespecificidade acarreta inúmeros efeitos colaterais, que podem ser apontados como lesão gástrica, mais relacionada aos AINEs não-seletivos, que apresentam grupos ácidos em suas estruturas (figura 4), já que a irritabilidade tópica desses agentes deve ser ressaltada. Outros efeitos colaterais são considerados bastante relevantes, tais como toxicidade renal e cardiovascular, cuja ocorrência é significativamente maior com os AINEs inibidores seletivos de COX-2 (BURKE et al., 2006; BIAVA et al., 2007; LÚCIO et al., 2008).

A classificação dos AINEs era realizada de acordo com categorias químicas, porém, com o avanço no desenvolvimento de novos fármacos, inibidores seletivos da COX-2, essa classificação tornou-se mais complexa. A classificação dos AINEs está representada nas tabelas I e II e cada um deles inibe a enzima COX por meio de mecanismos distintos (BURKE et al., 2006; BORNE et al., 2008). 
Tabela I. Classificação dos AINEs não-seletivos

Inibidores não-seletivos da COX

Salicilatos

ácido salicílico, ácido acetilsalicílico, salicilato de sódio, trissalicilato de magnésio e colina, salsalato, diflunisal, sulfassalazina, olsalazina

Derivados do para-aminofenol

paracetamol

Derivados do ácido acético

indometacina, sulindaco e etodolaco

Ácidos heteroaril acéticos

tolmetina, diclofenaco, cetorolaco

Derivados do Ácido Propiônico

flurbiprofeno

ibuprofeno, naproxeno, flurbiprofeno, cetoprofeno, fenoprofeno, oxaprozina,

Ácidos antranílicos (fenamatos)

ácido mefenâmico, ácido meclofenâmico, ácido flufenâmico

Ácidos enólicos (Oxicans)

piroxicam, meloxicam, tenoxicam, sodoxicam, isoxicam, ampiroxicam, droxicam, lornoxicam, cinoxicam

Outros Oxicans

nabumetona

Tabela II. Classificação dos AINEs seletivos para COX-2

Inibidores seletivos da COX -2

Furanonas diaril substituídas

rofecoxibe*

Pirazóis diaril substituídos

celecoxibe

Ácidos indolacéticos

etodolaco

Sulfonilanilidas

nimesulida

Outros coxibes

valdecoxibe, parecoxibe, lumiracoxibe, etoricoxibe

* Registro cancelado (ANVISA) 
Estão representadas as estruturas dos AINEs, inibidores não-seletivos das ciclooxigenases (figura 4) e dos inibidores seletivos da COX-2 (figura 5).

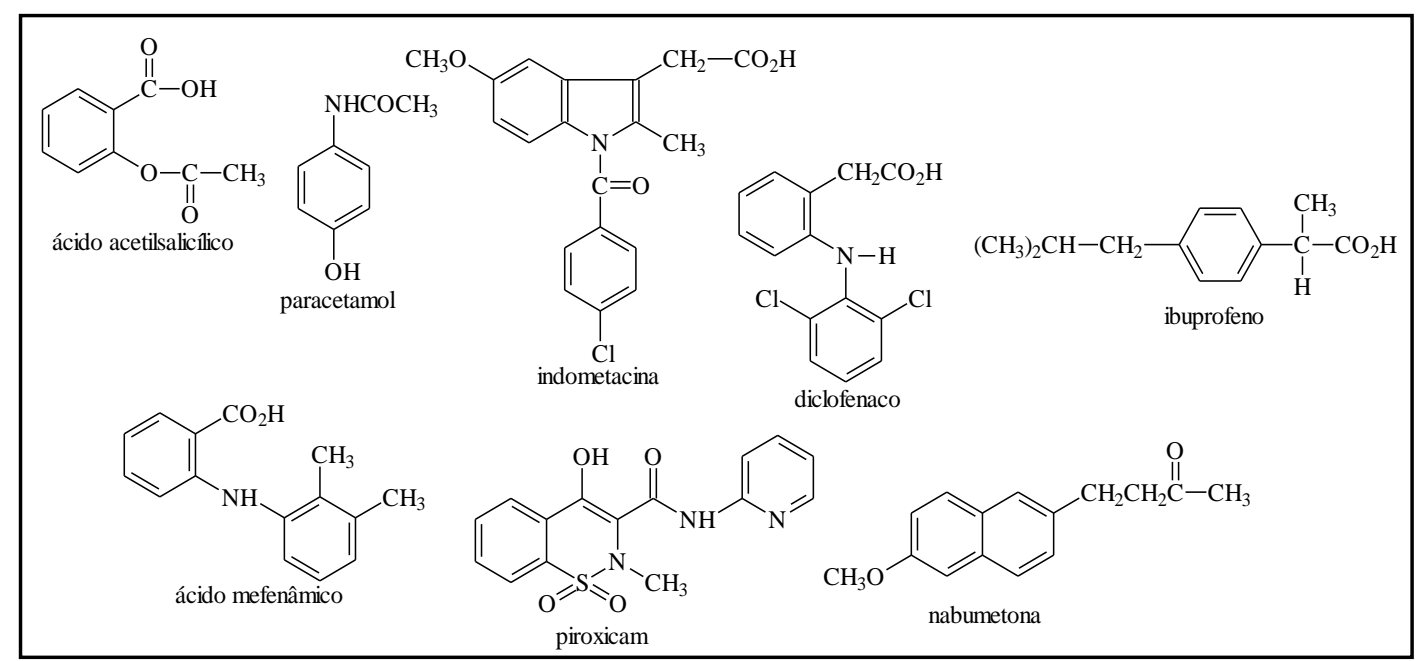

Figura 4. Representação estrutural de alguns dos AINEs inibidores da COX não-seletivos.

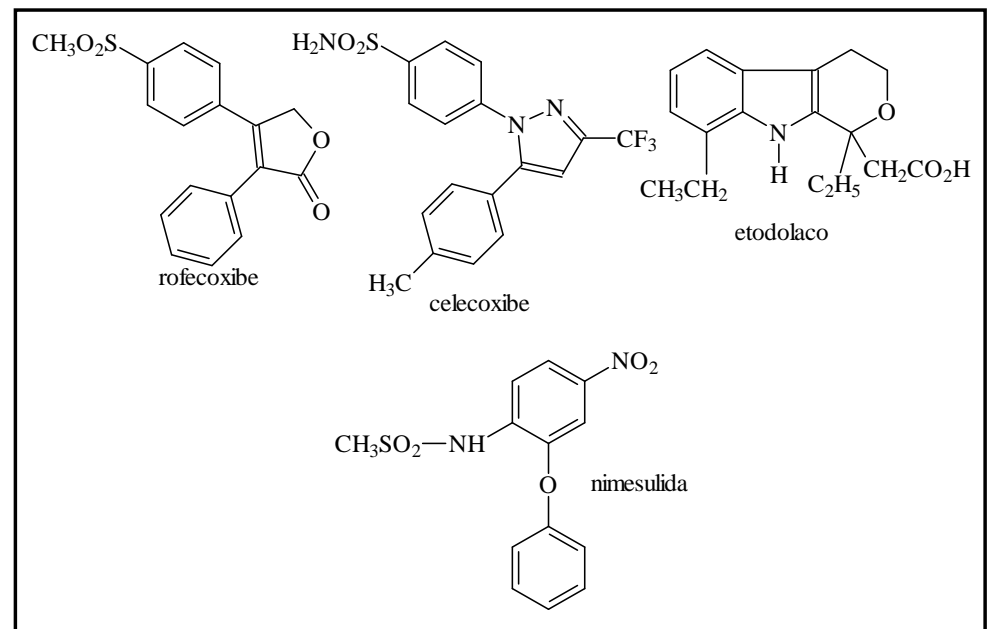

Figura 5. Representação estrutural dos AINEs inibidores seletivos de COX-2.

A partir da descoberta do protótipo DUP-697, diversos inibidores seletivos para COX-2 (COXIBES) têm sido relatados na literatura, sendo alguns terapeuticamente validados para o tratamento da artrite reumatóide e gota, tais como: celecoxibe (CELEBRA®), valdecoxibe (BEXTRA $\AA$ ), parecoxibe (BEXTRA IM/IV®), etoricoxibe (ARCOXIA®) e lumiracoxibe (PREXIGE®) (figura 6). Estes inibidores de COX-2 pertencem à segunda geração de AINEs e possuem em comum em, suas estruturas, grupo difenilheterociclo e presença de grupo sulfona ou sulfonamida. Apresentam perfil farmacológico parcialmente seguro e livre de efeitos colaterais ao nível gastrintestinal. Entretanto, efeitos colaterais ao nível cardiovascular e renal, foram 
relacionados à utilização de inibidores seletivos da COX-2, em pacientes portadores de artrite reumatóide, que ocasionou o cancelamento do registro do rofecoxibe (VIOXX®) e conseqüentemente sua retirada da terapêutica. O lumiracoxibe e valdecoxibe estão sob avaliação, que poderá resultar no mesmo ocorrido com o fármaco rofecoxibe. Em virtude disso a comercialização dos respectivos medicamentos está sob controle da Vigilância Sanitária (BOMBARDIER et al., 2000; ÖLGEN, NEBIOGLU, 2002; GERALD, 2003; BIAVA et al., 2007; GUAN et al., 2007; HARRAK et al., 2007; ANVISA, 2008).

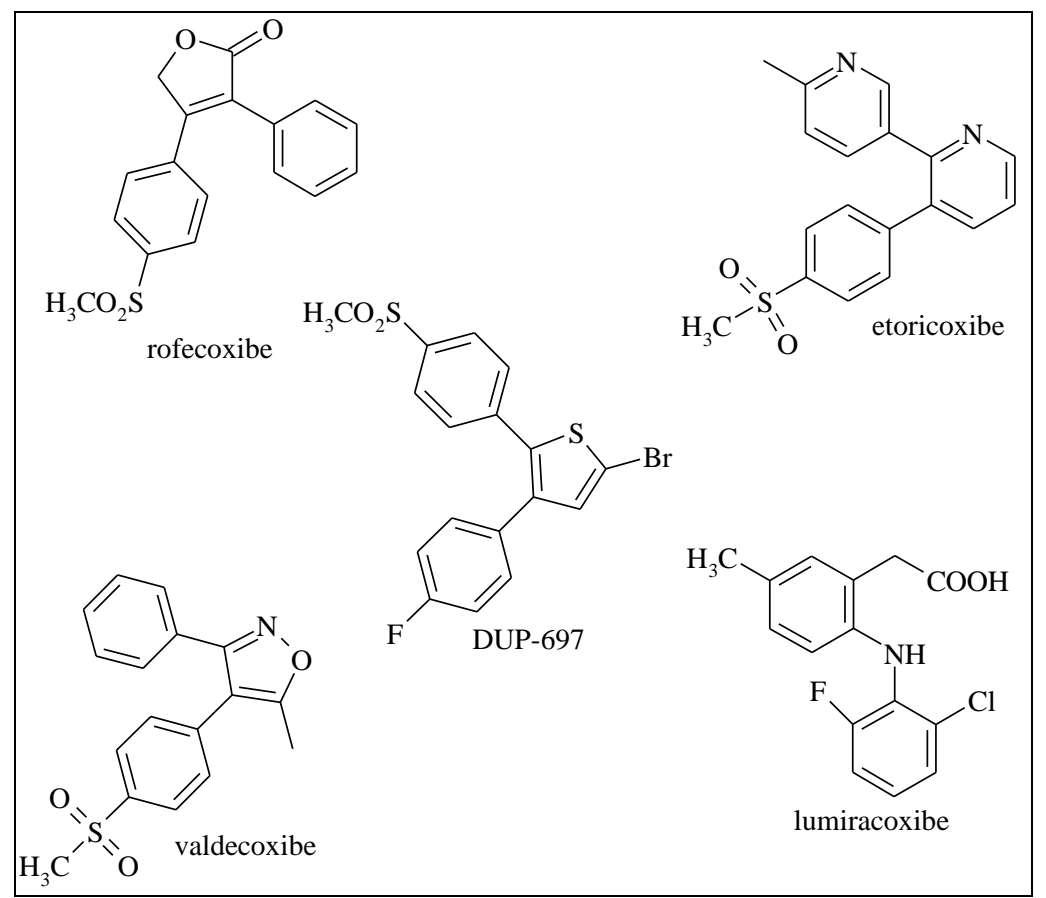

Figura 6. Representação estrutural de alguns inibidores seletivos da COX-2 de segunda geração.

A investigação da ação dos AINEs inibidores seletivos da COX-2 no tratamento da artrite reumatóide e doenças relacionadas continua, assim como a pesquisa de suas possíveis ações em doenças como câncer e Mal de Alzheimer (BORNE et al., 2008).

A classe de fármacos pertencente ao grupo dos arilalcanóicos, que inclui derivados de ácido acético e arilpropiônico, constitui um grande grupo dos AINEs. Esta é, atualmente, a classe mais estudada no planejamento e desenvolvimento de novos protótipos, candidatos a fármacos potencialmente antiinflamatórios (HARRAK et al., 2007; BORNE et al., 2008).

Estudos de Relação Estrutura Química-Atividade Biológica (REA) dessa classe de fármacos cita a importância dos grupos funcionais presentes na estrutura e correlaciona-os aos do 
ácido araquidônico, substrato da COX (figura 7). Sendo assim, os derivados arilalcanóicos apresentam em suas estruturas um centro planar, representado por anel aromático ou heteroaromático, relacionado com as duplas 5 e 8 do ácido araquidônico, uma segunda regiãolipofílica não-plana que pode ter relação com a dupla da posição 11 do ácido araquidônico e um grupo ácido, geralmente representado pelo ácido carboxílico ligado ao átomo de carbono adjacente ao centro aromático. Esta distância entre o centro aromático e o grupo ácido parece ser crucial para atividade farmacológica. A introdução de metila no átomo de carbono adjacente entre o centro aromático e o grupo ácido tende a aumentar a atividade antiinflamatória e gera um centro de quiralidade, no entanto a atividade farmacológica foi mais significativamente desempenhada pelo (S)-(+)-enantiômero (HARRAK et al., 2007; BORNE et al., 2008).

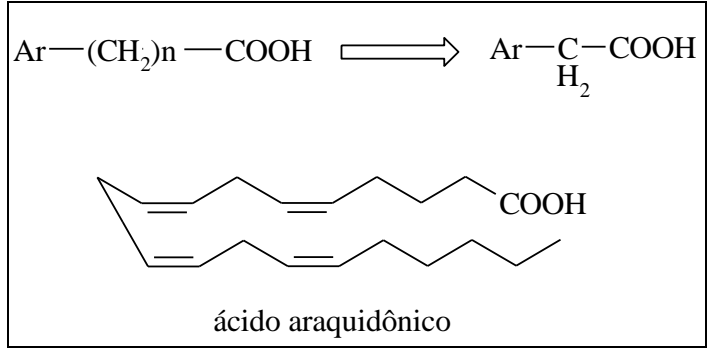

Figura 7: Representação comparativa entre a estrutura geral dos AINEs, derivados de ácido arilalcanóico e do ácido araquidônico.

O primeiro representante da classe dos derivados arilalcanóicos foi o fármaco indometacina (figura 8), sintetizada por Shen e colaboradores, em 1963 e introduzida na terapêutica em 1965 para o tratamento da artrite reumatóide e doenças relacionadadas (BURKE et al., 2006; BORNE et al., 2008).

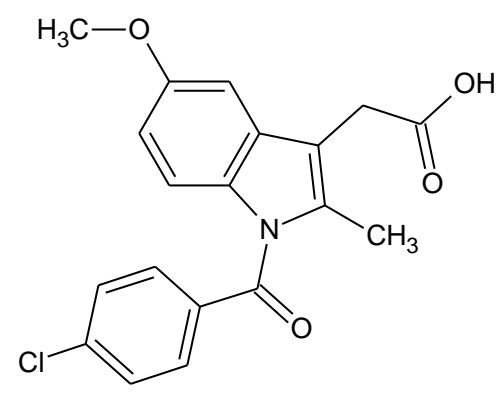

Figura 8: Representação estrutural da indometacina 
Inibe potencialmente a síntese de prostaglandinas por meio do bloqueio das enzimas ciclooxigenases. É ainda o AINE não-seletivo mais potente em uso na terapêutica. Além da ação antiinflamatória, possui ainda propriedades analgésicas e antipiréticas. Como desvantagem terapêutica, a indometacina apresenta alto índice de efeitos colaterais, principalmente ao nível gastrintestinal. Após administração oral, sua absorção ocorre rapidamente através do trato gastrintestinal, atingindo o pico de concentração plasmática após 2 a 3 horas. As concentrações plasmáticas necessárias para obtenção do efeito antiinflamatório estão abaixo de $1 \mu \mathrm{g} / \mathrm{mL}$ (BURKE et al., 2006; BORNE et al., 2008).

\subsubsection{Planejamento de Fármacos}

O planejamento de novas substâncias tem como principal objetivo a obtenção de compostos que possuam propriedades farmacoterapêuticas úteis, capazes de representarem novas entidades químicas, candidatas a protótipos de fármacos eficazes e seguros (BARREIRO et al., 2002).

A química farmacêutica medicinal possui métodos eficientes para otimizar a potência e o perfil farmacológico de substâncias, levando ao planejamento e síntese de substâncias cada vez mais ativas, com biodisponibilidade satisfatória, desprovidas de toxicidade e metabolismo adequado ao seu emprego terapêutico. Estes métodos podem consistir de aproximação intuitiva, tais como a síntese de análogos, isômeros e isósteros ou outros processos de modificação molecular, como a simplificação molecular, a latenciação, a modificação de sistemas anelares, entre outros (KOROLKOVAS, 1988; WERMUTH, 2003d).

A simplificação molecular consiste em estratégia de modificação molecular ou otimização de fármacos e/ou protótipos, permitindo a obtenção de novos análogos ativos de estruturas mais simples em relação ao protótipo. Na simplificação da estrutura do anestésico local cocaína à procaína, conservou-se a propriedade anestésica local, eliminando as propriedades narcóticas relacionadas à cocaína (figura 9) (KOROLKOVAS, 1988; BARREIRO, FRAGA, 2001; WERMUTH, 2003d). 


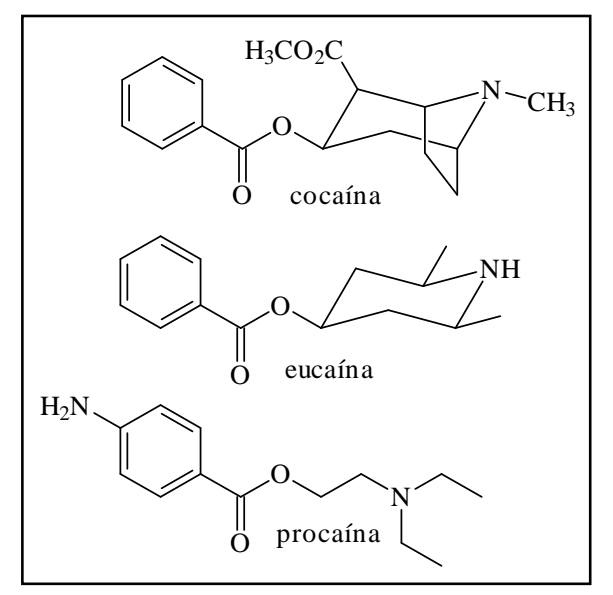

Figura 9. Modificação progressiva da estrutura da cocaína.

Quando moléculas ativas contêm sistemas cíclicos, eles podem ser abertos, expandidos, contraídos, retirados ou modificados de diversas maneiras. A disjunção de anéis tem como principal objetivo a simplificação progressiva em relação ao fármaco original. Essa modificação possibilita extrair informações sobre a estrutura mínima requerida para desenvolver atividade farmacológica (grupo farmacofórico) e, sobretudo alterar o perfil farmacocinético dos novos análogos. A síntese de tais moléculas é muito importante para explorar a interação ligantebiomacromolécula alvo (receptor) e para os estudos de modelagem molecular. A reorganização de sistemas anelares pode ser realizada por fusão ou dissociação destes sistemas de anéis (figura 10). Esta metodologia pode, às vezes, melhorar a solubilidade, alterando o perfil farmacológico e reduzindo a toxicidade do fármaco utilizado como protótipo (WERMUTH, 2003c).

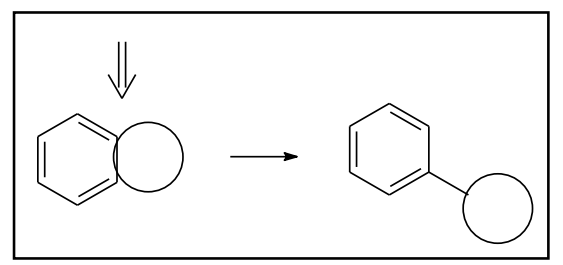

Figura 10. Dissociação de sistemas anelares fundidos. 


\subsubsection{Análogos da indometacina potencialmente antiinflamatórios}

Dentre os análogos da indometacina sintetizados , os compostos ácidos 5-benzoíla-1metilpirrol-2-acético, representados na figura 11 apresentaram atividade antiinflamatória, além da atividade analgésica e antipirética (CARSON et al., 1971).

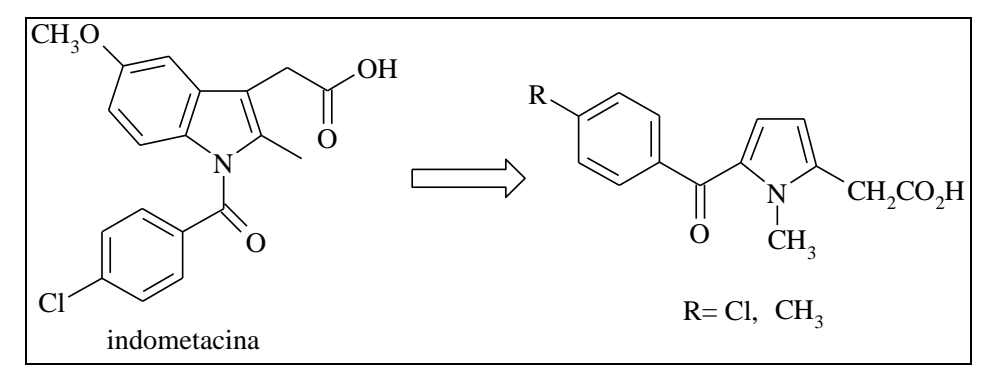

Figura 11: Análogos da indometacina

A fim de conhecer detalhadamente o mecanismo de inibição do fármaco indometacina, inúmeros estudos foram realizados com base no seu respectivo sítio de ação. Kurumbail e colaboradores (1996) realizaram estudo do complexo indometacina a enzima cicloxigenase-2 (COX-2) isolada por cristalografia de raios-X, cujas coordenadas foram dispostas no Protein Data Bank. Este fármaco, por sua vez, exibe comportamento cinético de inibição caracterizado como tempo-dependente (TD) e irreversível no sítio da COX-2. No complexo indometacina / COX-2, representado na figura 12, foi possível observar interações com diferentes resíduos de aminoácidos, tais como: (a) interação do átomo de cloro da indometacina com o resíduo de aa leucina (L384); (b) interações hidrofóbicas entre o grupo benzoíla do fármaco e resíduos de aa L384, fenilalanina (F381), tirosina (Y385) e triptofano (W387); (c) interação do grupo metoxila do fármaco com os resíduos de aa serina (S353), Y355 e valina (V323); (d) interação do grupo carboxilato $\left(\mathrm{COO}^{-}\right)$, grupo de grande importância para o efeito inibitório da $\mathrm{COX}-1$, à carga positiva do resíduo de aa arginina (R120); (e) interação do anel indólico do fármaco e os resíduos de aa V349 e S353. 


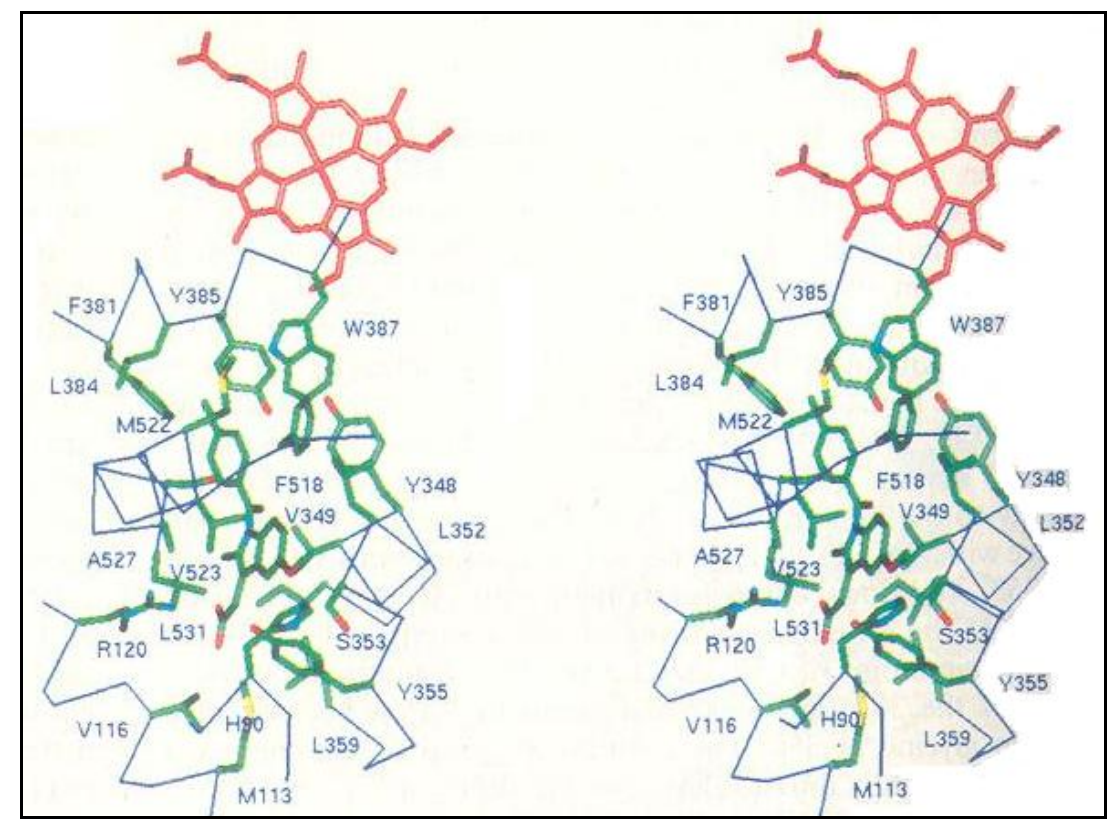

Figura 12:. Complexo indometacina/COX-2. A figura mostra, em diferentes ângulos, as possíveis interações formadas entre o sítio ativo da enzima COX-2 e o fármaco indometacina (Fonte: KURUMBAIL et al., 1996)

A substituição do grupo $p$-clorobenzoíla por $p$-clorobenzila aumenta a seletividade destes compostos para COX-2, sugerindo assim que a presença do átomo de oxigênio do grupo benzoíla da indometacina é mais importante para interação com o sítio ativo da COX-1 do que com o da COX-2 (BLACK et al., 1996; KURUMBAIL et al., 1996).

Outras modificações na estrutura da indometacina foram realizadas, tal como a esterificação do ácido carboxílico, com intuito de reduzir a lesão gástrica provocada por esse grupo, embora a toxicidade ao nível gastrintestinal dependa de outros fatores provocados pela inibição da COX-1. Essa modificação resultou contudo em aumento da atividade inibitória da COX-2 e menor eficácia no efeito inibitório na COX-1 (tabela III). A substituição do grupo ácido por amidas primárias e secundárias também aumenta a seletividade para COX-2 (tabela IV) (KALGUTKAR et al., 2000; OLGEN, NEBIOGLU, 2002). 
Tabela III. Potencial de inibição in vitro da COX-2 e COX-1 de ésteres alifáticos da indometacina

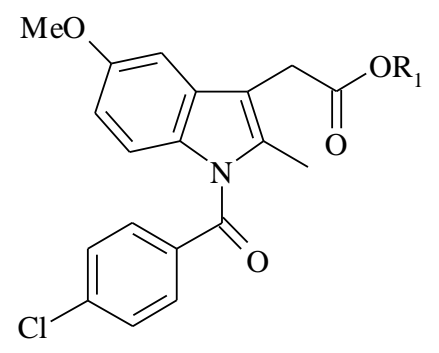

\begin{tabular}{ccc}
\hline $\boldsymbol{R}_{\boldsymbol{1}}$ & $\mathrm{IC}_{50}(\mu \mathrm{M})$ & $\mathrm{IC}_{50}(\mu \mathrm{M})$ \\
& $\mathbf{C O X}-\mathbf{2}$ & $\mathbf{C O X}-\mathbf{1}$ \\
\hline $\mathrm{CH}_{3}$ & 0,25 & 33 \\
$\mathrm{C}_{2} \mathrm{H}_{5}$ & 0,10 & $>66$ \\
$\mathrm{C}_{3} \mathrm{H}_{7}$ & 0,10 & $>66$ \\
$i s o-\mathrm{C}_{3} \mathrm{H}_{7}$ & 0,25 & 37 \\
$\mathrm{C}_{4} \mathrm{H}_{9}$ & 0,050 & $>66$ \\
$\mathrm{C}_{5} \mathrm{H}_{11}$ & 0,050 & $>66$ \\
$\mathrm{C}_{6} \mathrm{H}_{13}$ & 0,06 & $>66$ \\
\hline
\end{tabular}


Tabela IV. Potencial de inibição in vitro da COX-2 e COX-1 de derivados de amidas da indometacina<smiles>[R2]C(=O)Cc1c(C)n(C(=O)c2ccc(Cl)cc2)c2ccc(OC)cc12</smiles>

\begin{tabular}{|c|c|c|}
\hline $\boldsymbol{R}_{2}$ & $\begin{array}{l}\mathrm{IC}_{50}(\mu \mathrm{M}) \\
\text { COX-2 }\end{array}$ & $\begin{array}{l}\mathrm{IC}_{50}(\mu \mathrm{M}) \\
\text { COX-1 }\end{array}$ \\
\hline $\mathrm{NH}\left(\mathrm{CH}_{2}\right)_{2} \mathrm{C}_{6} \mathrm{H}_{5}$ & 0,060 & $>66$ \\
\hline $\mathrm{N}\left(\mathrm{CH}_{3}\right)\left(\mathrm{CH}_{2}\right)_{2} \mathrm{C}_{6} \mathrm{H}_{5}$ & $>17$ & $>66$ \\
\hline $\mathrm{NH}_{2}$ & 0,70 & $>20$ \\
\hline $\mathrm{NHCH}_{2} \mathrm{C}_{6} \mathrm{H}_{4}\left(2-\mathrm{CH}_{3}\right)$ & 0,15 & $>66$ \\
\hline $\mathrm{NHCH}_{2} \mathrm{C}_{6} \mathrm{H}_{4}\left(4-\mathrm{CH}_{3}\right)$ & 0,060 & 8,0 \\
\hline$\underset{i}{\mathrm{C}} \mathrm{H}_{3}$ & 0,060 & 4,0 \\
\hline & 0,20 & 4,0 \\
\hline
\end{tabular}

Nesse contexto é possível concluir que derivados neutros da indometacina apresentam maior capacidade de reconhecimento molecular com o sítio ativo da enzima COX-2 ao da COX1.

KALGUTKAR e colaboradores (2000) verificaram, ainda, que a ausência da metila na posição 2 da indometacina originou composto inativo. 
A extensão da cadeia do ácido carboxílico produziu homólogos que apresentaram aumento no perfil antiinflamatório, entretanto o homólogo $n$-pentanóico, com três carbonos a mais que o protótipo indometacina mostrou-se inativo para ambas as enzimas (LAGES et al., 1998; KALGUTKAR et al., 2000).

Com base nas estruturas dos fármacos indometacina e a classe dos diaril heterocíclicos (coxibes) como um todo, foi possível obter novos agentes antiinflamatórios com seletividade para COX-2, contendo núcleo pirrólico em suas estruturas. Estes são derivados de ácido 1,5diaril pirrol-3- acético e ésteres, como apresentado na figura 13 (BIAVA et al., 2005).

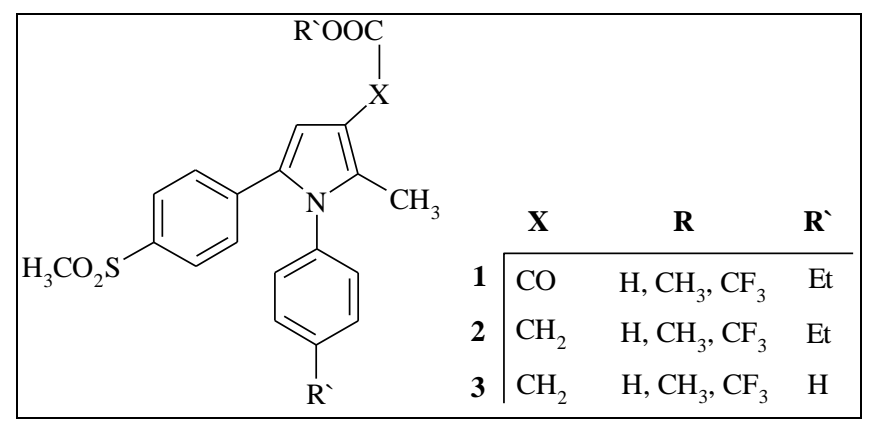

Figura 13: Derivados pirrólicos potencialmente antiinflamatórios com maior seletividade para COX-2.

O foco do trabalho foi a síntese do ácido 1,5-diarilpirrol-3-acético como novos inibidores seletivos de COX-2. O grupo pirrol acético e o esqueleto diarilheterociclo foram remanescentes da indometacina e da classe dos coxibes, respectivamente. Todos os compostos apresentaram atividade antiinflamatória nos testes "in vitro".

Em 2008, BIAVA e colaboradores relataram a síntese de derivados quirais de 1,5diarilpirróis (figura 15) com atividade inibitória nas ciclooxigenases (COX).

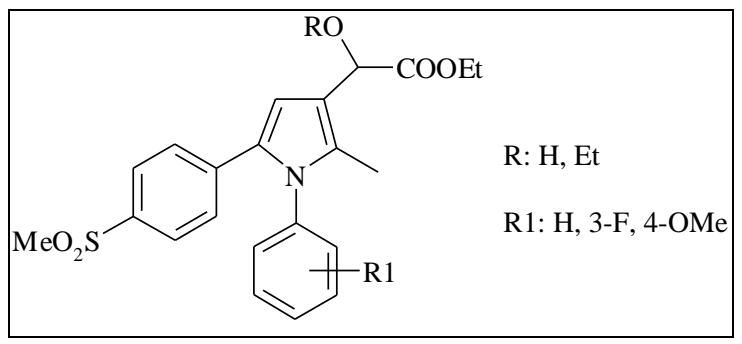

Figura 15: Representação estrutural dos derivados quirais de 1,5, diarilpirróis. 


\subsubsection{Planejamento sintético de derivados pirrólicos}

A quantidade de medicamentos de origem natural vem declinando paulatinamente, ao passo que aqueles de origem sintética aumentam constantemente. A síntese química está contribuindo cada vez mais com novos fármacos e esta, por sua vez, exige conhecimento dos mecanismos que regem as reações químicas, a interação com catalisadores e métodos especializados de purificação e identificação dos fármacos (KOROLKOVAS, 1988; FERREIRA, 2003).

O pirrol é um dos heterociclos mais importantes, conhecido a mais de 150 anos. Este se apresenta como esqueleto estrutural de inúmeros produtos naturais, como os alcalóides e sintéticos farmacêuticos, desempenhando atividades biológicas reconhecidas, tais como antibacteriana, antiviral, antioxidante, antiinflamatória, citotóxica, antitumoral, imunomoduladora e inibidora de citocinas responsáveis por mediar determinadas patologias (LEHUÉDÉ et al., 1999; DEMIR et al., 2002; RANU E DEY, 2003; MINETTO et al., 2004; BIAVA et al., 2005; DEMIR, EMRULLAHOGLU, 2005; BIAVA et al., 2007; ATTANASI et. al., 2008; DAVIS, et. al., 2008; FAN, et. al., 2008).

Por esta razão, vários métodos de aplicação geral foram desenvolvidos para a construção deste importante heterociclo nitrogenado.

O caminho sintético mais conhecido e explorado é a síntese de Paal-Knorr. Esta rota utiliza compostos 1,4-dicarbonílicos como intermediários-chave e aminas, que na presença de catalisadores ácidos ou básicos levam à formação do anel pirrólico (Esquema 3) (PAAL, 1885; KNORR, 1885; CURINI et al., 2003; RAIMAN et al., 2003; MINETTO et al., 2004; BIAVA et al., 2005; BIAVA et al., 2007).

\section{ESQUEMA 3}

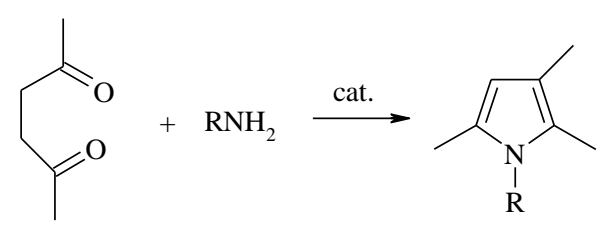

Um fator limitante desta reação é o alto custo do material de partida (composto 1,4dicarbonílico) e condições drásticas de reação.

Compostos contendo núcleo pirrólico com ação antagonista de receptores $\mathrm{EP}_{1}$ foram sintetizados via metodologia de Paal-Knorr (HALL et al., 2006). Estes compostos desempenham 
ação antiinflamatória, uma vez que esses receptores $\mathrm{EP}_{1}$, pertencem à família dos receptores $\mathrm{EP}_{1 \text { - }}$ 4, que correspondem ao sítio de ligação das prostaglandinas, tal como $\mathrm{PGE}_{2}$, importante mediador pró-inflamatório (Esquema 4).

\section{ESQUEMA 4}

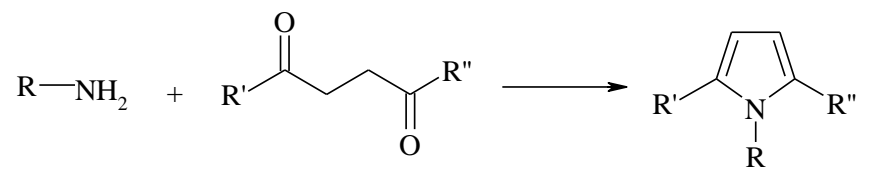

HARRAK e colaboradores (2007) realizaram a síntese do núcleo pirrólico partindo de anilinas, comercialmente disponíveis e 2,5-dimetoxitetraidrofurano em meio ácido, obtendo assim compostos pirrólicos providos de atividade antiinflamatória. Essa metodologia já havia sido utilizada por SÁNCHEZ e PUJOL (1999), na qual a obtenção do pirrol foi via adaptação da síntese de Paal-Knorr, por meio da condensação de 2-fluoroanilina e 2,5dimetoxitetrahidrofurano em meio ácido (Esquema 5).

\section{ESQUEMA 5}

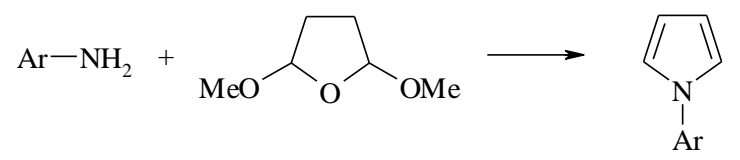

Outra rota sintética clássica de obtenção de pirróis é a metodologia de Hantzsch, que consiste na condensação de $\alpha$-halocetonas, compostos 1,3-dicarbonílicos, na presença de amonia (ROMI, MAcDONALD, 1970; TRAUTWEIN et al., 1998; DEMIR et al., 2002). A principal característica desta metodologia é o emprego do acetoacetato de etila, reagente de baixo custo e facilmente acessível (Esquema 6).

\section{ESQUEMA 6}

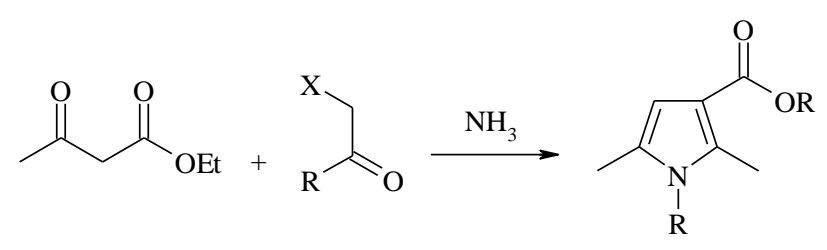

Uma variável desta reação foi feita por KASCHERES (2003) substituindo $\alpha$-halocetona por $\alpha$ diazocetona (Esquema 7). 
ESQUEMA 7

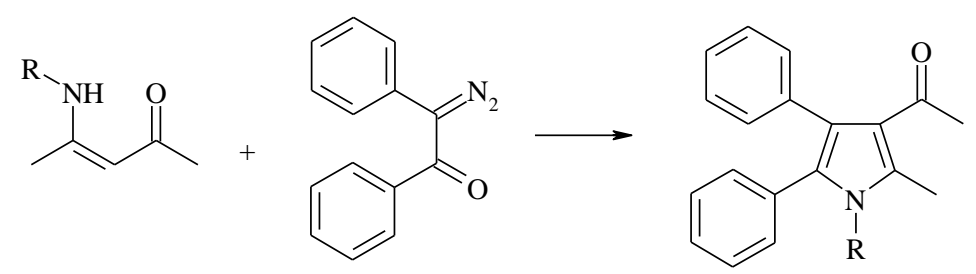

Mais tarde REDDY e colaboradores (2005) observaram também que reagindo $\alpha$-azido acetofenona com acetoacetato de metila sob as mesmas condições descritas anteriormente, levava a formação de pirrol trissubstituído, por mecanismo ainda desconhecido (Esquema 8).

ESQUEMA 8

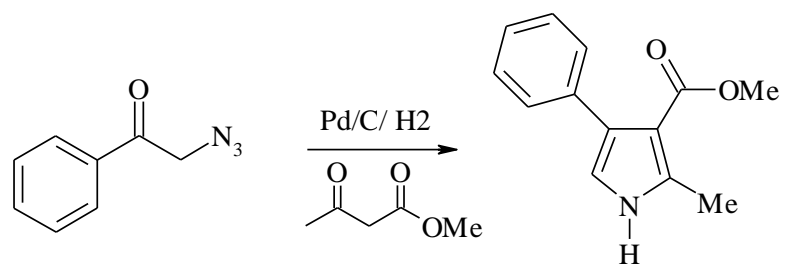

Como visto anteriormente, os compostos 1,3-dicarbonílicos são intermediários de fácil acesso. Assim, duas outras metodologias foram desenvolvidas para a síntese de pirróis. Em 1991, BRANDT e colaboradores mostraram que a ciclização seguida de eliminação de derivados de enaminonas preparadas a partir do acetoacetato de etila, levam a sistemas pirrólicos funcionalizados na posição 3 (Esquema 9).

ESQUEMA 9
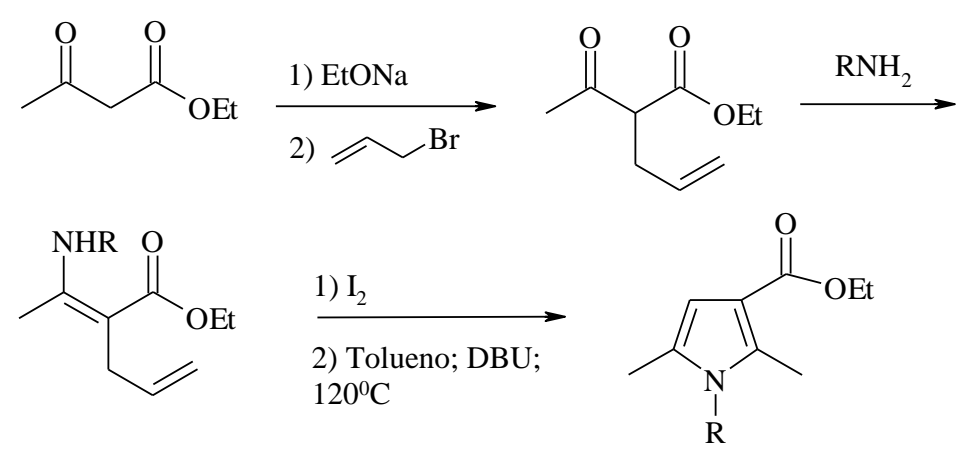

Demir et al., 2002 utilizaram também enaminonas para a mesma finalidade, via ciclização de brometos vinílicos na presença de base (Esquema 10). 


\section{ESQUEMA 10}

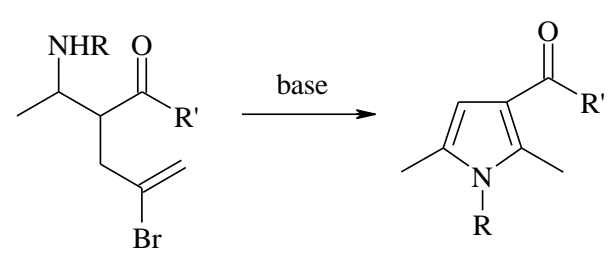

Outra rota envolvendo a condensação de três componentes: aldeídos ou cetonas cíclicas, nitroalcenos e aminas foi descrita recentemente (RANU e DEY, 2003). Esta reação ocorre em uma única etapa, semelhante à metodologia de Hantzsch mostrada anteriormente. Inicialmente ocorre a formação da enamina - imina e esta, por sua vez reage com o nitroalceno formando o pirrol desejado (Esquema 11).

\section{ESQUEMA 11}

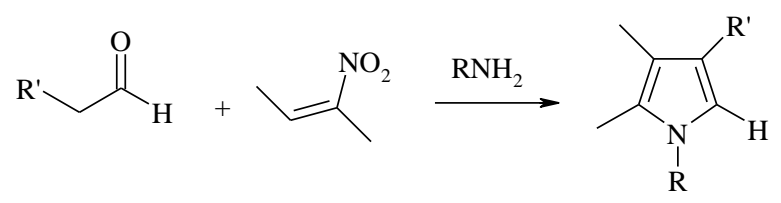

Compostos contendo núcleo pirrólico potencialmente inibidores da síntese de colesterol, resultante do bloqueio da HMG-CoA redutase foram sintetizados via metodologia de BartonZard, que consiste na reação de nitroalceno e isocianoacetato de etila, na presença de DBU resultando na formação de diferentes pirróis (PFEFFERKORN et. al.,2007). Utilizando metodologia semelhante à citada anteriormente, Bratton e colaboradores (2007) sintetizaram derivados com potencial atividade inibidora da HMG-CoA redutase, a partir de nitro-estireno e isocianoacetato de etila na presença de terc-butóxido de potássio (Esquema 12).

\section{ESQUEMA 12}

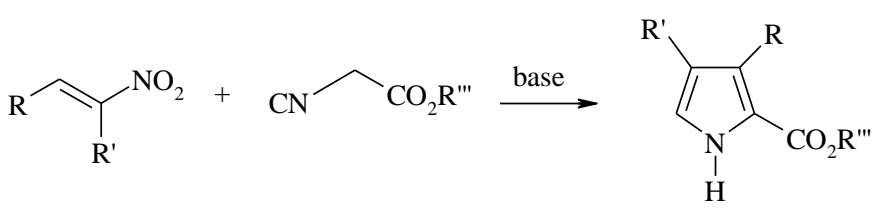

Compostos pirrólicos, com atividade antioxidante comprovada foram preparados a partir de nitrilas (LEHUÉDÉ et al.,1999). Nesta metodologia, deve-se destacar que apenas pirróis simétricos são obtidos. Derivados de aril nitrilas são transformados inicialmente em 
iminas/enaminas que, após oxidação com tetraacetato de chumbo, levam ao tetraarilpirrol (Esquema 13).

\section{ESQUEMA 13}

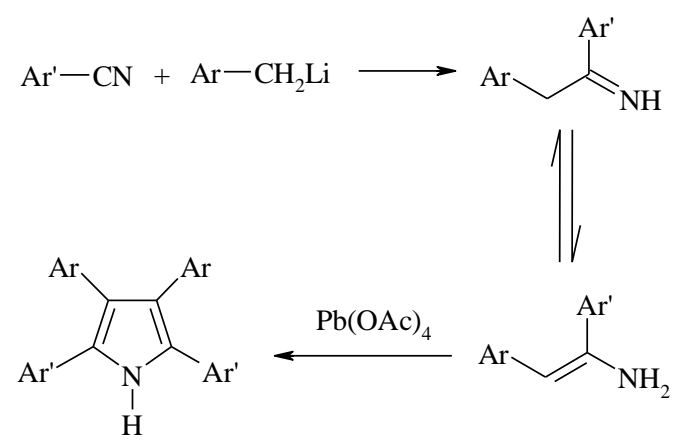

Outra metodologia desenvolvida por Demir e Emrullahoglu (2005) forneceu derivados 2aminopirróis, análogos do ácido $\delta$-aminobutírico (GABA). Estes, foram sintetizados a partir da alquilação de compostos $\beta$-dicarbonílicos com bromoacetonitrila, rendendo intermediários $\alpha$ cianometil- $\beta$-dicarbonílicos, que após reação de condensação com aminas e ácido para-tolueno sulfônico $(\mathrm{TsOH})$ como catalisador resultou na formação das enaminas correspondentes. Finalmente, a ciclização ocorreu via adição da amina à tripla ligação do carbono-nitrogênio do grupo nitrila (Esquema 14).

ESQUEMA 14

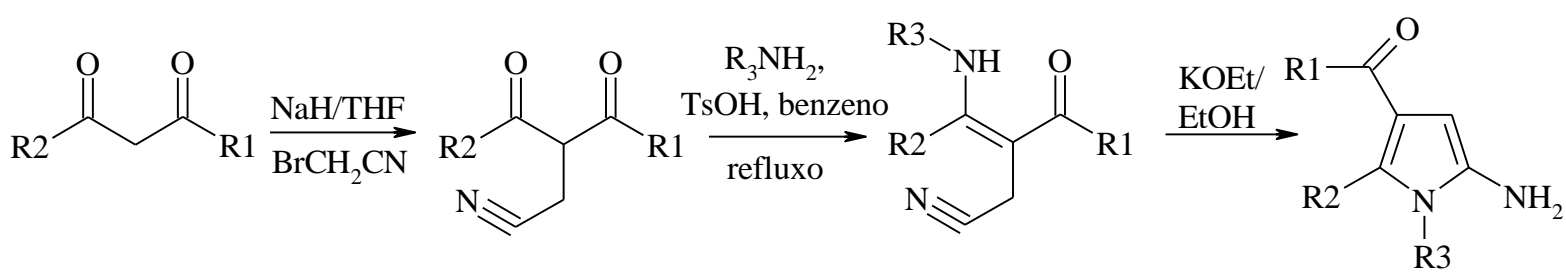

\subsubsection{Síntese de enaminas}

Dentre os vários métodos de preparação de derivados pirrólicos destacam-se as reações envolvendo enaminas, como intermediários versáteis para síntese de análogos biologicamente ativos, incluindo taxol, anticonvulsivantes, antiinflamatórios, antitumorais, bem como quinolinas antibacterianas e antimaláricas (BRANDT et al., 2004; REDDY, et al., 2005; ZHAO et al., 2005; ZHANG, HU, 2006; ZHANG et al., 2006; ZHANG et al., 2007). 
Um dos protocolos mais utilizados para preparação de enaminas envolve reações de adição de aminas a aldeídos e cetonas. Uma classe especial de enaminas, conhecidas como $\beta$ enaminonas, é definida pelos compostos que contêm o sistema $\alpha, \beta$-insaturado com o grupo carbonila. As $\beta$-enaminonas apresentam sistema conjugado e possuem 5 centros reativos, sendo 2 eletrofílicos (2 e 4) e 3 nucleofílicos (1, 3 e 5) (Esquema 15).

\section{ESQUEMA 15}

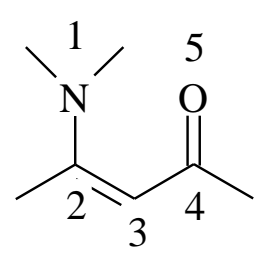

UDDIN e colaboradores (2004) realizaram a síntese de olefinas acíclicas, potencialmente antiinflamatórias e estudos de docking na enzima (COX-2), a fim de estudar a geometria das moléculas e identificar nova classe de olefinas, além de comprovar potente atividade antiinflamatória dos compostos avaliados. Outro estudo mais recente revelou que algumas $\beta$ enaminonas simples são biologicamente ativas (ZHAO et al., 2005).

Um dos métodos mais utilizados para obtenção de $\beta$-enaminonas é a condensação direta de compostos $\beta$-dicarbonílicos e aminas com retirada azeotrópica da água formada na reação, sob refluxo em solventes aromáticos. Para isto, costuma-se empregar o aparelho Dean-Stark. São utilizados também alumina neutra e montmorilonita K-10 como suporte sólido para remoção da água formada durante a reação (GRENHILL, 1971; BARALDI et al., 1983; BRAIBANTE et al., 1990).

Grande número de reações de síntese orgânica tem sido realizado, utilizando aparelho de microondas. Este pode acelerar de maneira significativa o tempo da reação, fornecendo bons rendimentos. Enaminocetonas foram preparadas a partir de $\beta$-dicetonas e diferentes aminas, utilizando montmorillonita ou sílica como suporte sólido, sob irradiação em microondas (VARMA et al., 1997; RECHSTEINER et al., 1993; SADICOFF et al., 2000).

$\beta$-enaminocetonas foram preparadas pelo uso de suporte sólido (montmorillonita - K10) sob irradiação por ultra-som, apresentando bons rendimentos, em pouco tempo de reação (BRAIBANTE et al., 1990; VALDUGA et al., 1998). 
Finalmente, $\beta$-enaminoésteres foram facilmente sintetizados, em excelentes rendimentos, a partir de $\beta$-cetoésteres e aminas, na presença de 0,1 equivalente de ácido acético glacial, sob irradiação em ultrassom, seguindo os princípios de Química Verde ("green chemistry") (Esquema 16) (BRANDT et al., 2004). A partir dessas enaminas torna-se possível a obtenção de derivados pirrólicos planejados.

ESQUEMA 16

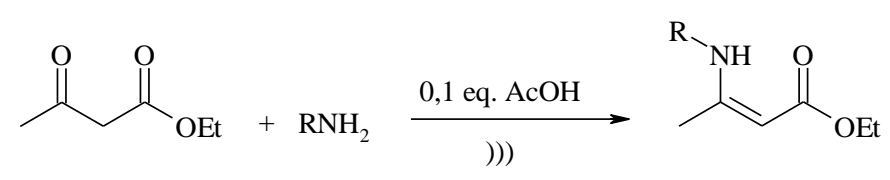

Zhao e colaboradores (2005) sintetizaram $\beta$-enaminonas e $\beta$-enaminoésteres a partir de acetato de amônio e $\beta$-cetoéster, utilizando ortosilicato de tetraetila $\left(\mathrm{Si}(\mathrm{OEt})_{4}\right)$ no meio reacional e etanol como solvente (Esquema 17). Este último é descrito na literatura como agente desidratante e levou a propicia obtenção de $\beta$-enaminonas e $\beta$-enaminoésteres em rendimentos satisfatórios.

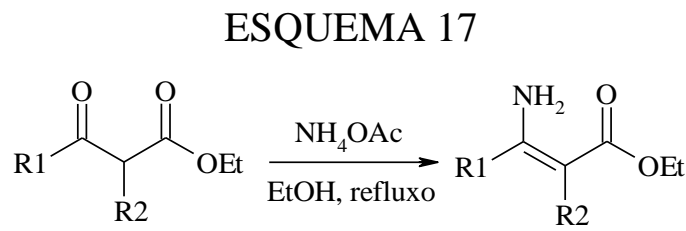

Enaminoésteres, também denominados carbamatos vinílicos, foram obtidos em apenas uma etapa de reação (“one-pot”), utilizando azidas alquílicas e $\beta$-cetoésteres como material de partida, sob atmosfera de hidrogênio. Foi adicionado $10 \%$ de $\mathrm{Pd} / \mathrm{C}$ no meio reacional, fornecendo os enaminoésteres correspondentes, apresentado no esquema 18 (REDDY et al., 2005).

ESQUEMA 18

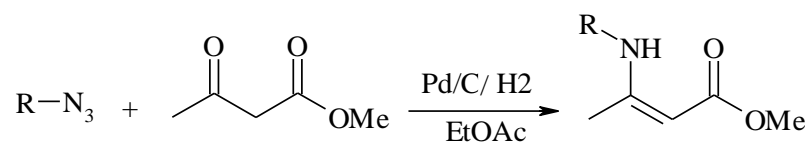


Uma série de $\beta$-enaminoésteres e $\beta$-enaminocetonas foram obtidas em bons rendimentos por meio da reação de compostos $\beta$-dicarbonílicos e aminas na presença de quantidade catalítica de tribrometo de índio e ausência de solvente (Esquema 19) (ZHANG et al., 2006).

\section{ESQUEMA 19}<smiles>[R4]NC([R1])=C([R2])C([R3])=O</smiles>

Outra série de $\beta$-enaminoésteres e $\beta$-enaminonas foram sintetizadas pela reação de compostos 1,3-dicarbonílicos com aminas na presença de quantidade catalítica de cloreto de cobalto(II), à temperatura ambiente na ausência de solventes. Os produtos foram isolados em rendimentos satisfatórios, como apresentado no esquema 20 (ZHANG, HU, 2006).

\section{ESQUEMA 20}<smiles>[R14]NC([R1])=C([R2])C([R3])=O</smiles>

A enaminação de compostos 1,3-dicarbonílicos também foi realizada por Zhang e colaboradores (2007), utilizando tetracloreto de estanho $\left(\mathrm{SnCl}_{4} .5 \mathrm{H}_{2} \mathrm{O}\right)$ como catalisador, na ausência de solventes (Esquema 21).

\section{ESQUEMA 21}

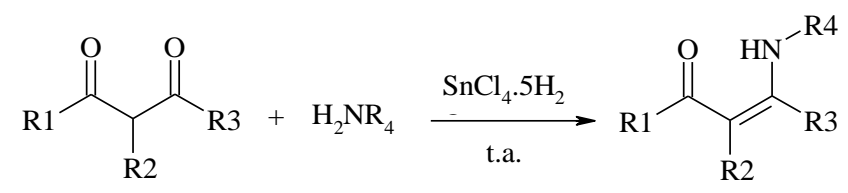




\subsubsection{Obtenção de pirróis via desidro-halogenação}

Em 1988, ANTONIOLETTI e colaboradores realizaram a síntese de derivados contendo núcleo furano, via ciclização de compostos 1,3-dicarbonílicos, resultando na obtenção de diidropirróis (III). A reação de eliminação, utilizando DBU como base rendeu na formação do intermediário IV. Visto que os derivados diidrofuranos (IV), não apresentaram tendência à aromatização, foi necessário acrescentar ácido ao meio, obtendo assim os furanos desejados (V) (Esquema 22).

\section{ESQUEMA 22}<smiles>[R3]Cc1cc(C([R2])=O)c([R])o1</smiles>

A partir daí tornou-se muito comum a utilização de DBU em reações de eliminação. Nesse contexto, IVANOVA e colaboradores (2005) investigaram a eliminação do iodo sob refluxo por 2 horas, em benzeno e 2,5 equivalente de DBU (Esquema 23).

ESQUEMA 23

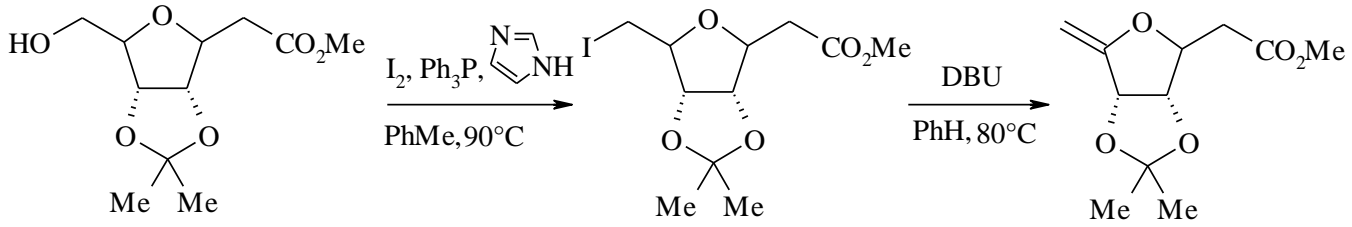

Inicialmente, eliminação do iodo de $\alpha$-iodo- $\beta$-alquilsulfonila ou arilsulfonila era realizada sob refluxo em benzeno e piridina ou trietilamina, variando os solventes, a temperatura ambiente ou aquecimento. Mais tarde, WOLFF e colaboradores (2006) realizaram a mesma eliminação com alumina neutra em temperatura ambiente, resultando na obtenção de sulfonas vinílicas em alto rendimento e pureza (Esquema 24).

ESQUEMA 24

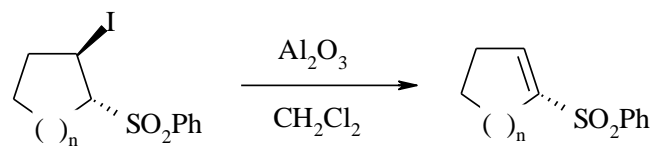




\subsubsection{Uso do ultrassom no contexto da Química Verde}

As atividades produtivas na área de química vão desde diversos combustíveis aos mais complexos medicamentos. Estas são, normalmente de risco e potenciais causadoras de poluição, uma vez que se trabalha com substâncias, na maioria das vezes tóxicas e/ou inflamáveis e após um processo químico normalmente geram resíduos que precisam ser tratados (PRADO, 2003; DA SILVA et al., 2005).

Em 1972 ocorreu a conferência de Estocolmo, que foi um grande marco na preocupação com o meio ambiente. A partir daí o mundo entrou em estado de alerta para os malefícios que a deteriorização do ecossistema poderia causar à humanidade como um todo (DA SILVA et al., 2005).

Inserida nesse contexto está a Química Verde, que consiste na criação, desenvolvimento e aplicação de produtos e processos químicos para reduzir ou eliminar o uso e a geração de substâncias tóxicas (PRADO, 2003; DA SILVA et al., 2005; MASON, 2007; TALAWAR et al., 2009).

Diante desse cenário, os pesquisadores não medem esforços no desenvolvimento de novas metodologias que se enquadram no ramo da Química Verde, dentre elas vale ressaltar a minimização do uso de solventes orgânicos, somado à utilização do ultrassom, como forma de transferência de energia (DA SILVA et al., 2005; MASON, 2007).

O ultrassom foi descoberto em 1880 por Curie, mas somente em 1927, Alfredo Loomis foi o primeiro químico a reconhecer o efeito sonoquímico, definido como efeito anômalo de ondas sonoras intensas propagando-se pelo líquido. A partir de 1980, a sonoquímica obteve grande importância, sendo relatada em inúmeros trabalhos recentes. O símbolo internacional de ultrassom é ))) (SUSLICK, 1989; DA SILVA et al., 2005; MASON, 2007; TALAWAR et al., 2009).

Atualmente, a sonoquímica é uma das oportunidades de desenvolver novas metodologias de sínteses limpa e rápida, de acordo com os emergentes princípios da Química Verde. O fenômeno químico associado ao ultrassom acontece pelo efeito da cavitação e tem sido utilizado em sínteses orgânicas, principalmente em meio aquoso e bifásico, uma vez que aumenta 
significativamente o rendimento, a velocidade e a seletividade das reações, reduzindo assim a quantidade de reagentes utilizados (MARTINES et al., 2000; DA SILVA et al., 2005; MASON, 2007). 
CAPÍTULO 3

PARTE EXPERIMENTAL 


\subsection{MATERIAL}

\subsubsection{Equipamentos (Síntese e Análises Químicas)}

- aparelho de ultra-som UNIQUE 1600 A, frequiência $40 \mathrm{KHz}$, potência 100W

- aparelhos e vidrarias de rotina em um laboratório de síntese

- balança analítica CHYO JL-180

- cromatógrafo a gás SHIMADZU GC 14A

- espectrômetro de ressonância magnética nuclear 300 MHz BRÜKER, modelo Advance DPX300

- cromatógrafo a gás / espectrômetro de massas SHIMADZU GCMS modelo QP 550A

- estufa para secagem FANEM modelo 515C

- forno KUGELROHR BÜCHI GKR-51 (destilação horizontal)

- rotaevaporador R-114 BÜCHI

- bomba de alto vácuo modelo E2M5 EDWARDS

- lâmpada de radiação ultravioleta 254/365 mm; SPETROLINE modelo ENF-260C para revelação de cromatograma

\subsubsection{Equipamentos (Avaliação Biológica e Toxicológica)}

- fluxo laminar TROX

- estufa de cultura $\mathrm{CO}_{2}$ WATER ICUBATOR FORMA SCIENTIFIC

- centrífuga MISTRAL 2L MSE

- balança OHAUS

- aspirador e lavador de células CELL HARVESTER LKB 1295-001

- espectrofotômetro= LABSYSTEM MULTISKAN MS-UNISCIENCE

- hidropletismógrafo modelo 7140, Ugo Basile

- paquímetro Universal 125MEB-12/300 


\subsubsection{Reagentes, Solventes e Outros (Síntese e Análises Químicas)}

- acetato de etila (Merck)

- acetoacetato de etila (Merck)

- acetona (Merck)

- ácido acético glacial (Merck)

- alumina neutra (Merck)

- alumina básica (Merck)

- anilina (Merck)

- benzilamina (Merck)

- bicarbonato de sódio (Synth)

- brometo de alila (MERCK)

- cloreto de sódio (MERCK)

- clorofórmio deuterado (Isotec)

- cromatofolhas AI TLC, Sílica gel 60 F254 (Merck)

- diclorometano p.a. (Merck)

- etanol (Synth)

- hexano (Synth)

- $n$-hexilamina (Merck)

- hidróxido de lítio monoidratado (Merck)

- iodo (Merck)

- sílica gel 60, tamanho de partícula 0,063-0,2000mm (Merck)

- sulfato de sódio anidro (Nuclear)

- tetrahidrofurano (THF) (Aldrich)

- tolueno (Synth)

- tiossulfato de sódio (Merck)

Todos os solventes comerciais utilizados foram previamente secos e purificados quando necessário, segundo os padrões estabelecidos pela literatura (Perrin et al., 1980). 


\subsubsection{Reagentes, Solventes e Outros (Avaliação Biológica e Toxicológica)}

- agente edematogênico carragenina (Aldrich)

- solvente dimetilsulfóxido (DMSO) (Merck)

- corante Hema ${ }^{3 \circledR}$ (Fisher Scientific Company, USA)

- kit para dosagem de $\mathrm{PGE}_{2}$ (Cayman Chemical, USA)

- brometo de 3,4,5-dimetiltiazol-2il 2,5-difenil tetrazol (MTT) (Sigma Aldrich Co., USA)

- meio de cultura RPMI 1640 (Sigma)

\subsubsection{Fármacos}

- indometacina (Indocid®);

- DUP-697 (Cayman Chemical, USA);

\subsubsection{Animais}

Foram utilizados camundongos Swiss machos, de peso compreendido entre 18 e $20 \mathrm{~g}$, obtidos do Biotério de criação da Faculdade de Ciências Farmacêuticas da Universidade de São Paulo (FCF-USP). Os animais foram mantidos em condições padronizadas de biotério, com água e alimentação ad libitum, até o momento dos experimentos. Esses estudos foram realizados segundo as normas determinadas pelo Colégio Brasileiro de Experimentação Animal (COBEA), sob o protocolo CEEA n ${ }^{\circ} 189$, de responsabilidade da Comissão de Ética em Experimentação Animal (CEEA) da FCF-USP, em 11/08/2008.

\subsection{METODOLOGIA SINTÉTICA}

O plano de trabalho está dividido em: preparação do composto $\beta$-dicarbonílico alquilado (2-acetil-pent-4-enoato de etila) (2); preparação de $\beta$-enaminoésteres (3a-b; 4a-c); preparação de 3-acilpirróis (5a, $\mathbf{5 b}, \mathbf{7 a}, \mathbf{7 b}$ e 7c), conforme representado de forma esquemática na figura 17. 


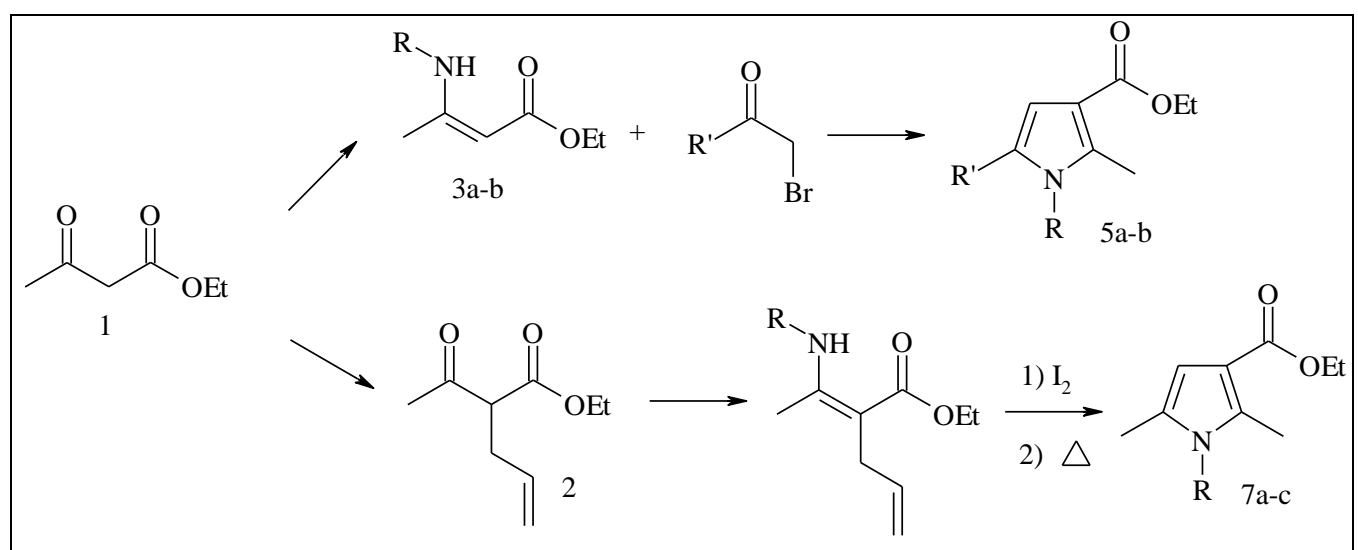

Figura 17: Resumo do plano de trabalho. Derivados pirrólicos obtidos a partir de acetoacetato de etila (1).

\subsubsection{Preparação dos intermediários de síntese $\beta$-dicarbonílico alquilado e dos $\beta$ -} enaminoésteres

\subsubsection{Obtenção do 2-acetil-pent-4-enoato de etila (2)}

O intermediário $\beta$-dicarbonílico alquilado (2) foi obtido via adaptação da metodologia descrita por ANTONIOLETTI e colaboradores (1992), representado no esquema 25.

\section{ESQUEMA 25}

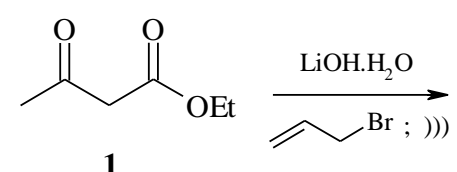

1<smiles>C=CCC(C(C)=O)C(=O)OCC</smiles> 


\section{Procedimento:}

Foram adicionados a um frasco acetoacetato de etila $(10,5 \mathrm{mmol})$, brometo de alila $(10,0$ mmol), hidróxido de lítio $(10,5 \mathrm{mmol})$ e $2,5 \mathrm{~mL}$ de água. A mistura reacional foi submetida à irradiação em ultra-som durante 10 minutos. Ao término da reação, a mistura reacional foi diluída com diclorometano $(20 \mathrm{~mL})$, lavada com água $(10 \mathrm{~mL})$. A fase orgânica foi seca com sulfato de sódio anidro, filtrada e evaporada. O resíduo foi destilado à pressão reduzida.

\subsubsection{Obtenção dos $\beta$-enaminoésteres}

Os intermediários $\beta$-enaminoésteres (3a-b; 4a-c) foram obtidos de acordo com a metodologia descrita por BRANDT e colaboradores (2004). Esta consiste da condensação de $\beta$ cetoésteres e aminas na presença de ácido acético sob irradiação em ultra-som (Esquema 26).

\section{ESQUEMA 26}
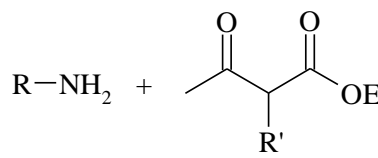

R: benzilamina, anilina e $n$-hexilamina $\mathrm{R}$ : $\mathrm{H}$ ou alila

\section{Procedimento:}

Foram adicionados os $\beta$-cetoésteres (1 e 2) (10,0 mmol), 1 equivalente das aminas correspondentes (benzilamina e $n$-hexilamina) ou 2 equivalentes de anilina e 0,1 equivalentes de ácido acético glacial (1,0 mmol) a um frasco. A mistura reacional foi submetida à irradiação em ultra-som por períodos de 20 minutos a 3horas (tabela V), dependendo da enamina utilizada. A temperatura do banho não ultrapassou a temperatura de $30^{\circ} \mathrm{C}$. Ao término da reação, a mistura reacional foi diluída em etanol $(10,0 \mathrm{~mL})$, seca em sulfato de sódio anidro, filtrada, e concentrada em rotoevaporador. Logo após, o material de partida foi destilado em forno de Kugelrohr BÜCHI GKR-51, a pressão reduzida, obtendo assim os $\beta$-enaminoésteres esperados (3a-b; 4a-c). 
Tabela V: Síntese de $\beta$-enaminoésteres a partir de aminas e $\beta$-cetoésteres (ultra-som).

\begin{tabular}{|c|c|c|}
\hline AMINAS & PRODUTOS & TEMPO (h) \\
\hline BENZILAMINA & & $\begin{array}{c}0,2\left(\mathrm{R}^{\prime}=\mathrm{H}\right)(\mathbf{3 a}) \\
0,5\left(\mathrm{R}^{\prime}=\mathrm{alila}\right)^{\mathrm{a}} \mathbf{( 4 a )}\end{array}$ \\
\hline ANILINA & & $3,0\left(\mathrm{R}^{\prime}=\mathrm{alila}\right)^{\mathrm{a}}(\mathbf{4 b})$ \\
\hline$N$-HEXILAMINA $\widehat{()_{4}} \mathrm{NH}_{2}$ & & $\begin{array}{c}0,2\left(\mathrm{R}^{\prime}=\mathrm{H}\right)(\mathbf{3 b}) \\
0,5\left(\mathrm{R}^{\prime}=\mathrm{alila}\right)^{\mathrm{a}}(\mathbf{4 c})\end{array}$ \\
\hline
\end{tabular}

${ }^{\mathrm{a}}$ Foram utilizados 2 equivalentes de amina

\subsubsection{Preparação de derivados pirrólicos}

Para obtenção dos derivados pirrólicos foram utilizadas, como base, duas metodologias:

a. Adaptação da metodologia de Hantzsch, descrita por ROOMI e MAcDONALD (1970)

b. Metodologia de ciclofuncionalização, descrita por BRANDT e colaboradores (1991).

\subsubsection{Obtenção de derivados pirrólicos (5a-b).}

Para obtenção dos produtos 5a-b utilizou-se a metodologia descrita por ROOMI e MAcDONALD (1970) como base, porém, de maneira modificada, partindo de $\beta$-enaminoésteres (3a-b) já sintetizados (BRANDT et al., 2004) e $\alpha$-halocetonas (CATCH et al., 1948; LAVENE, 1943), como apresentado no esquema 27. 
ESQUEMA 27

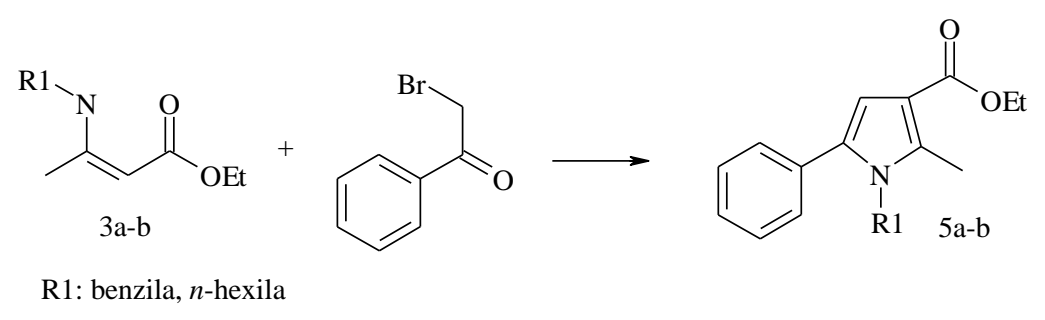

\section{Procedimento geral:}

Foram adicionados os respectivos $\quad \beta$-enaminoésteres (3a-b) $\quad(10,0 \quad \mathrm{mmol})$, bromoacetofenona $(5,0 \mathrm{mmol})$, e etanol $(5,0 \mathrm{~mL})$ a um frasco. A mistura reacional foi submetida à irradiação em ultra-som durante 60 minutos, utilizando sistema aberto. $\mathrm{O}$ banho foi mantido à temperatura de $60^{\circ} \mathrm{C}$. Ao término da reação, a mistura foi diluída em acetato de etila $(20,0 \mathrm{~mL})$, lavada com solução alcalina $\left(\mathrm{NaHCO}_{3} 10 \%\right)$, seca com sulfato de sódio anidro, e filtrada. Sua concentração foi realizada em rotoevaporador e a destilação em forno de Kugelrohr BÛCHI GKR-51, a pressão reduzida. O produto foi purificado em coluna de sílica gel utilizando hexano:acetato de etila (4:1) como eluente.

O produto obtido foi caracterizado por espectrometria de massas e RMN ${ }^{1} \mathrm{He} \mathrm{e}^{13} \mathrm{C}$, infravermelho e CG/MS.

3.2.2.2. Obtenção de derivados pirrólicos (7a-c) via metodologia de ciclofuncionalização/eliminação.

A obtenção dos produtos desejados (7a-c) foi realizada em duas etapas distintas, conforme representado nos esquemas 28 e 29. Inicialmente foram obtidos os diidropirróis, via iodociclização dos respectivos $\beta$-enaminoésteres (4a-c), de acordo com a metodologia descrita por BRANDT e colaboradores (1991) (esquema 28). A última etapa consistiu na desidrohalogenação e consequientemente na obtenção dos derivados pirrólicos desejados (esquema 29), via adaptação e otimização da metodologia descrita por WOLFF e colaboradores (2006). 


\section{$1^{a}$ etapa:}

\section{ESQUEMA 28}

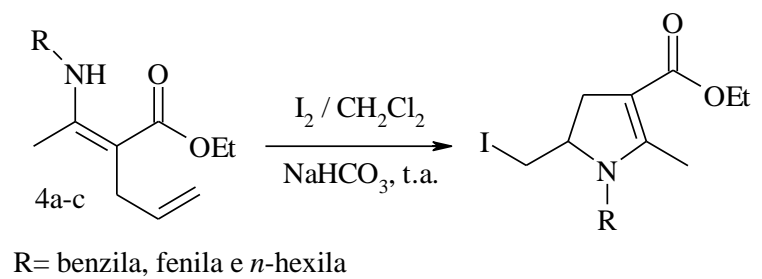

\section{Procedimento:}

A um balão de 50,0 $\mathrm{mL}$ munido de um tubo secante, foram adicionados o $\beta$ enaminoéster (4a-c) $(10,0 \mathrm{mmol})$, diclorometano $(80 \mathrm{~mL}), \mathrm{NaHCO}_{3}(11,5 \mathrm{mmol})$ e iodo $\left(\mathrm{I}_{2}\right)$ $(11,5 \mathrm{mmol})$. Em seguida, agitou-se a mistura por 12 horas, à temperatura ambiente. A reação foi então extraída com acetato de etila, seco com sulfato de sódio anidro e filtrado em seguida. A solução orgânica foi concentrada por evaporação do solvente e o produto bruto foi purificado em coluna de sílica gel, utilizando como eluente diclorometano. O produto obtido foi caracterizado por espectrometria de massas e $\mathrm{RMN}{ }^{1} \mathrm{H}$ e ${ }^{13} \mathrm{C}$.

\section{$2^{a}$ etapa:}

Para a etapa de eliminação partiu-se da quantidade equivalente a 1 mmol do produto ciclizado. Não foi necessário a purificação do iodeto.

\section{ESQUEMA 29}

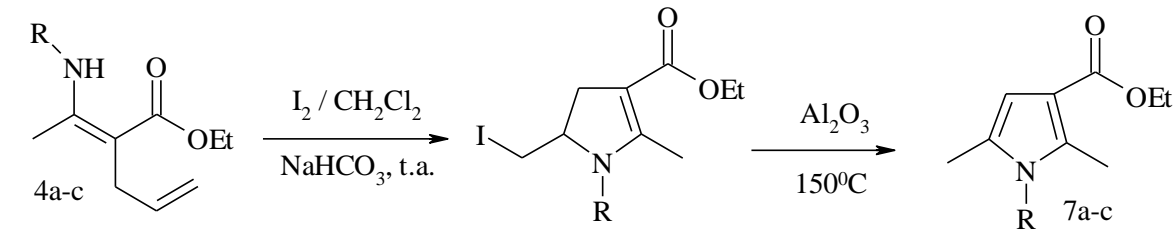

$\mathrm{R}=$ benzila, fenila e $n$-hexila

\section{Procedimento:}

À fase orgânica resultante da ciclização adicionou-se alumina neutra (30g) a fim de promover melhor adsorção do produto de ao suporte sólido, evaporando o solvente em seguida. A mistura foi submetida a aquecimento a $150{ }^{\circ} \mathrm{C}$ por um período de 15 minutos. A mistura reacional foi extraída com diclorometano, seca com sulfato de sódio anidro e filtrada. A solução 
orgânica foi concentrada por evaporação do solvente resultando no produto de alta pureza, caracterizado por espectrometria de $\mathrm{RMN}{ }^{1} \mathrm{He}^{13} \mathrm{C}$.

\subsection{MÉTODOS ANALÍTICOS}

\subsubsection{Cromatografia em camada delgada (CCD)}

As análises de pureza foram realizadas por meio de $\mathrm{CCD}$, utilizando placas comerciais do tipo 60 - $\mathrm{F}_{254}$ de alumínio cobertas com sílica gel (Merck). Para a revelação das placas, utilizouse iodo e lâmpada ultravioleta (UV).

\subsubsection{Cromatografia gasosa (CG)}

As análises dos produtos foram realizadas por cromatografia gasosa, em equipamento HP 6890, utilizando coluna de metilsilicone (30 metros de comprimento e $0,32 \mathrm{~mm}$ de diâmetro interno). Utilizou-se $\mathrm{N}_{2}$ (g) como fase móvel e um detector de ionização de chama (FID).

\subsubsection{Ressonância magnética nuclear (RMN)}

As análises dos produtos foram realizadas por meio de espectrômetro de ressonância magnética nuclear BRUKER $300 \mathrm{MHz}$, modelo Advance DPX-300. Os produtos submetidos à análise foram dissolvidos em clorofórmio deuterado. Os deslocamentos químicos $(\delta)$ estão relatados em partes por milhão (ppm), com tetrametilsilano (TMS) como padrão interno. Nas

atribuições dos sinais dos espectros de RMN ${ }^{1} \mathrm{H}$ foram utilizadas as letras: s para singleto, $\mathrm{d}$ para dubleto, dd para duplo dubleto, $\mathrm{t}$ para tripleto, q para quarteto, quint. para quinteto e $\mathrm{m}$ para multipleto. A constante de acoplamento (J) é dada em Hertz (Hz).

\subsubsection{Espectrômetro de massas}

As análises de fragmentação das moléculas foram realizadas em cromatógrafo gasoso acoplado a espectrômetro de massas (CGMS), modelo QP 550 A, coluna J \& W SCIENTIFIC, modelo DB-5 com $30 \mathrm{M}$ de comprimento, diâmetro $25 \mathrm{~mm}$ e filme $0,25 \mu \mathrm{m}$, empacotamento (5\%-fenil)-metilpolisiloxano.

\subsubsection{Espectrômetro de infravermelho}

Os espectros de absorção no infravermelho (IV) foram registrados em forma de pastilha de $\mathrm{KBr}$, no espectrofotômetro BOMEM, modelo MD-155S. 


\subsection{AVALIAÇÃO BIOLÓGICA}

Os ensaios de avaliação biológica foram realizados no Instituto Butantan, Laboratório de Farmacologia, Unidade de Inflamação coordenada pela Dra. Catarina de Fátima Pereira Teixeira, sob orientação da Dra. Vanessa Moreira.

\subsubsection{Análise estatística}

Os dados foram apresentados como média \pm erro padrão da média e analisados estatisticamente pela Análise de Variância (ANOVA), seguida por comparações múltiplas pelo método de Tukey. O nível de significância adotado foi de $\mathrm{p}<0,05$.

\subsubsection{Ensaios "in vitro"}

\subsubsection{Determinação do efeito citotóxico de $5 \mathrm{a}$ e $5 \mathrm{~b}$}

\subsection{Cultura de células}

Para os ensaios de citotoxicidade, macrófagos residentes foram obtidos da cavidade peritoneal. Para a coleta das células, os animais foram mortos sob atmosfera excessiva de $\mathrm{CO}_{2}$ e a cavidade peritoneal lavada com 2,0 mL de solução salina apirogênica 0,9 \% pH 7,2. Após a coleta e homogeneização do líquido de lavagem, uma alíquota foi diluída (1:20 v/v) em solução de Turk, para a contagem do número total de leucócitos, em câmara de Neubauer e microscopia de luz. A predominância de macrófagos (>95\%) foi confirmada por características morfológicas e de coloração, em esfregaços celulares corados com Hema ${ }^{3 \circledR}$ (Fisher, USA). Uma alíquota contendo $2 \times 10^{5}$ células foi então centrifugada a $130 \mathrm{~g}$, por 6 minutos, a $22^{\circ} \mathrm{C}$. O precipitado celular foi ressuspenso em meio de cultura RPMI (Sigma Aldrich Company, USA) e incubados em placas de 96 poços com RPMI (controle negativo) ou Triton (controle positivo) ou 5a ou 5b em concentrações decrescentes (de $10 \mu \mathrm{g} / \mathrm{mL}$ a $0,1875 \mu \mathrm{g} / \mathrm{mL}$ ), em períodos de 8 e 24 horas.

3.4.2.1.2. Redução do brometo de 3,4,5-dimetiltiazol-2il 2,5-difenil tetrazol (MTT) 
A determinação do efeito citotóxico foi realizada por meio de ensaio da redução do brometo de 3,4,5-dimetiltiazol-2il 2,5-difenil tetrazol (MTT), descrita por MOSMANN (1983), em macrófagos peritoneais isolados em cultura.

Após cada período de incubação, descritos no item 3.4.2.1.1., as células foram centrifugadas a $130 \mathrm{~g}$, por 10 minutos, e o sobrenadante de cada amostra foi retirado. A seguir, foram acrescentados, em cada poço, $100 \mu \mathrm{L}$ de meio RPMI e $10 \mu \mathrm{L}$ de MTT em solução a 5 $\mathrm{mg} / \mathrm{mL}$, tamponada. Em seguida, os macrófagos isolados foram incubados a $37^{\circ} \mathrm{C}$, em estufa a $5 \%$ de $\mathrm{CO}_{2}$, por 3 horas. Para dissolver os cristais de formazan, oriundos da redução do MTT pelas células viáveis, foram adicionados $100 \mu \mathrm{L}$ de uma solução de dodecil sulfato de sódio (SDS) $5 \%$, em $\mathrm{HCl} 0,01 \mathrm{~N}$. As placas foram então incubadas por mais 18 horas. Após este período a densidade ótica (D.O.) foi determinada a $540 \mathrm{~nm}$, em espectrofotômetro. A viabilidade celular foi definida como a porcentagem de diminuição da D.O., observada nas células submetidas à ação dos compostos 5a e 5b, em relação aos controles RPMI (controle negativo) e Triton-X (controle positivo).

\subsubsection{Determinação do efeito de 5 a e 5 b sobre a liberação de PGE $_{2}$ induzida por LPS}

\subsubsection{Preparo das amostras}

Para os estudos in vitro, os macrófagos residentes foram obtidos da cavidade peritoneal e submetidos à cultura celular segundo o método descrito no item 3.4.2.1.1. Alíquotas de $2 \times 10^{5}$ de células foram incubadas em placas de 96 poços com $1 \mu \mathrm{g} / \mathrm{mL}$ de LPS ou com RPMI (controle). Após 2 horas os macrófagos isolados foram incubados em concentrações decrescentes dos compostos $5 \mathrm{a}(0,75 \mu \mathrm{g} / \mathrm{mL}, 0,387 \mu \mathrm{g} / \mathrm{mL}$ e $0,1875 \mu \mathrm{g} / \mathrm{mL})$ ou $5 \mathrm{~b}(2,0 \mu \mathrm{g} / \mathrm{mL}, 1,0 \mu \mathrm{g} / \mathrm{mL}$ e 0,5 $\mu \mathrm{g} / \mathrm{mL}$ ) ou indometacina (5 $\mu \mathrm{g} / \mathrm{mL}$ ) (controle positivo) ou DUP-697 (0,075 $\mu \mathrm{M}$ ) (controle positivo) ou RPMI (controle negativo) nos períodos de 8 e 24 horas. Ao final de cada período de incubação, as placas foram centrifugadas a $130 \mathrm{~g}$, por 6 minutos, a $22^{\circ} \mathrm{C}$. A seguir, o sobrenadante foi utilizado para a dosagem de $\mathrm{PGE}_{2}$, por EIA.

3.4.2.2. Determinação da concentração de $\mathrm{PGE}_{2}$ por ensaio imunoenzimático específico (EIA) 
A análise foi realizada por meio de kit comercial (Cayman Chemical, USA). Assim, alíquotas de $50 \mu \mathrm{L}$ de cada amostra, obtidos segundo a descrição do item 3.4.2.2.1. foram adicionadas às placas de 96 poços e incubadas com igual volume do prostanóide conjugado à acetilcolinesterase e antisoro específico de coelho. Após a adição do substrato, a absorbância das amostras foi determinada em espectofotômetro de microplaca (Labsystem Multiscan®) a $405 \mathrm{~nm}$ e as concentrações foram estimadas a partir da curva padrão específica em concentrações em pg/mL. O teor de recuperação de $\operatorname{PGE}_{2}(>95 \%)$ foi confirmado com aplicação dos respectivos padrões.

\subsubsection{Ensaios "in vivo"}

A determinação da atividade antiinflamatória, mais especificamente a atividade antiedematogênica do composto 5a foi realizada, conforme metodologia descrita por WINTER e RISLEY (1962).

Os ensaios biológicos ocorreram no Laboratório de Farmacologia do Instituto de Ciências Biológicas da Universidade de São Paulo (ICB / USP), em colaboração com a pós-graduanda Carly de Faria Coelho, sob orientação do Prof. Dr. Marcelo Nicolas Muscará. A atividade antiedematogênica do derivado 5a (p-benzil) foi avaliada através da indução de Edema de pata, através de injeção subplantar de carragenina (1mg/pata) na pata posterior esquerda de ratos wistar. O volume da pata foi medido através de hidropletismógrafo.

Previamente à administração de carragenina, foi realizada uma medição inicial dos volumes das patas esquerdas, que serviu como controle individual. Os valores dos volumes foram registrados 1, 2, 4, 6, 12 e 24 horas inicialmente após a injeção de carragenina. As medições foram realizadas em triplicata, a média dos valores foi registrada em cada período e a média individual (MI) foi subtraída. Os valores de edema assim calculados foram plotados em função do tempo e as áreas sob as curvas edema versus tempo foram calculadas pelo método dos trapézios (ANOVA).

O derivado 1-benzil-2-metil-5-fenil-1H -pirrol-3-carboxilato de etila (5a), foi solubilizado em DMSO : CMC (0,5\%). A administração se deu por meio de injeção intraperitoneal, nas doses de 10, 30 e 100mg/kg de 5a (p-benzil) e indometacina (10mg/Kg) como controle positivo. 
CAPÍTULO 4

RESULTADOS E DISCUSSÃO 


\subsection{RESULTADOS E DISCUSSÃO}

\subsubsection{Parte Experimental: Síntese Orgânica}

4.1.1.1. Obtenção do 2-acetil-pent-4-enoato de etila (2)

Reação realizada:

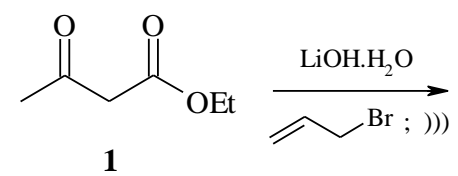<smiles>C=CCC(C(C)=O)C(=O)OCC</smiles>

$\mathrm{C}_{9} \mathrm{H}_{14} \mathrm{O}_{3}$; PM: 170,21 g/mol; P.E: $115^{\circ} \mathrm{C} / 16 \mathrm{mmHg}$; Aspecto: líquido transparente; Rendimento: $90 \%$
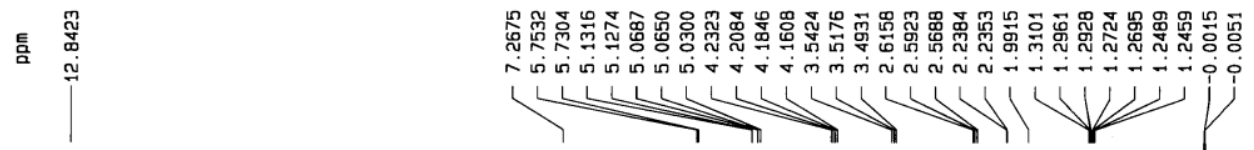

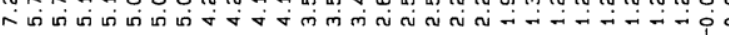

$\longrightarrow \rightarrow$<smiles>C=CCC(C(C)=O)C(=O)OCC</smiles>
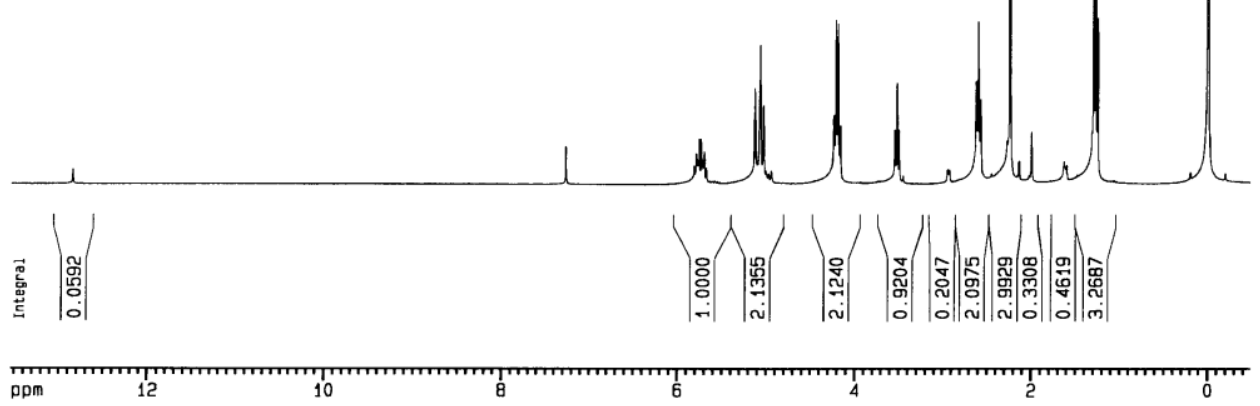

Espectro 1: Espectro de $\mathrm{RMN}{ }^{1} \mathrm{H}$ do 2-acetil-pent-4-enoato de etila (2).

Tabela VII: Dados de $\mathrm{RMN}{ }^{1} \mathrm{H}$ do 2 -acetil-pent-4-enoato de etila (2).

\section{RMN ${ }^{1} \mathrm{H}:\left(\mathrm{CDCl}_{3}-300 \mathrm{MHz}-\delta=\mathrm{ppm}\right)$}

$1,27\left(\mathrm{t}, 3 \mathrm{H}_{8}, \mathrm{~J}=7,1 \mathrm{~Hz}\right) ; 2,24\left(\mathrm{~s}, 3 \mathrm{H}_{6}\right) ; 2,60\left(\mathrm{t}, 2 \mathrm{H}_{3}, \mathrm{~J}=7,2 \mathrm{~Hz}\right) ; 3,52\left(\mathrm{t}, 1 \mathrm{H}_{2}\right.$, $\mathrm{J}=7,2 \mathrm{~Hz}) ; 4,20\left(\mathrm{q}, 2 \mathrm{H}_{9}, \mathrm{~J}=7,1 \mathrm{~Hz}\right) ; 5,05\left(\mathrm{~d}, 1 \mathrm{H}_{5}\right.$ cis $\left., \mathrm{J}=10,0 \mathrm{~Hz}\right) ; 5,10\left(\mathrm{~d}, 1 \mathrm{H}_{5}\right.$ trans, $\mathrm{J}=18,9 \mathrm{~Hz}) ; 5,70-5,80\left(\mathrm{~m}, 1 \mathrm{H}_{4}\right)$. 


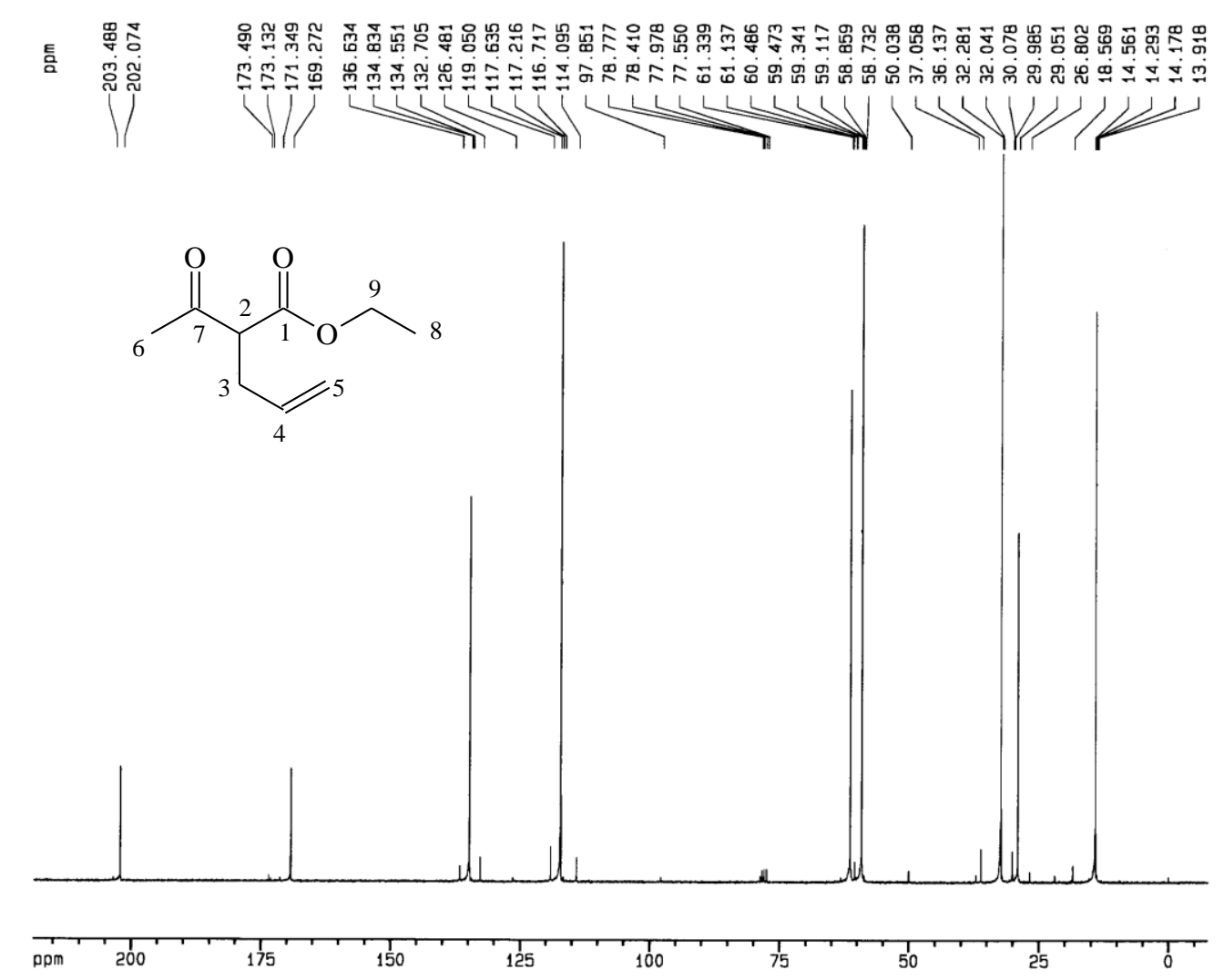

Espectro 2: Espectro de RMN ${ }^{13} \mathrm{C}$ do 2-acetil-pent-4-enoato de etila (2).

Tabela VIII: Dados de $\mathrm{RMN}{ }^{13} \mathrm{C}$ do 2-acetil-pent-4-enoato de etila (2).

\section{$\mathrm{RMN}^{13} \mathrm{C}\left(\mathrm{CDCl}_{3}-75 \mathrm{MHz}-\delta=\mathrm{ppm}\right)$}

$13,8\left(\mathrm{C}_{8}\right) ; 26,8\left(\mathrm{C}_{6}\right) ; 32,1\left(\mathrm{C}_{3}\right) ; 58,8\left(\mathrm{C}_{2}\right) ; 61,16\left(\mathrm{C}_{9}\right) ; 117,0\left(\mathrm{C}_{5}\right) ; 134,0\left(\mathrm{C}_{4}\right)$;

$168,9\left(\mathrm{C}_{1}\right) ; 201,9\left(\mathrm{C}_{7}\right)$. 
ANTONIOLETTI e colaboradores (1992) relataram a obtenção do $\beta$-dicarbonílico alquilado (2) utilizando brometo de alila como agente alquilante e hidróxido de lítio monoidratado como base. Essa reação fornece, além do produto alquilado desejado (2), um subproduto dialquilado (2') (esquema 30).

\section{ESQUEMA 30}

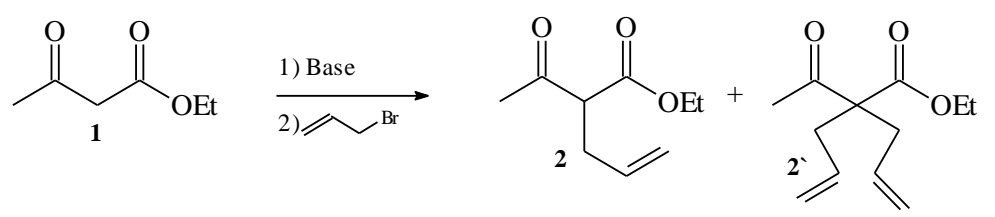

Essa metodologia foi inicialmente utilizada em nosso Laboratório para síntese do intermediário 2-acetil-pent-4-enoato de etila (2). A mistura reacional permanecia sob agitação por um período de 24 horas, a temperatura de $50{ }^{\circ} \mathrm{C}$. Após inúmeras tentativas de síntese, visando condições reacionais mais vantajosas, atingiu-se excelente resultado através de ultra-som. Dessa forma, o produto (2) foi obtido em apenas 15 minutos de reação, na ausência de solvente, uma vez que no procedimento anterior utilizava-se THF, solvente de alto custo. Com essa nova metodologia o produto desejado monoalquilado e o subproduto dialquilado foram obtidos na proporção de 93:7, respectivamente. Em contrapartida, na metodologia utilizada anteriormente (ANTONIOLETTI et al., 1992) essa proporção foi de 85:15.

A obtenção do 2-acetil-pent-4-enoato de etila (2) foi confirmada no espectro 1 de RMN de ${ }^{1} \mathrm{H}$, onde os hidrogênios 2 e 3 absorvem na forma tripleto em 3,52 ppm e 2,60 ppm, respectivamente.

Essa nova metodologia desenvolvida em nosso Laboratório foi extremamente eficiente, podendo ser amplamente aplicável, uma vez que a conversão do acetoacetato de etila (1) em 2-acetil-pent-4-enoato de etila (2) ocorreu com seletividade satisfatória e tempo significativamente reduzido. Além disso, utilizam-se reagentes de baixo custo, condições brandas de reação e ausência de solvente, que está de acordo com os princípios da Química Verde. 


\subsubsection{2. $\beta$-enaminoésteres (3a, 3b, 4a, $\mathbf{4 b}, \mathbf{e} \mathbf{4 c})$}

$\underline{\text { Reação realizada: }}$<smiles>[R]N[CH+]C(C)C([R])C(=O)OCC</smiles><smiles>[R]NC(C)=C([R])C(=O)OCC</smiles>

R: BENZILAMINA, ANILINA, $N$-HEXILAMINA $\mathrm{R}$ : $\mathrm{H}$ ou alila

Tabela VIII: Síntese de $\beta$-enaminoésteres a partir de aminas e $\beta$-cetoésteres (ultra-som)

\begin{tabular}{|c|c|c|c|}
\hline AMINAS & PRODUTOS & TEMPO (h) & RENDIMENTO (\%) \\
\hline BENZILAMINA & 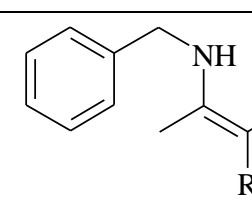 & $\begin{array}{l}0,2\left(\mathrm{R}^{\prime}=\mathrm{H}\right) \\
0,5\left(\mathrm{R}^{\prime}=\text { alila }\right)\end{array}$ & $\begin{array}{l}98\left(\mathrm{R}^{\prime}=\mathrm{H}\right)(\mathbf{3 a}) \\
98\left(\mathrm{R}^{\prime}=\text { alila }\right)^{\mathrm{a}}(\mathbf{4 a})\end{array}$ \\
\hline ANILINA & & $3,0\left(\mathrm{R}^{\prime}=\right.$ alila $)$ & $60\left(\mathrm{R}^{\prime}=\text { alila }\right)^{\mathrm{a}}(4 \mathrm{~b})$ \\
\hline $\begin{array}{l}N- \\
\text { HEXILAMINA } \\
()_{4} \mathrm{NH}_{2}\end{array}$ & & $\begin{array}{l}0,2\left(\mathrm{R}^{\prime}=\mathrm{H}\right) \\
0,5\left(\mathrm{R}^{\prime}=\text { alila }\right)\end{array}$ & $\begin{array}{l}96\left(\mathrm{R}^{\prime}=\mathrm{H}\right)(\mathbf{3 b}) \\
92\left(\mathrm{R}^{\prime}=\text { alila }\right)^{\mathrm{a}}(\mathbf{4 c})\end{array}$ \\
\hline
\end{tabular}

${ }^{\text {a }}$ Foram utilizados 2 equivalentes de amina 
4.1.1.2.1. (2Z)-3-(benzilamino)but-2-enoato de etila (3a)

Tabela IX: Dados analíticos do composto (2Z)-3-(benzilamino)but-2-enoato de etila (3a)

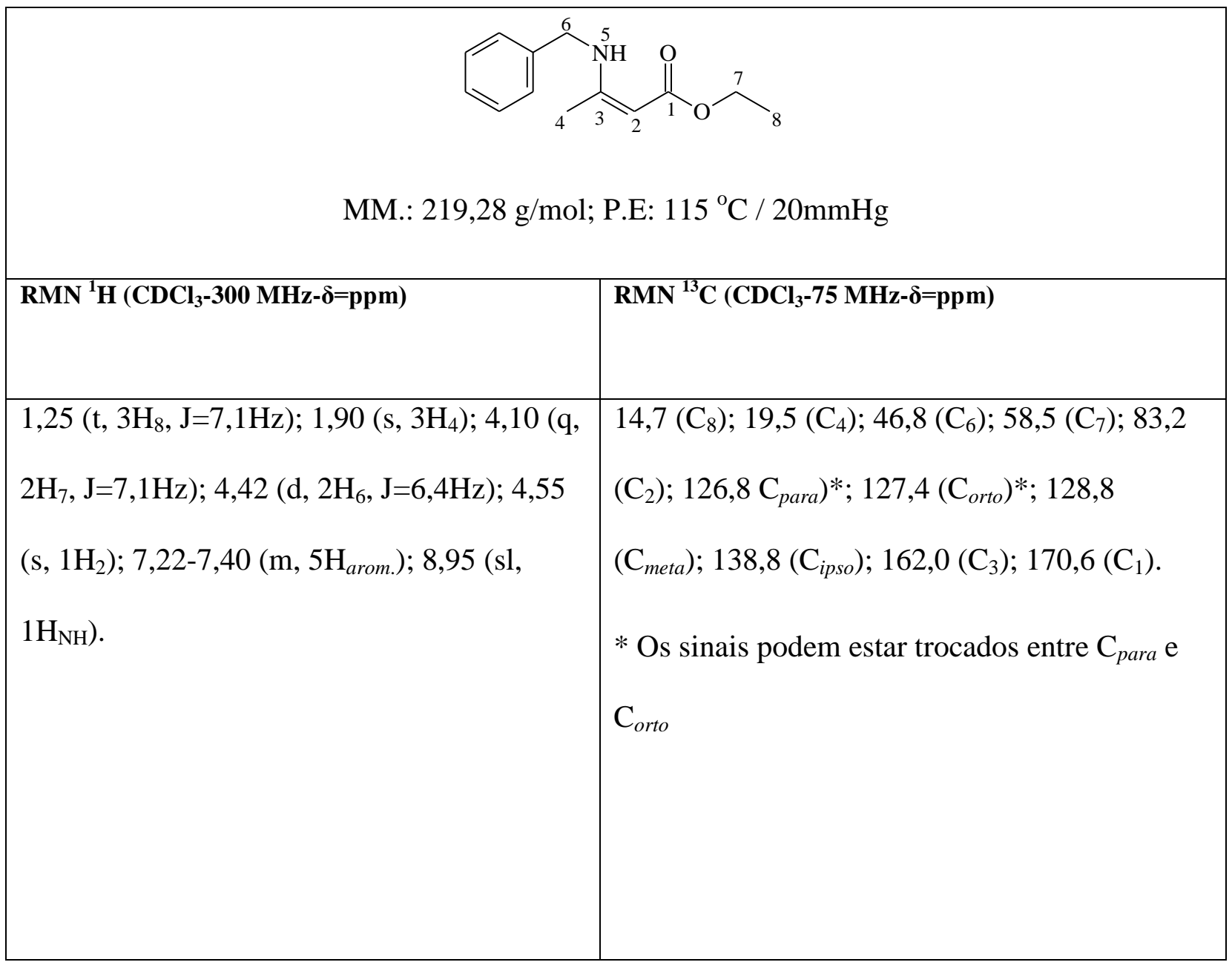


4.1.1.2.2. 2-[1-(benzilamino) etilideno] pent-4-enoato de etila (4a).

Tabela X: Dados analíticos do composto 2-[1-(benzilamino) etilideno] pent-4-enoato de etila (4a).

\begin{tabular}{|c|c|}
\hline \multicolumn{2}{|c|}{ MM: $259,34 \mathrm{~g} / \mathrm{mol}$; P.E.: $115^{\circ} \mathrm{C} / 0,20 \mathrm{mmHg}$} \\
\hline $\mathrm{RMN}^{1}{ }^{1} \mathrm{H}\left(\mathrm{CDCl}_{3}-300 \mathrm{MHz}-\delta=\mathbf{p p m}\right)$ & $\mathrm{RMN}^{13} \mathrm{C}\left(\mathrm{CDCl}_{3}-75 \mathrm{MHz}-\delta=\mathbf{p p m}\right)$ \\
\hline $\begin{array}{l}1,24\left(\mathrm{t}, 3 \mathrm{H}_{8}, \mathrm{~J}=7,1 \mathrm{~Hz}\right) ; 1,89\left(\mathrm{~s}, 3 \mathrm{H}_{6}\right) ; 3,00(\mathrm{~d}, \\
\left.2 \mathrm{H}_{3}, \quad \mathrm{~J}=5,7 \mathrm{~Hz}\right) ; 4,11\left(\mathrm{q}, \quad 2 \mathrm{H}_{9}, \quad \mathrm{~J}=7,1 \mathrm{~Hz}\right) ; \\
4,40\left(\mathrm{~d}, 2 \mathrm{H}_{10}, \mathrm{~J}=6,2 \mathrm{~Hz}\right) ; 4,87-4,98\left(\mathrm{~m}, 2 \mathrm{H}_{5}\right) ; \\
5,72-5,89\left(\mathrm{~m}, 1 \mathrm{H}_{4}\right) ; 7,2-7,34\left(\mathrm{~m}, 5 \mathrm{H}_{\text {arom }}\right) ; \\
9,76\left(\mathrm{~m}, 1 \mathrm{H}_{\mathrm{NH}}\right) .\end{array}$ & $\begin{array}{l}14,5\left(\mathrm{C}_{8}\right) ; 14,7\left(\mathrm{C}_{6}\right) ; 31,2\left(\mathrm{C}_{3}\right) ; 46,9\left(\mathrm{C}_{10}\right) ; \\
58,6\left(\mathrm{C}_{9}\right) ; 90,3\left(\mathrm{C}_{2}\right) ; 112,8\left(\mathrm{C}_{5}\right) ; 126,6\left(\mathrm{C}_{\text {orto }}\right) ; \\
127,0\left(\mathrm{C}_{\text {para }}\right) ; 128,6\left(\mathrm{C}_{\text {meta }}\right) ; 138,2\left(\mathrm{C}_{4}\right) ; 139,1 \\
\left(\mathrm{C}_{\text {ipso. }}\right) ; 160,4\left(\mathrm{C}_{7}\right) ; 170,6\left(\mathrm{C}_{1}\right) .\end{array}$ \\
\hline
\end{tabular}


4.1.1.2.3. (2Z)-2[1-(fenilamino)etilideno]pent-4-enoato de etila (4b)

Tabela XI: Dados analíticos do composto (2Z)-2[1-(fenilamino)etilideno]pent-4-enoato de etila (4b)

\begin{tabular}{|c|c|}
\hline \multicolumn{2}{|c|}{ MM: $245,32 \mathrm{~g} / \mathrm{mol}$} \\
\hline $\mathrm{RMN}^{1} \mathrm{H}\left(\mathrm{CDCl}_{3}-300 \mathrm{MHz}-\delta=p p m\right)$ & $\mathrm{RMN}^{13} \mathrm{C}\left(\mathrm{CDCl}_{3}-75 \mathrm{MHz}-\delta=\mathrm{ppm}\right)$ \\
\hline $\begin{array}{l}1,27\left(\mathrm{t}, 3 \mathrm{H}_{8}, J=7,2 \mathrm{~Hz}\right), 2,01\left(\mathrm{~s}, 3 \mathrm{H}_{6}\right), 3,06 \\
\left(\mathrm{~d}, 2 \mathrm{H}_{3}, J=5,8 \mathrm{~Hz}\right), 4,19\left(\mathrm{q}, 2 \mathrm{H}_{9}, J=7,2\right. \\
\mathrm{Hz}), 4,93-5,13\left(\mathrm{~m}, 2 \mathrm{H}_{5}\right), 5,69-5,90(\mathrm{~m}, 1 \\
\left.\mathrm{H}_{4}\right), 7,02\left(\mathrm{~d}, 2 \mathrm{H}_{\text {orto }}, J=7,5 \mathrm{~Hz}\right), 7,17(\mathrm{t}, 1 \\
\left.\mathrm{H}_{\text {para }} J=7,5 \mathrm{~Hz}\right), 7,30\left(\mathrm{t}, 2 \mathrm{H}_{\text {meta }}, J=7,5\right. \\
\mathrm{Hz}), 11,06(\mathrm{sl}, 1 \mathrm{H}, \mathrm{NH}) .\end{array}$ & $\begin{array}{l}14,5\left(\mathrm{C}_{8}\right), 16,4\left(\mathrm{C}_{6}\right), 31,4\left(\mathrm{C}_{3}\right), 58,1\left(\mathrm{C}_{9}\right), 93,8 \\
\left(\mathrm{C}_{2}\right), 113,3\left(\mathrm{C}_{5}\right), 124,4\left(\mathrm{C}_{\text {arom. }}\right), 124,6\left(\mathrm{C}_{\text {arom. }}\right), \\
128,9\left(\mathrm{C}_{\text {arom. }}\right), 137,5\left(\mathrm{C}_{4}\right), 139,9\left(\mathrm{C}_{\text {arom. }}\right), \\
157,9\left(\mathrm{C}_{7}\right), 170,5\left(\mathrm{C}_{1}\right) .\end{array}$ \\
\hline
\end{tabular}


4.1.1.2.4. (2Z)-3-(hexilamino)but-2-enoato de etila (3b)

Tabela XII: Dados analíticos do composto (2Z)-3-(hexilamino)but-2-enoato de etila (3b)

\begin{tabular}{|c|c|c|}
\hline \multicolumn{3}{|c|}{ MM: $213,32 \mathrm{~g} / \mathrm{mol} ;$ P. E. $=105-110^{\circ} \mathrm{C} / 0.20 \mathrm{mmHg}$} \\
\hline IV (film) $v_{\text {max. }}\left(\mathbf{c m}^{-1}\right)$ & $\mathrm{RMN}^{1} \mathrm{H}\left(\mathrm{CDCl}_{3}-300 \mathrm{MHz}-\delta=\mathrm{ppm}\right)$ & $\mathrm{RMN}^{13} \mathrm{C}\left(\mathrm{CDCl}_{3}-75 \mathrm{MHz}-\delta=\mathrm{ppm}\right)$ \\
\hline 1655,1606 & $\begin{array}{l}0,89\left(\mathrm{t}, 3 \mathrm{H}_{11}, \mathrm{~J}=6,7 \mathrm{~Hz}\right) ; 1,24\left(\mathrm{t}, 3 \mathrm{H}_{13},\right. \\
\mathrm{J}=7,1 \mathrm{~Hz}) ; 1,22-1,41 \quad\left(\mathrm{~m}, 6 \mathrm{H}_{10,9,8}\right) ; \\
1,51-1,60\left(\mathrm{~m}, 2 \mathrm{H}_{7}\right) ; 1,91\left(\mathrm{~s}, 3 \mathrm{H}_{4}\right) ; 3,19 \\
\left(\mathrm{q}, 2 \mathrm{H}_{6}, \mathrm{~J}=6,7 \mathrm{~Hz}\right) ; 4,08 \quad\left(\mathrm{q}, 2 \mathrm{H}_{12},\right. \\
\mathrm{J}=7,1 \mathrm{~Hz}) ; 4,42 \quad\left(\mathrm{~s}, 1 \mathrm{H}_{2}\right) ; 8,56 \quad(\mathrm{sl}, \\
\left.1 \mathrm{H}_{\mathrm{NH}}\right) .\end{array}$ & $\begin{array}{l}13,6\left(\mathrm{C}_{11}\right) * 14,3\left(\mathrm{C}_{13}\right)^{*} ; 18,9 \\
\left(\mathrm{C}_{4}\right) ; 22,2\left(\mathrm{C}_{10}\right) ; 26,2\left(\mathrm{C}_{8}\right) ; \\
30,1\left(\mathrm{C}_{9}\right) ; 31,2\left(\mathrm{C}_{7}\right) ; 42,7\left(\mathrm{C}_{6}\right) ; \\
57,8\left(\mathrm{C}_{12}\right) ; 81,5\left(\mathrm{C}_{2}\right) ; 161,5 \\
\left(\mathrm{C}_{3}\right) ; 170,3\left(\mathrm{C}_{1}\right) . \\
* \text { Os sinais podem estar } \\
\text { trocados entre } \mathrm{C}_{11} \text { e } \mathrm{C}_{13} .\end{array}$ \\
\hline
\end{tabular}


4.1.1.2.5. 2-[1-(hexilamino)etilideno]pent-4-enoato de etila (4c)

Tabela XIII: Dados analíticos do composto 2-[1-(hexilamino)etilideno]pent-4-enoato de etila (4c)

\begin{tabular}{|l|l|}
\hline & \\
\hline &
\end{tabular}

As $\beta$-enaminonas constituem uma classe especial de enaminas e é definida pelos compostos que contém o sistema amino $\alpha$ - $\beta$-insaturado com o grupo carbonila. Esses compostos são intermediários versáteis para síntese de inúmeros compostos de grande interesse farmacológico, mais especificamente antiinflamatório, classe correspondente ao presente trabalho (BRANDT et al., 2004).

A partir de estudos realizados em nosso laboratório, foi possível verificar que a utilização de catálise ácida favorecia o ataque nucleofílico do $\mathrm{N}$ ao $\mathrm{C}$ carbonílico. Somado ao uso de ultrasom, ambos resultaram na redução significativa do tempo da reação, além de fornecer rendimentos próximos do quantitativo (tabela VIII). Com base nestes estudos, os $\beta$ enaminoésteres (3a-b; 4a-c) foram preparados a partir de acetoacetato de etila (1) e aminas primárias, utilizando ultra-som, na presença de ácido acético glacial (BRANDT et al., 2004). A 
obtenção dos compostos $\mathbf{3 a}, \mathbf{3 b}, \mathbf{4 a}, \mathbf{4 b}$ e $\mathbf{4 c}$ foi confirmada através de espectros de $\mathrm{RMN}{ }^{1} \mathrm{H}$ e RMN ${ }^{13} \mathrm{C}$ (tabelas de IX a XIII), verificando-se a presença do hidrogênio 2 na forma de singleto em, aproximadamente 4,5 ppm nos derivados não alquilados (3a-b) e nos $\beta$-enaminoésteres alquilados (4a-c) nota-se o aparecimento de um dubleto, correspondente ao hidrogênio $\mathrm{H}_{3}$ em aproximadamente 3,00 ppm e ausência de hidrogênio 2. É importante ressaltar que no material de partida (2) dos análogos alquilados, o e ausência de hidrogênio 3 absorveu em 2,60 ppm, na forma de tripleto.

Os melhores resultados foram obtidos quando se utilizou aminas mais nucleofílicas, tais como benzilamina e $n$-hexilamina, as quais forneceram produtos próximos do rendimento quantitativo ( $\sim 90 \%)$ e em curto período de tempo ( $1 / 2$ hora). Em contrapartida, com anilina, amina menos reativa (4b), houve redução do rendimento para 60\% e aumento do tempo para 3 horas, apresentado na tabela VIII.

As vantagens desse novo método para síntese de $\beta$-enaminoésteres utilizando ácido acético como catalisador são as condições simples de reação, processos econômicos, bons rendimentos, curto período de tempo e facilidade na extração.

\subsubsection{Derivados pirrólicos obtidos via metodologia de Hantzsch (5a-b)}

Reação realizada:

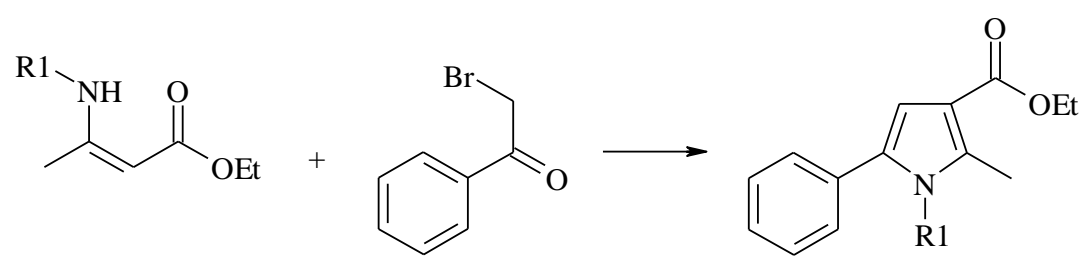

R1: BENZILA, N-HEXILA 
4.1.1.3.1. 1-benzil-2-metil-5-fenil-1 $H$-pirrol-3-carboxilato de etila (5a)

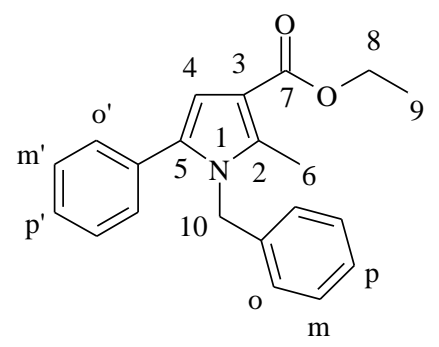

$\mathrm{C}_{21} \mathrm{H}_{21} \mathrm{NO}_{2}$; MM: 319,39 g/mol; Aspecto: líquido amarelado viscoso; Rendimento: 46,9\%; CLog P: 4,61

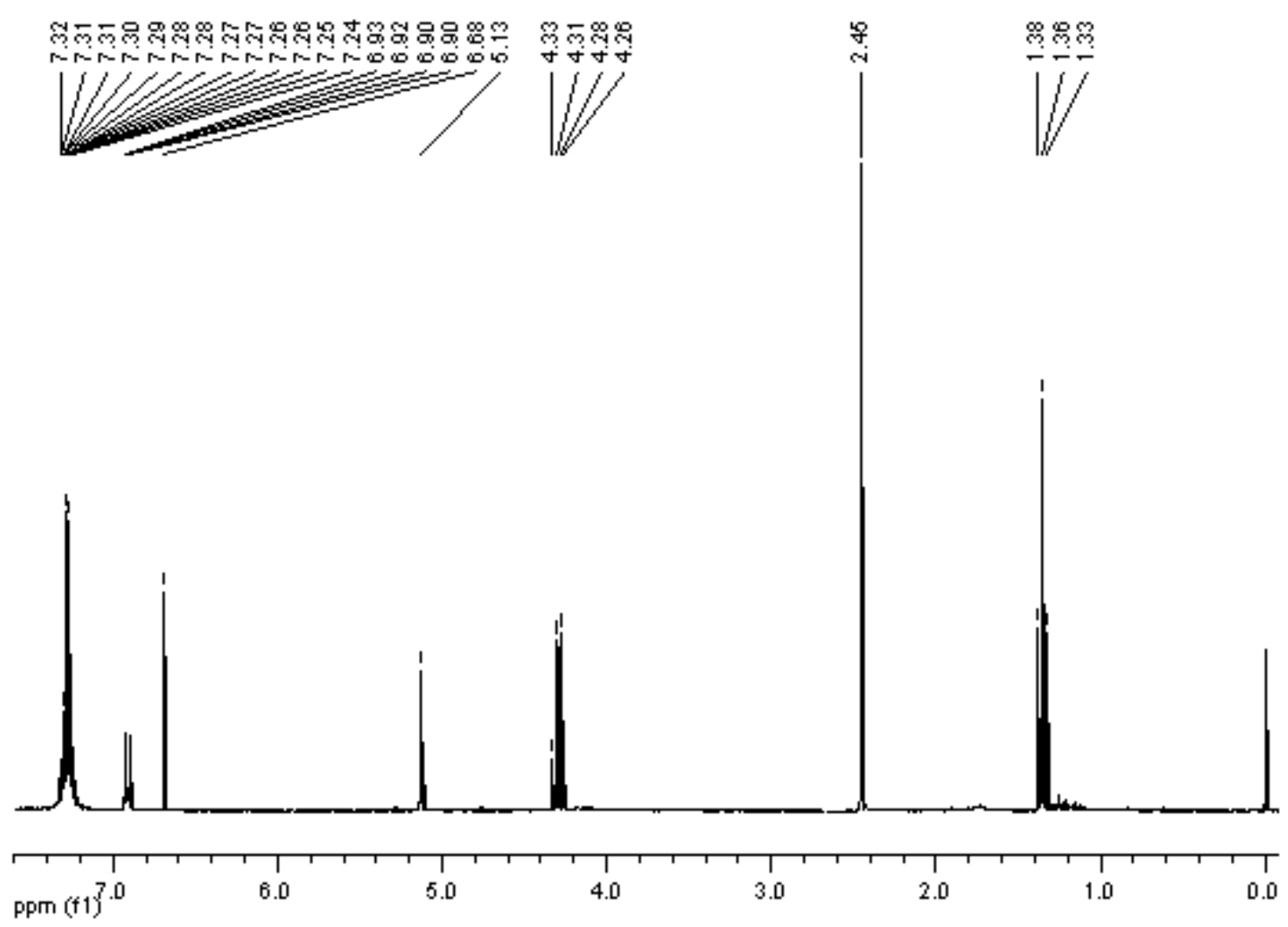

Espectro 2: Espectro de RMN ${ }^{1} \mathrm{H}$ do 1-benzil-2-metil-5-fenil-1 $H$-pirrol-3-carboxilato de etila (5a)

Tabela XIV: Dados de RMN ${ }^{1} \mathrm{H}$ do 1-benzil-2-metil-5-fenil-1H-pirrol-3-carboxilato de etila (5a)

$\mathbf{R M N}^{1} \mathbf{H}$ : $\left(\mathbf{C D C l}_{\mathbf{3}} \mathbf{- 3 0 0} \mathbf{M H z}-\boldsymbol{\delta}=\mathbf{p p m}\right)$

1,36 (t, $\left.3 \mathrm{H}_{9}, \mathrm{~J}=6,9 \mathrm{~Hz}\right) ; 2,45$ (s, $3 \mathrm{H}_{6}$ ); 4,29 (q, $2 \mathrm{H}_{8, \mathrm{~J}} \mathrm{=6,9Hz);} \mathrm{5,13} \mathrm{(s,} 2 \mathrm{H}_{10}$ ); 6,68 (s,

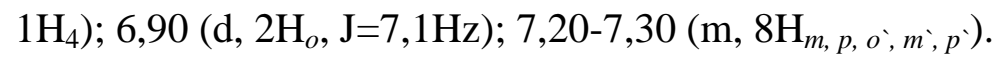



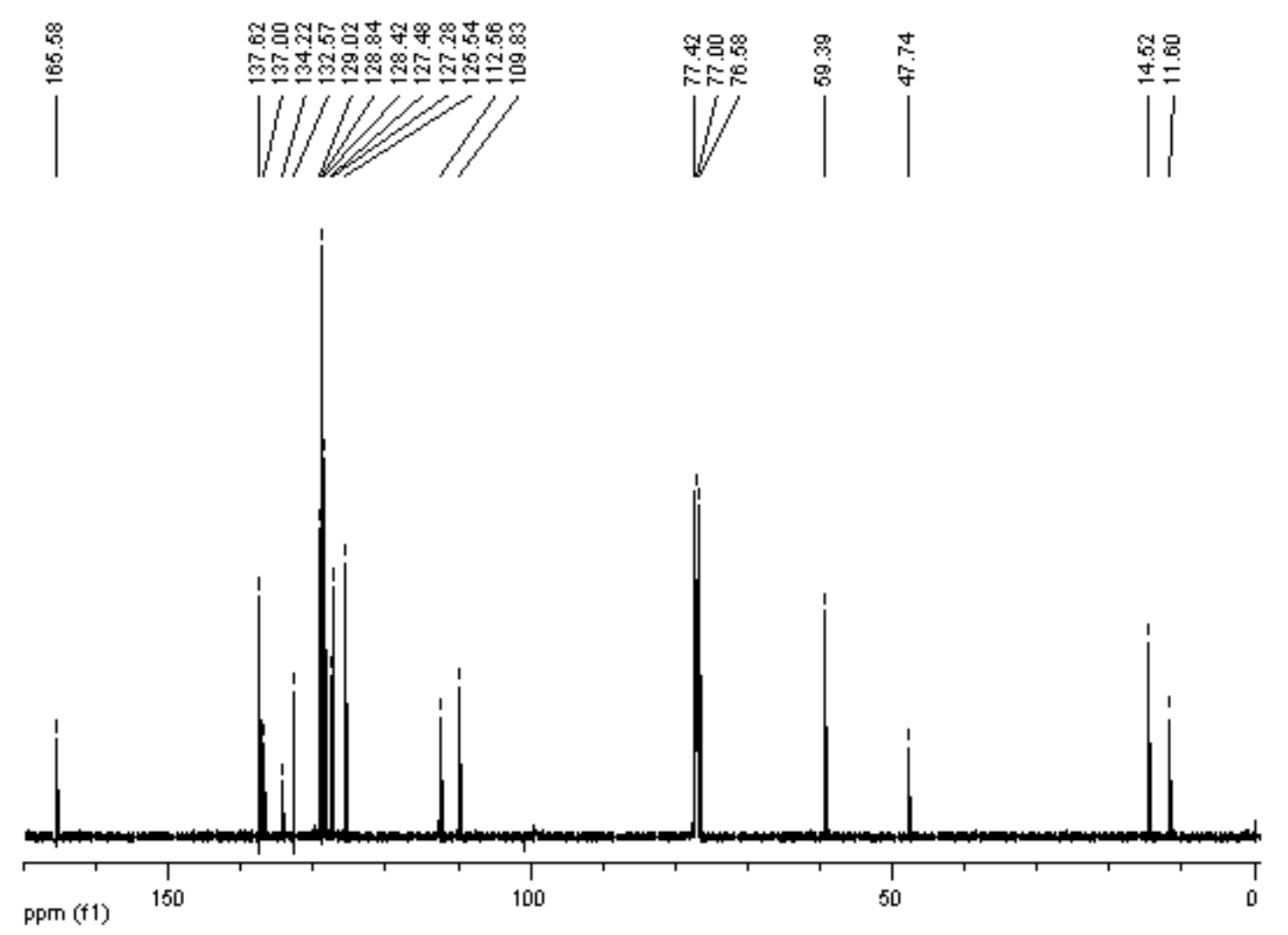

Espectro 3: Espectro de $\mathrm{RMN}{ }^{13} \mathrm{C}$ do 1-benzil-2-metil-5-fenil-1H-pirrol-3-carboxilato de etila (5a)

Tabela XV: Dados de RMN ${ }^{13} \mathrm{C}$ do 1-benzil-2-metil-5-fenil-1H-pirrol-3-carboxilato de etila (5a)

\section{$\mathrm{RMN}^{13} \mathrm{C}\left(\mathrm{CDCl}_{3}-75 \mathrm{MHz}-\delta=\mathrm{ppm}\right)$}

11,6 ( $\left.\mathrm{C}_{6}\right) ; 14,5\left(\mathrm{C}_{9}\right) ; 47,7\left(\mathrm{C}_{10}\right) ; 59,4\left(\mathrm{C}_{8}\right) ; 109,8\left(\mathrm{C}_{4}\right) ; 112,6\left(\mathrm{C}_{3}\right) ; 125,5\left(\mathrm{C}_{o}\right) ; 127,3\left(\mathrm{C}_{p}\right)$;

$127,5\left(\mathrm{C}_{p}\right) ; 128,4\left(\mathrm{C}_{o}\right) ; 128,8\left(\mathrm{C}_{m}\right) ; 129,0\left(\mathrm{C}_{m}\right) ; 132,6\left(\mathrm{C}_{5}\right)^{*} ; 134,2\left(\mathrm{C}_{2}\right)^{*} ; 137,0$

$\left(\mathrm{C}_{i p s o}\right)^{* * ;}$ 137,6 ( $\left.\mathrm{C}_{i p s o}\right)^{* *} ; 165,6\left(\mathrm{C}_{7}\right)$.

* Os sinais do $\mathrm{C}_{5}$ e $\mathrm{C}_{2}$ podem estar trocados.

** Os sinais do $\mathrm{C}_{i p s o}$ - e $\mathrm{C}_{\text {ipso }}$ podem estar trocados. 


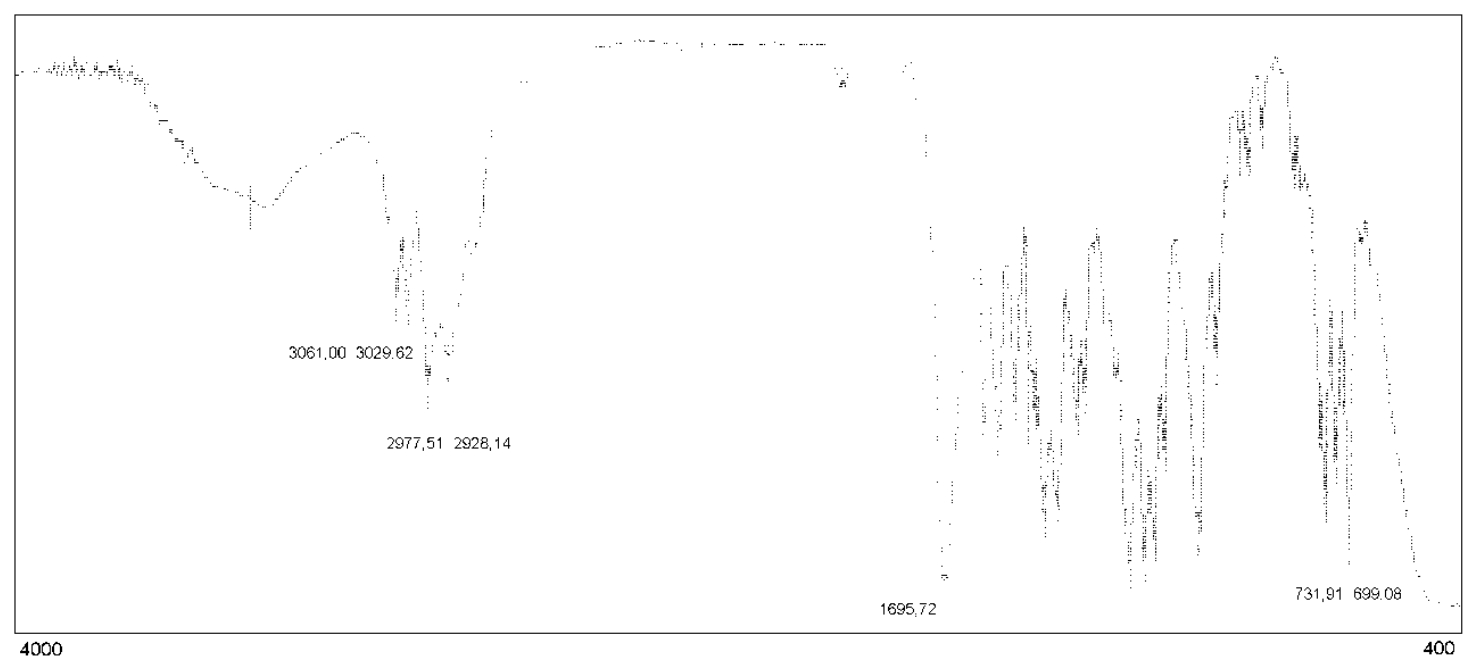

Espectro 4: Espectro de IV do 1-benzil-2-metil-5-fenil-1H-pirrol-3-carboxilato de etila (5a)

Tabela XVI: Dados de IV do 1-benzil-2-metil-5-fenil-1H-pirrol-3-carboxilato de etila (5a) IV-V max. $\left(\mathrm{cm}^{-1}\right)$

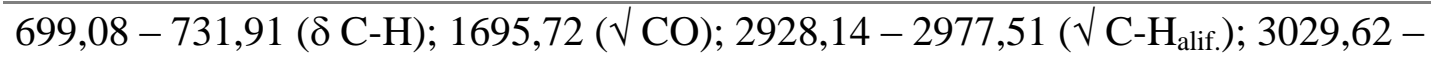
3061,00 ( $\left.\sqrt{ } \mathrm{C}-\mathrm{H}_{\text {arom. }}\right)$. 


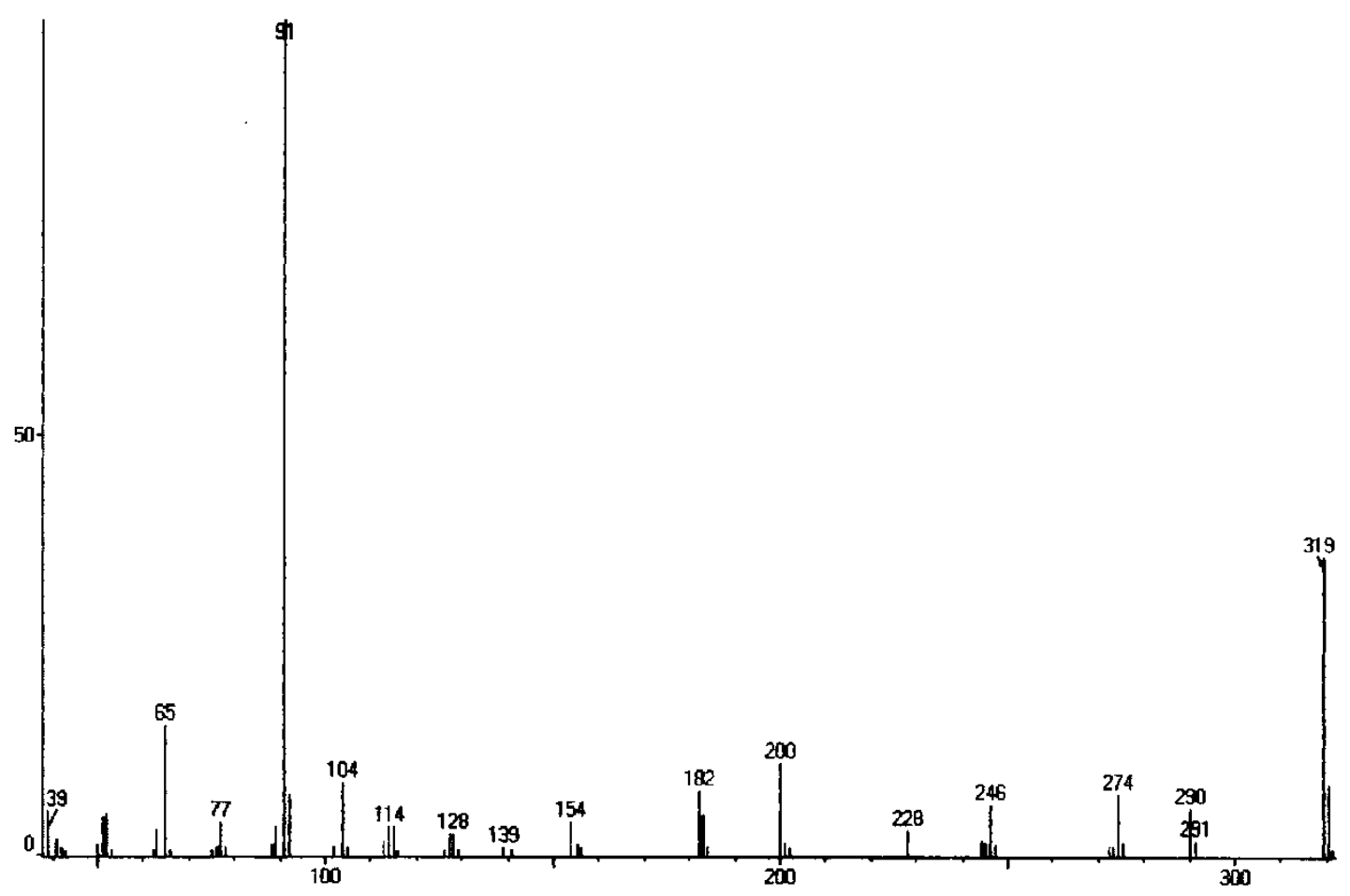

Espectro 5: Espectro de massas do 1-benzil-2-metil-5-fenil-1H-pirrol-3-carboxilato de etila (5a)

Tabela XVII: Dados do espectro de massas do 1-benzil-2-metil-5-fenil-1H-pirrol-3-carboxilato de etila (5a)

CG / MS - razão massa / carga $(\mathrm{m} / \mathrm{z})$ : intensidade relativa

$319[\mathrm{M}]^{+}: 35,52 ; 290\left[\mathrm{M}-\mathrm{C}_{2} \mathrm{H}_{5}\right]^{+}: 5,74 ; 274\left[\mathrm{M}-\mathrm{OC}_{2} \mathrm{H}_{5}\right]^{+}: 7,48 ; 246\left[\mathrm{M}-\mathrm{CO}_{2} \mathrm{C}_{2} \mathrm{H}_{5}\right]^{+}:$

6,$23 ; 91\left[\mathrm{C}_{6} \mathrm{H}_{5} \mathrm{CH}_{2}\right]^{+}: 100$. 
4.1.1.3.2. 1-hexil-2-metil-5-fenil-1Hpirrol-3-carboxilato de etila (5b)

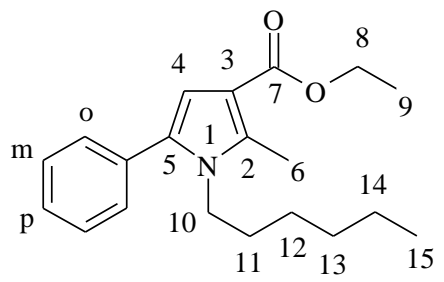

$\mathrm{C}_{20} \mathrm{H}_{27} \mathrm{NO}_{2}$; MM: 313,43 g/mol; Aspecto: líquido viscoso alaranjado; Rendimento: 59,5\%; CLog P: 4,84

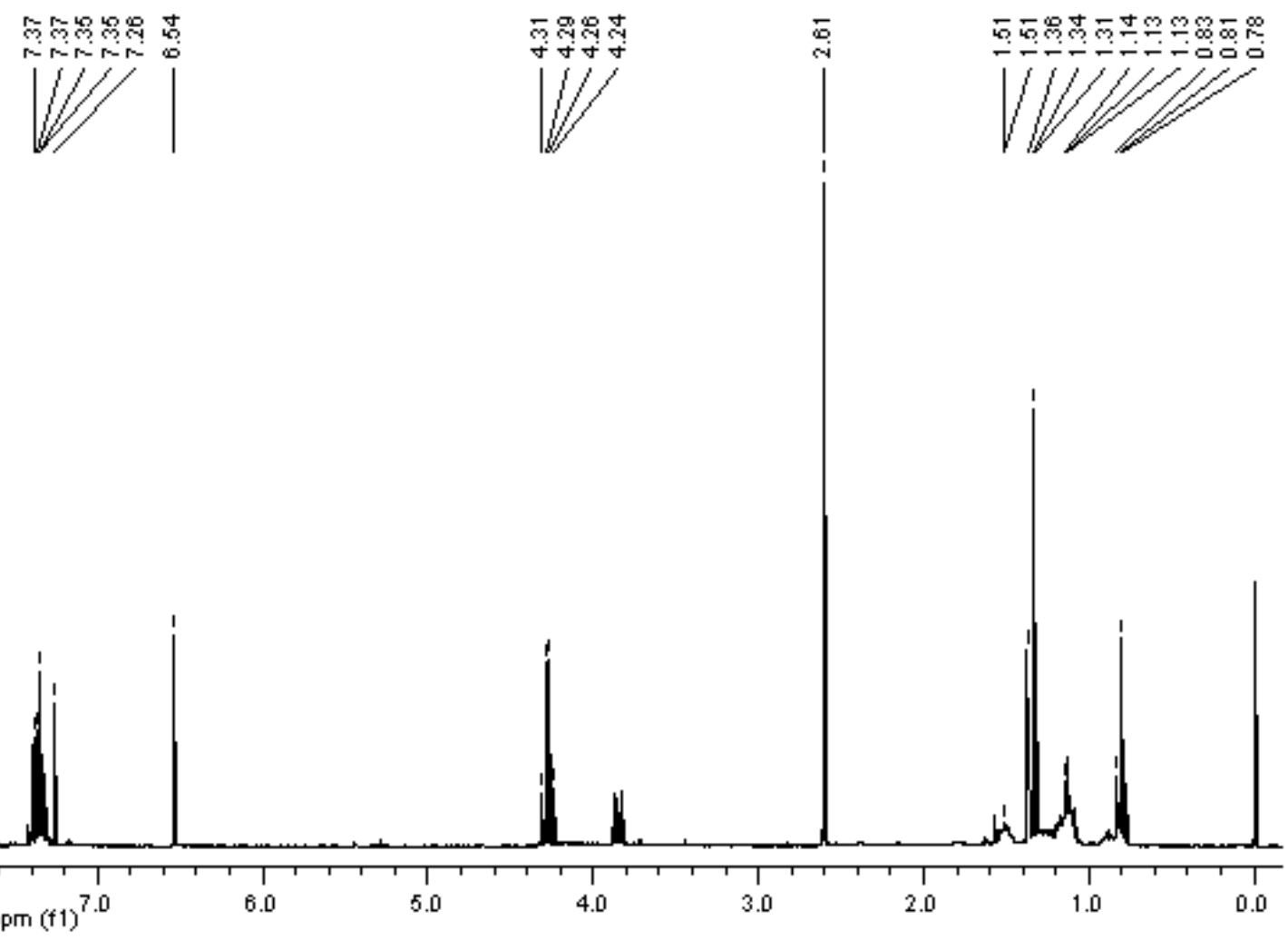

Espectro 6: Espectro de $\mathrm{RMN}{ }^{1} \mathrm{H}$ do 1-hexil-2-metil-5fenil-1Hpirrol-3-carboxilato de etila (5b)

Tabela XVIII: Dados de RMN ${ }^{1} \mathrm{H}$ do 1-hexil-2-metil-5fenil-1Hpirrol-3-carboxilato de etila (5b) $\mathrm{RMN}^{1} \mathrm{H}:\left(\mathrm{CDCl}_{3}-300 \mathrm{MHz}-\delta=\mathrm{ppm}\right)$

$0,81\left(\mathrm{t}, 3 \mathrm{H}_{15}, \mathrm{~J}=6,9 \mathrm{~Hz}\right) ; 1,12-1,36\left(\mathrm{~m}, 6 \mathrm{H}_{12,13,14}\right) ; 1,34$ (t, 3H $\left., \mathrm{J}=7,2 \mathrm{~Hz}\right) ; 1,48$ (quint., $\left.2 \mathrm{H}_{11}, \mathrm{~J}=6,9 \mathrm{~Hz}\right) ; 2,61\left(\mathrm{~s}, 3 \mathrm{H}_{6}\right) ; 3,85\left(\mathrm{t}, 2 \mathrm{H}_{10}, \mathrm{~J}=6,9 \mathrm{~Hz}\right) ; 4,27$ (q, 2 $\left.\mathrm{H}_{8}, \mathrm{~J}=7,2 \mathrm{~Hz}\right) ; 6,54$ (s, $\left.1 \mathrm{H}_{4}\right) ; 7,32-7,39\left(\mathrm{~m}, 5 \mathrm{H}_{\text {arom. }}\right)$ 


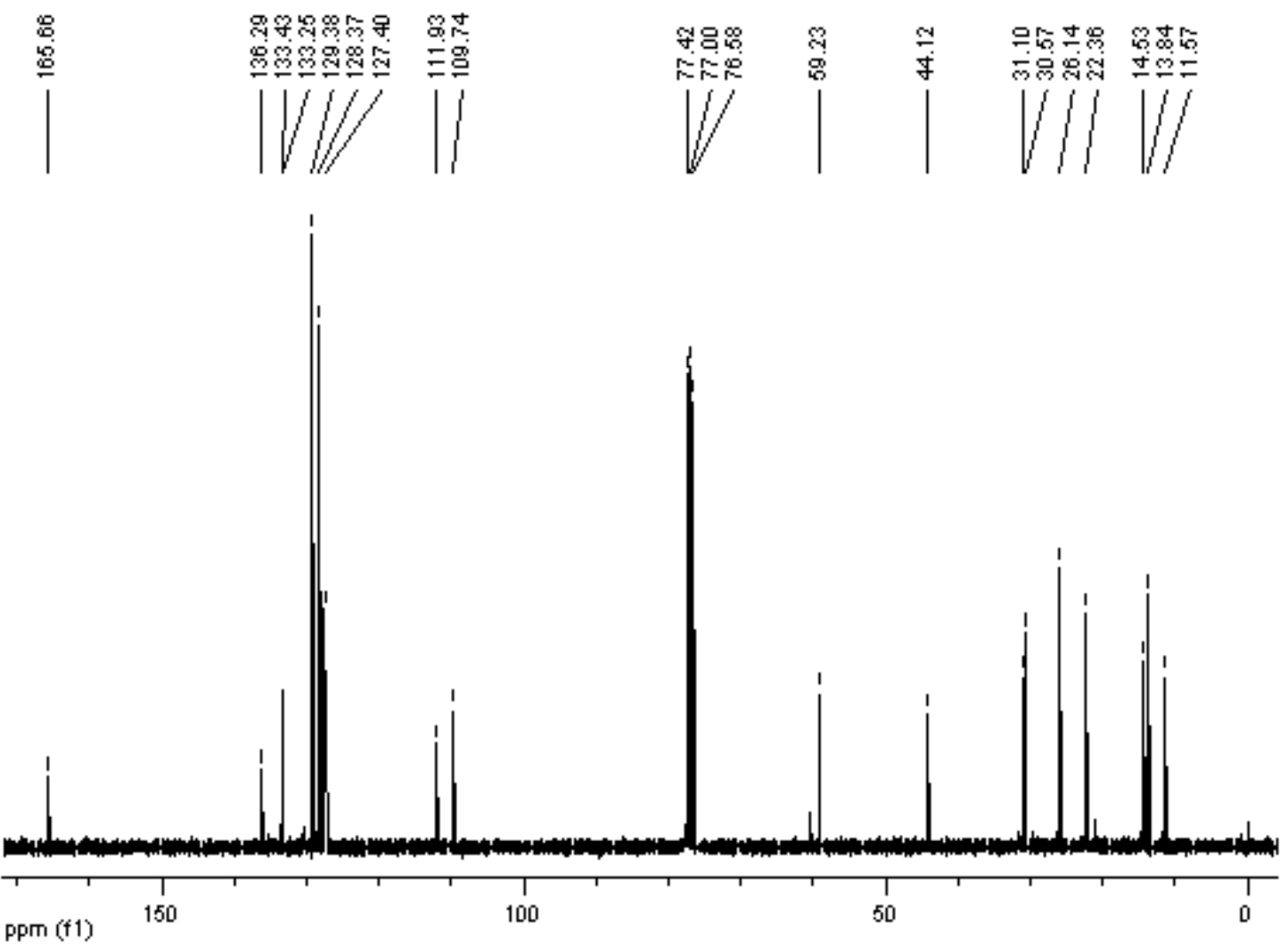

Espectro 7: Espectro de $\mathrm{RMN}{ }^{13} \mathrm{C}$ do 1-hexil-2-metil-5-fenil-1Hpirrol-3-carboxilato de etila (5b)

Tabela XIX: Dados de RMN ${ }^{13} \mathrm{C}$ do 1-hexil-2-metil-5-fenil-1Hpirrol-3-carboxilato de etila (5b) $\mathrm{RMN}^{13} \mathrm{C}\left(\mathrm{CDCl}_{3}-75 \mathrm{MHz}-\delta=\mathrm{ppm}\right)$

$11,6\left(\mathrm{C}_{6}\right) ; 13,9\left(\mathrm{C}_{9}\right)^{*} ; 14,6\left(\mathrm{C}_{15}\right)^{*} ; 22,4\left(\mathrm{C}_{14}\right) ; 26,2\left(\mathrm{C}_{12}\right) ; 30,6\left(\mathrm{C}_{13}\right) ; 31,1\left(\mathrm{C}_{11}\right) ; 59,3$

$\left(\mathrm{C}_{8}\right) ; 109,8\left(\mathrm{C}_{4}\right) ; 112,0\left(\mathrm{C}_{3}\right) ; 127,4\left(\mathrm{C}_{p}\right) ; 128,4\left(\mathrm{C}_{o}\right) ; 129,4\left(\mathrm{C}_{m}\right) ; 133,3\left(\mathrm{C}_{5}\right)^{* *} ; 133,5$

$\left(\mathrm{C}_{2}\right)^{* *} ; 136,3\left(\mathrm{C}_{\text {ipso }}\right) ; 165,7\left(\mathrm{C}_{7}\right)$.

* Os sinais do $\mathrm{C}_{9}$ e $\mathrm{C}_{15}$ podem estar trocados.

** Os sinais do $\mathrm{C}_{5}$ e $\mathrm{C}_{2}$ podem estar trocados. 


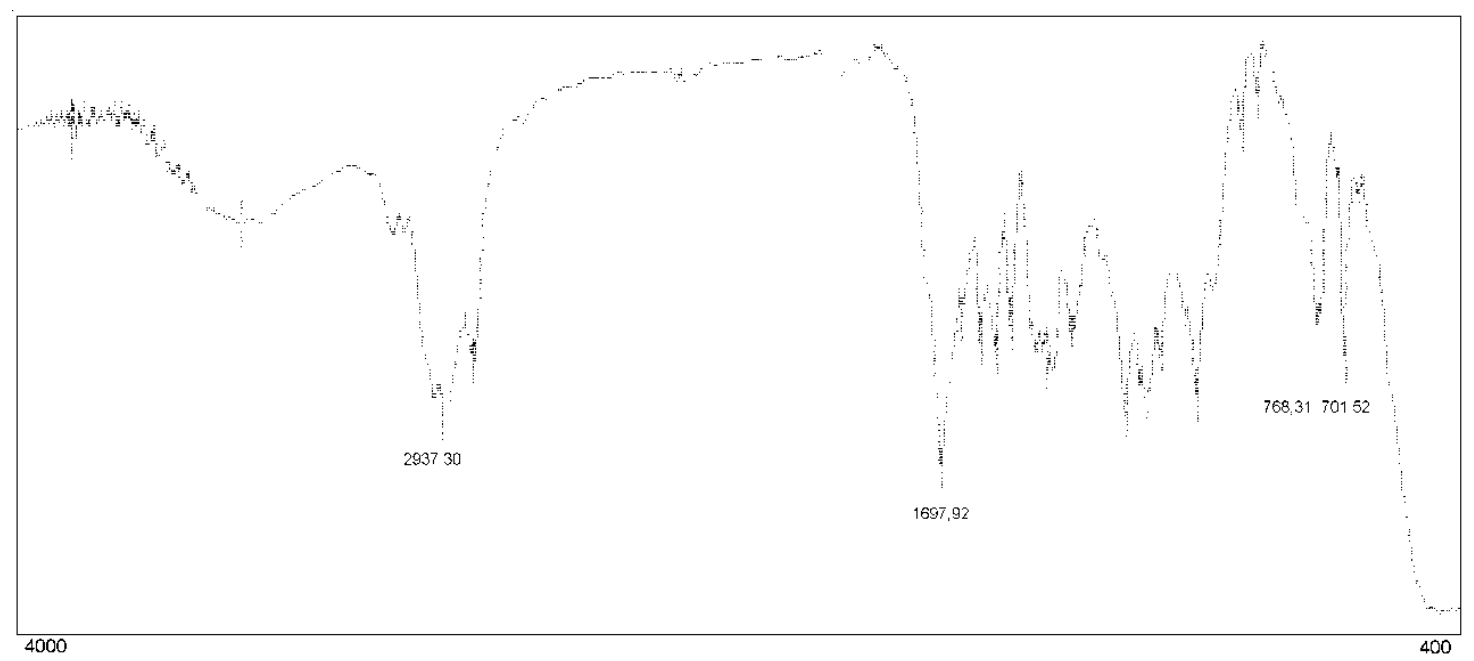

Espectro 8: Espectro de IV do 1-hexil-2-metil-5-fenil-1Hpirrol-3-carboxilato de etila (5b)

Tabela XX: Dados de IV do 1-hexil-2-metil-5-fenil-1Hpirrol-3-carboxilato de etila (5b) IV-V max. $\left(\mathrm{cm}^{-1}\right)$ 701,52 - 768,31 ( $\delta \mathrm{C}-\mathrm{H}) ; 1697,92(\sqrt{ } \mathrm{CO}) ; 2937,30\left(\sqrt{ } \mathrm{C}-\mathrm{H}_{\text {alif. e arom. }}\right)$. 


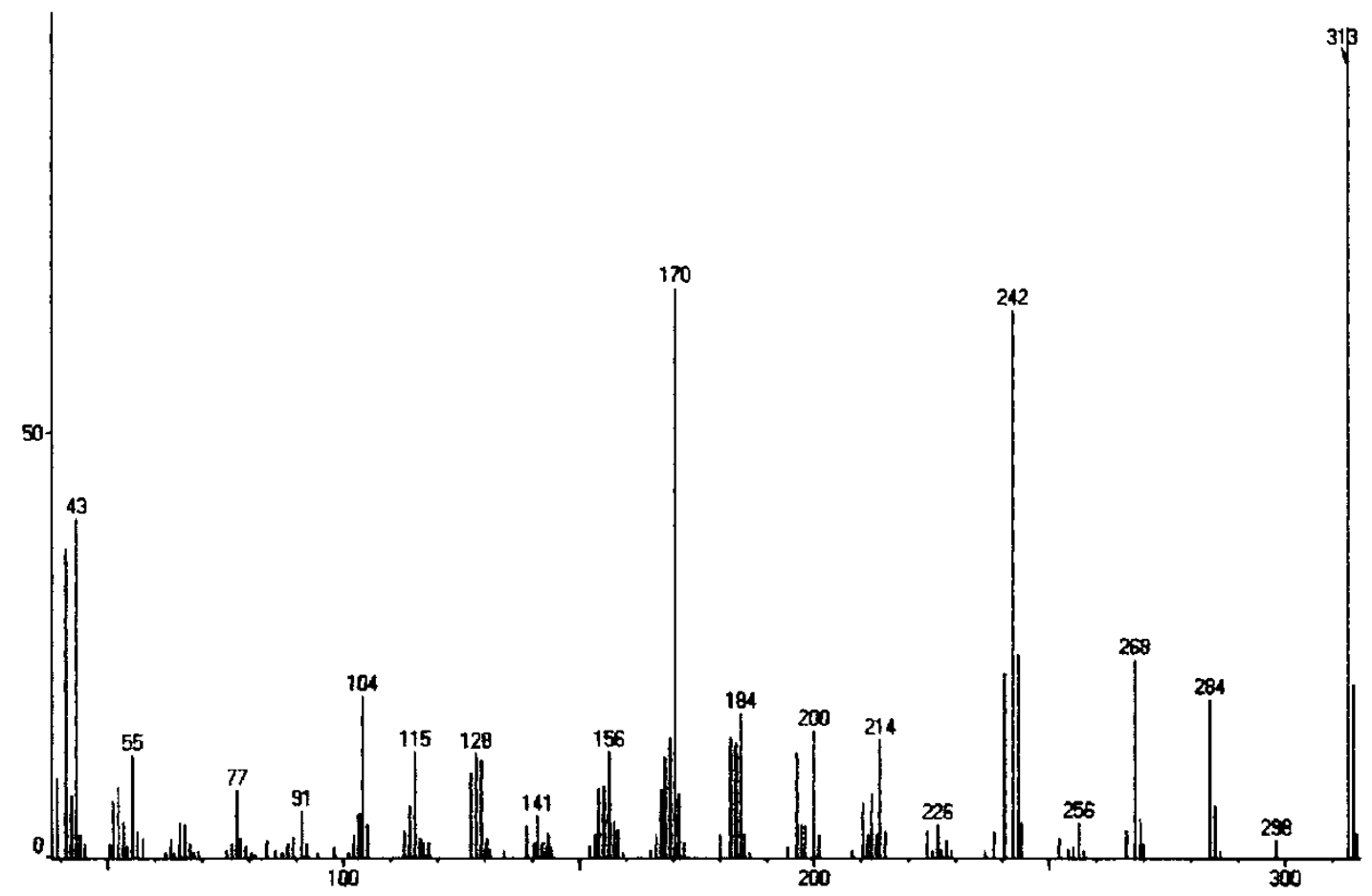

Espectro 9: Espectro de massas do 1-hexil-2-metil-5-fenil-1Hpirrol-3-carboxilato de etila (5b)

Tabela XXI: Dados do espectro de massas do 1-hexil-2-metil-5-fenil-1Hpirrol-3-carboxilato de etila (5b)

CG / MS - razão massa / carga $(\mathrm{m} / \mathrm{z})$ : intensidade relativa $313[\mathrm{M}]^{+}: 100 ; 268\left[\mathrm{M}-\mathrm{OC}_{2} \mathrm{H}_{5}\right]: 23,34 ; 214\left[\mathrm{M}-\mathrm{C}_{2} \mathrm{H}_{4}\right.$, rearranjo Mc Lafferty]: 14,06; $170\left[\mathrm{M}-\mathrm{CO}_{2}\right] 66,91 ; 77\left[\mathrm{C}_{6} \mathrm{H}_{5}\right]^{+}: 7,96$. 
A obtenção dos derivados pirrólicos (5a-b) a partir de enaminas (3a-b) foi resultado de estudo minucioso da reação de Hantzsch, descrita por ROOMI e MAcDONALD (1970), que consiste na condensação de $\alpha$-halocetonas e compostos 1,3-dicarbonílicos, na presença de amônia. A principal característica desta metodologia é o emprego do acetoacetato de etila (1), reagente de baixo custo e facilmente acessível. Visando a otimização da rota sintética, recorreuse à metodologia baseada na irradiação por ultra-som, que permite condições reacionais mais brandas e de acordo com princípios da Química Verde. Essa nova metodologia adaptada e desenvolvida em nosso Laboratório (PANCOTE, 2004) forneceu dois compostos (5a-b) em rendimentos satisfatórios (46,9\% e 59,5\%, respectivamente) utilizando $\beta$-enaminoésteres (3a-b) e $\alpha$-halocetonas como materiais de partida.

Acredita-se que a primeira etapa para preparação dos derivados pirrólicos consiste na alquilação da enamina pela $\alpha$-halocetona e posteriormente na formação de uma imina, que cicliza, seguida de eliminação de água, de acordo com esquema 31 representado abaixo.

\section{ESQUEMA 31}

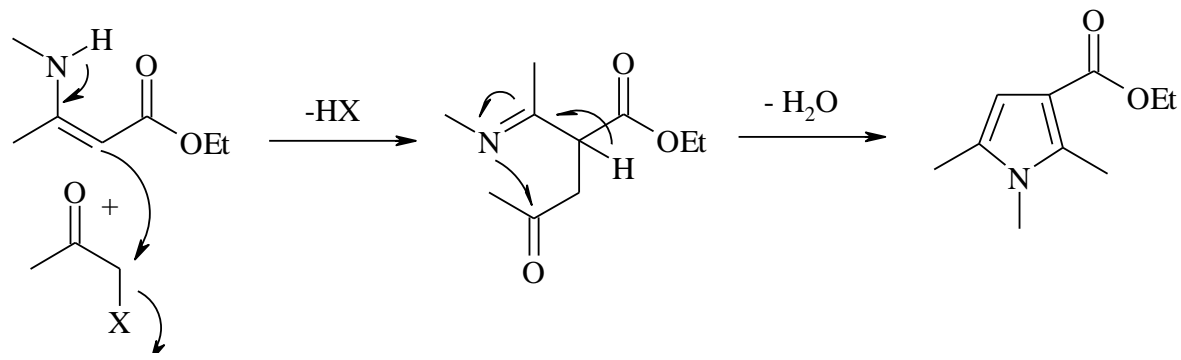

Partindo dessa hipótese, inúmeras tentativas foram realizadas. As condições reacionais variadas nos procedimentos para obtenção dos derivados pirrólicos foram: o solvente da reação (etanol ou DMF), a $\alpha$-haloacetona utilizada ( $\alpha$-bromoacetona ou $\alpha$-cloroacetona), a quantidade de reagentes, a condição do sistema (aberto ou fechado) e catálise ácida, por meio da adição de 0,1 eq. de ácido acético glacial na mistura reacional, baseando-se na metodologia descrita por BRANDT e colaboradores (2004) para síntese de enaminas, a fim de se obter derivados pirrólicos de forma eficiente, em maiores rendimentos.

Após rigorosa análise dos resultados experimentais concluiu-se que a obtenção dos derivados pirrólicos seria possível utilizando o ultrassom.

O etanol foi o solvente de escolha, pelo fato de ser economicamente mais viável e menos tóxico. 
A $\alpha$-bromoacetona foi eleita como $\alpha$-halocetona de partida, uma vez que a condensação entre o $\beta$-enaminoéster e a $\alpha$-cloroacetona não foi observada, além do fato do bromo ser melhor grupo de partida, o que facilitou, significativamente, a alquilação (Esquema 32). Inúmeros procedimentos alternativos foram realizados, visando o consumo total da 2-bromoacetofenona e conseqüentemente maior formação do produto desejado. Neste sentido, a quantidade de $\beta$ enaminoéster utilizada e o tempo de reação foram, inicialmente as variáveis modificadas, entretanto concluiu-se que o aumento do tempo de reação não foi fator determinante para o consumo total da 2-bromoacetofenona. Sendo assim, o tempo estipulado nesta reação foi de 60 minutos. A utilização de quantidades equimolares de $\alpha$-bromoacetona e $\beta$-enaminoéster (3 a-b) resultou em baixa formação de produtos (5 a-b), fornecendo o respectivo $\beta$-cetoéster e a amina correspondente (esquema 32), mostrando claramente a hidrólise dos mesmos.

\section{ESQUEMA 32}

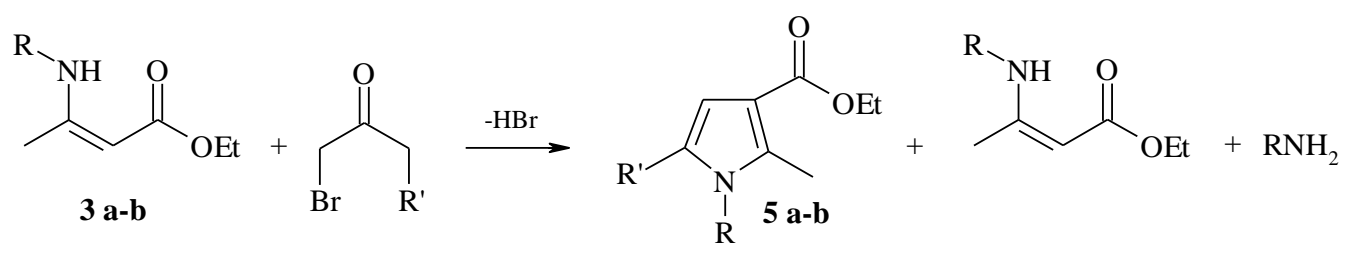

Essa hidrolise, provavelmente seria favorecida por meio da liberação de ácido bromídrico (HBr) no meio. Optou-se então por utilizar trietilamina como aceptora de $\mathrm{HBr}$, acarretando em resultado insatisfatório. Por fim observou-se que o acréscimo da quantidade do $\beta$-enaminoéster (3 a-b) adicionado à mistura reacional foi mais eficiente como aceptor de $\mathrm{HBr} \mathrm{e}$ consequentemente na formação dos 3-acilpirróis desejados (5 a-b), conforme observado nos espectros 2 a 9.

Vale ressaltar que a $\alpha$-bromoacetona, material de partida necessário para a produção de 3- acilpirróis, foi obtida a partir de reagentes de fácil acesso como acetona e bromo (Esquema 33). A preparação da $\alpha$-bromoacetona foi realizada segundo dados obtidos na literatura (LAVENE, 1943; CATCH et al., 1948). 


\section{ESQUEMA 33}

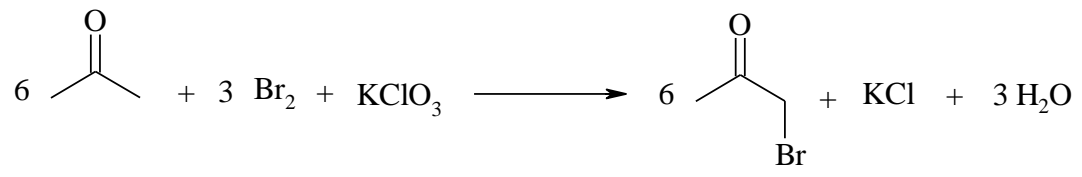

Entretanto, a síntese da $\alpha$-bromoacetona desenvolvida em laboratório foi bastante complexa e exigiu longo período de tempo, uma vez que foi encontrada dificuldade para purificação do produto, não sendo possível reproduzir o relatado em referências utilizadas. Utilizou-se então o produto bruto com $10 \%$ em excesso para síntese dos compostos planejados (5a-b).

\subsubsection{Derivados pirrólicos obtidos via ciclofuncionalização $(\mathbf{7 a}, \mathbf{7 b}$ e $7 \mathbf{c})$}

$1^{a}$ etapa: Obtenção dos derivados diidropirróis (6a-c), via metodologia de ciclofuncionalização descrita por BRANDT e colaboradores (1991)

\section{$\underline{\text { Reação realizada: }}$}

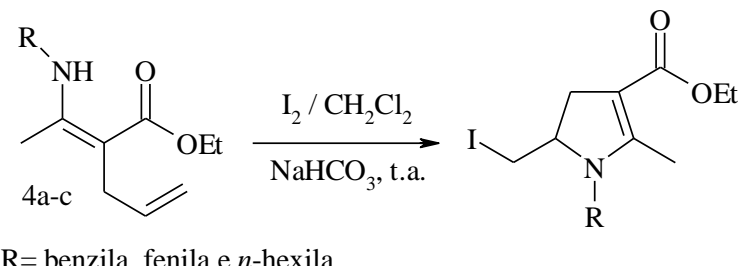


4.1.1.4.1. 1-benzil-2-metil-3-carbetoxi-5-iodometil-4,5-diidropirrol (6a)

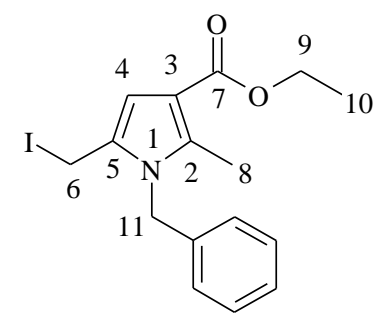

$\mathrm{C}_{16} \mathrm{H}_{20} \mathrm{NO}_{2} \mathrm{I} ; \mathrm{MM}$ : 385,24; Aspecto: líquido escuro viscoso; Rendimento: 85\%

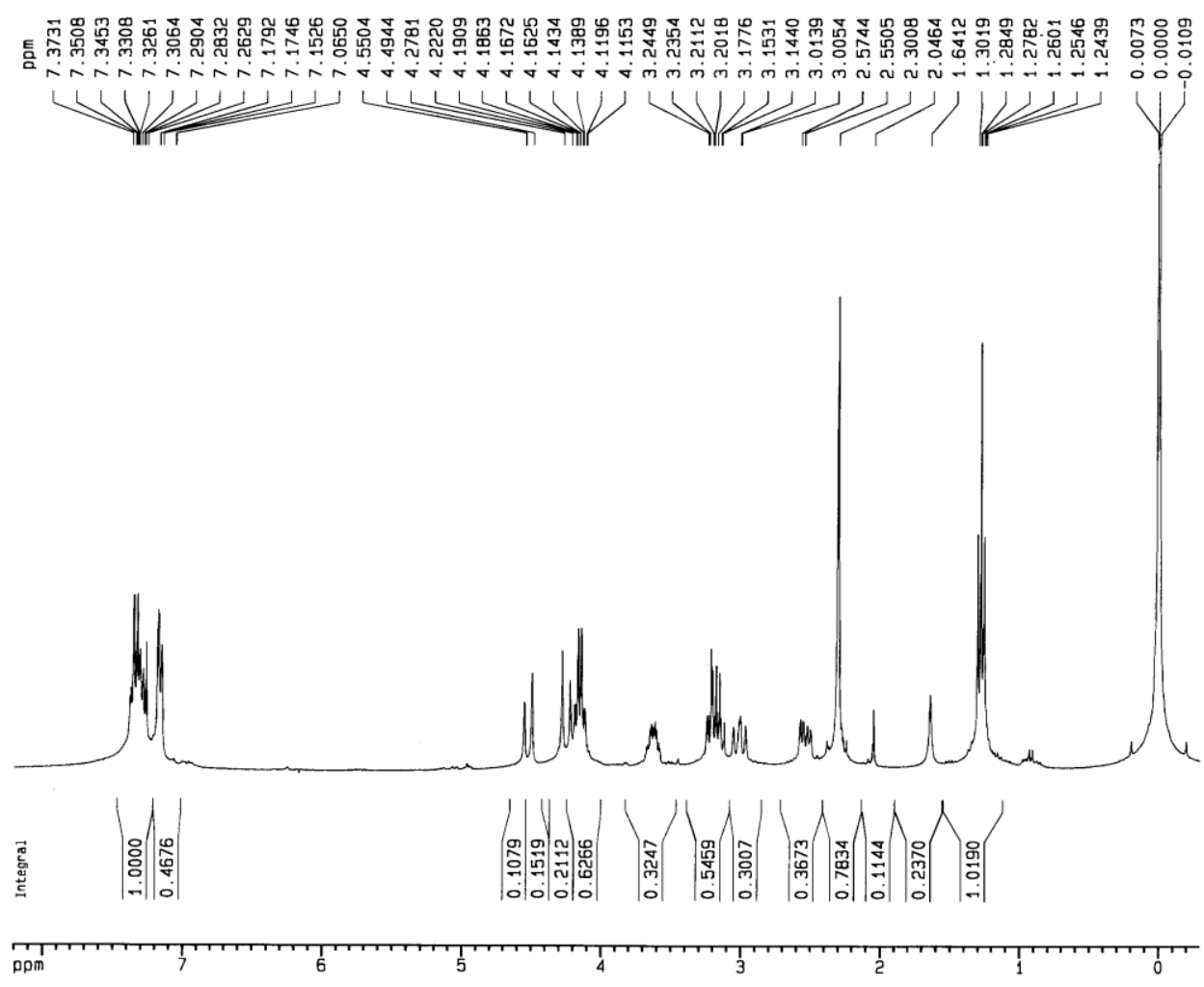

Espectro 10: Espectro de RMN ${ }^{1} \mathrm{H}$ do 1-benzil-2-metil-3-carbetoxi-5-iodometil-4,5diidropirrol (6a).

Tabela XXII: Dados de RMN ${ }^{1} \mathrm{H}$ do 1-benzil-2-metil-3-carbetoxi-5-iodometil-4,5diidropirrol (6a).

\section{RMN ${ }^{1} \mathrm{H}:\left(\mathrm{CDCl}_{3}-300 \mathrm{MHz}-\delta=\mathrm{ppm}\right)$}

$1,27\left(\mathrm{t}, 3 \mathrm{H}_{10}, \mathrm{~J}=7,1 \mathrm{~Hz}\right) ; 2,29\left(\mathrm{~s}, 3 \mathrm{H}_{8}\right) ; 2,53\left(\mathrm{dd}, 1 \mathrm{H}_{4 \mathrm{a}}, \mathrm{J}=7,2 \mathrm{e} 15,1 \mathrm{~Hz}\right) ; 3,04\left(\mathrm{dd}, 1 \mathrm{H}_{4 \mathrm{~b}}\right.$,

$\mathrm{J}=11,2$ e $15,1 \mathrm{~Hz}) ; 3,10-3,20\left(\mathrm{~m}, 2 \mathrm{H}_{6}\right) ; 3,54-3,67\left(\mathrm{~m}, 1 \mathrm{H}_{5}\right) ; 4,15\left(\mathrm{q}, 2 \mathrm{H}_{9}, \mathrm{~J}=7,1 \mathrm{~Hz}\right) ; 4,25(\mathrm{~d}$,

$\left.1 \mathrm{H}_{11 \mathrm{a}}, \mathrm{J}=16,8 \mathrm{~Hz}\right) ; 4,52\left(\mathrm{~d}, 1 \mathrm{H}_{11 \mathrm{~b}}, \mathrm{~J}=16,8 \mathrm{~Hz}\right) ; 7,14-7,35\left(\mathrm{~m}, 5 \mathrm{H}_{\text {arom. }}\right)$. 


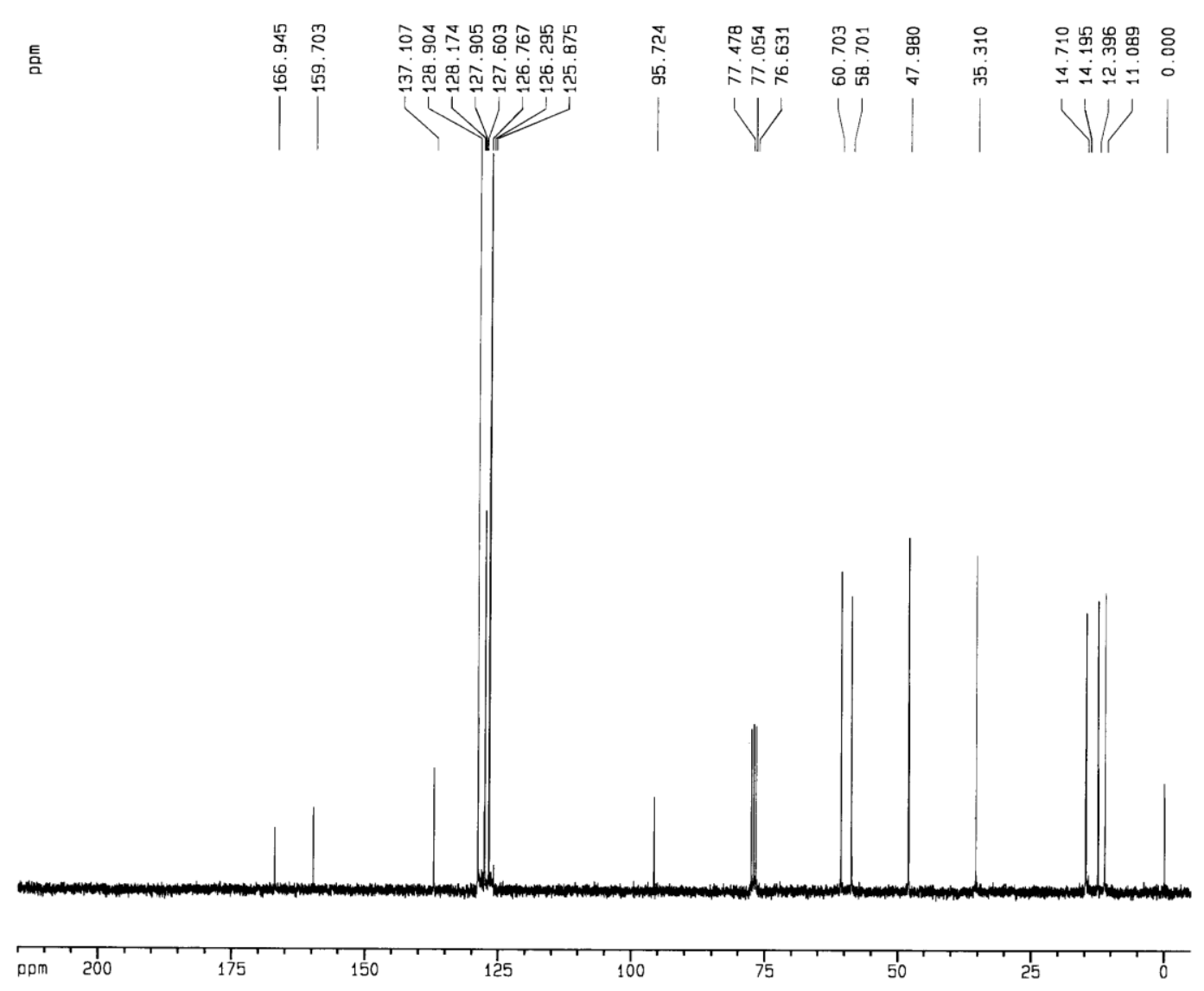

Espectro 11: Espectro de RMN ${ }^{13} \mathrm{C}$ do 1-benzil-2-metil-3-carbetoxi-5-iodometil-4,5diidropirrol (6a).

Tabela XXIII: Dados de RMN ${ }^{13} \mathrm{C}$ do 1-benzil-2-metil-3-carbetoxi-5-iodometil-4,5diidropirrol (6a).

$\mathrm{RMN}^{13} \mathrm{C}\left(\mathrm{CDCl}_{3}-75 \mathrm{MHz}-\delta=\mathrm{ppm}\right)$

$11,09\left(\mathrm{C}_{6}\right) ; 12,4\left(\mathrm{C}_{10}\right) ; 14,7\left(\mathrm{C}_{8}\right) ; 35,3\left(\mathrm{C}_{4}\right) ; 48,0\left(\mathrm{C}_{11}\right) ; 58,7\left(\mathrm{C}_{5}\right) ; 60,7\left(\mathrm{C}_{9}\right) ; 95,7\left(\mathrm{C}_{3}\right) ;$ $126,8\left(\mathrm{C}_{\text {para }}\right) ; 127,6\left(\mathrm{C}_{\text {orto }}\right) ; 128,9\left(\mathrm{C}_{\text {meta }}\right) ; 137,11\left(\mathrm{C}_{\text {ipso }}\right) ; 159,7\left(\mathrm{C}_{2}\right) ; 169,9\left(\mathrm{C}_{7}\right)$. 
4.1.1.4.2. 5-(iodometil)-2-metil-1-fenil-4,5-diidro-1H-pirrol-3-carboxilato de etila (6b)
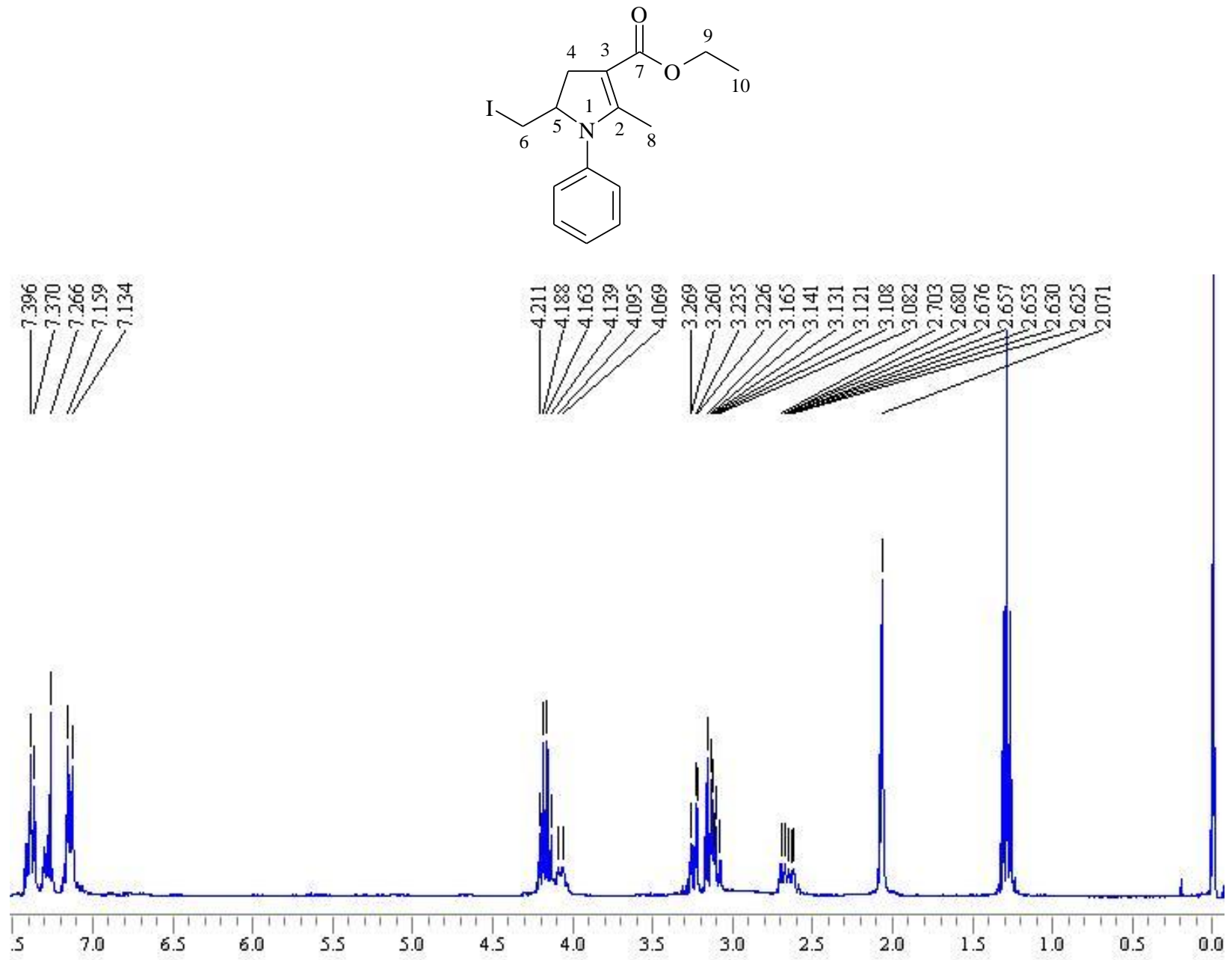

Espectro 12: Espectro de RMN ${ }^{13} \mathrm{C}$ do 5-(iodometil)-2-metil-1-fenil-4,5-diidro-1Hpirrol-3-carboxilato de etila (6b)

Tabela XXIV: Dados de RMN ${ }^{1} \mathrm{H}$ do 5-(iodometil)-2-metil-1-fenil-4,5-diidro-1H-pirrol3-carboxilato de etila (6b)

\section{$\mathrm{RMN}^{1} \mathrm{H}:\left(\mathrm{CDCl}_{3}-300 \mathrm{MHz}-\boldsymbol{\delta}=\mathbf{p p m}\right)$}

$1,29\left(\mathrm{t}, 3 \mathrm{H}_{10}, \mathrm{~J}=7,3 \mathrm{~Hz}\right) ; 2,07\left(\mathrm{~s}, 3 \mathrm{H}_{8}\right) ; 2,66\left(\mathrm{dd}, 1 \mathrm{H}_{4 \mathrm{a}}, \mathrm{J}=7,9\right.$ e $\left.13,8 \mathrm{~Hz}\right) ; 3,00-3,13\left(\mathrm{~m}, 1 \mathrm{H}_{4 \mathrm{~b}}\right)$;

3,10-3,27(m, 2 $\left.\mathrm{H}_{6}\right) ; 4,00-4,15\left(\mathrm{~m}, 1 \mathrm{H}_{5}\right) ; 4,17\left(\mathrm{q}, 2 \mathrm{H}_{9}, \mathrm{~J}=7,3 \mathrm{~Hz}\right) ; 7,14\left(\mathrm{~d}, 2 \mathrm{H}_{\text {orto }}, \mathrm{J}=7,9 \mathrm{~Hz}\right)$;

7,28(t, $\left.1 \mathrm{H}_{\text {para }}, \mathrm{J}=7,9 \mathrm{~Hz}\right) ; 7,40\left(\mathrm{t}, 2 \mathrm{H}_{\text {meta }}, \mathrm{J}=7,9 \mathrm{~Hz}\right)$. 
Ciclofuncionalização é o processo no qual a adição de um eletrófilo a um alceno, contendo um nucleófilo interno, promove ciclização. O substrato acíclico é, portanto, ciclizado e concomitantemente funcionalizado (CLIVE et al., 1977).

Em geral este processo envolve dois modos possíveis de ciclização, "endo" e "exo", como ilustra o esquema 34.

\section{ESQUEMA 34}
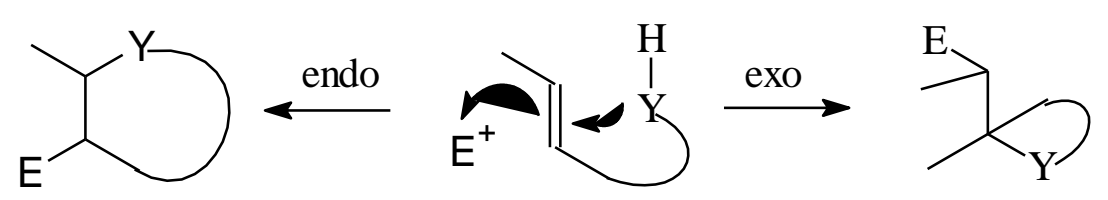

Segundo BALDWIN (1976), o modo de fechamento "endo" versus "exo" depende de inúmeros fatores, sendo que há freqüentemente uma forte preferência estereoeletrônica pelo modo de fechamento "exo", quando há competição entre anel de cinco e seis membros.

Inicialmente, o mecanismo geral para reações de iodociclizações, envolve a formação de um íon halônio, que seria posteriormente aberto por ataque do nucleófilo interno. No entanto, LINSTEAD e MAY (1927) sugeriram que o mecanismo envolvido reflete uma adição e um fechamento de anel simultâneo. O nucleófilo reage com o complexo $\pi$ formado pelo eletrófilo e a ligação dupla (Esquema 35).

\section{ESQUEMA 35}

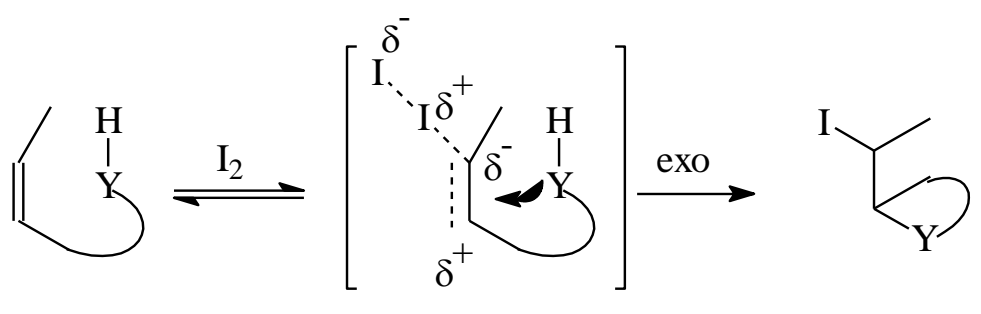

Complexo $\pi$

No caso dos compostos obtidos neste trabalho, o anel de cinco membros foi preferido, devido ao posicionamento da cadeia alquenílica em 4 (Esquema 36). 
ESQUEMA 36

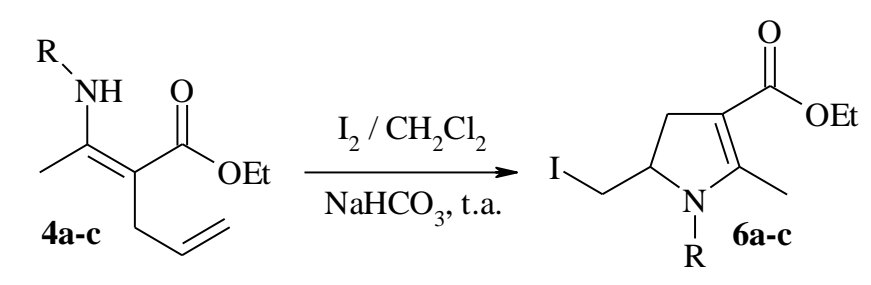

$\mathrm{R}=$ benzila, fenila e $n$-hexila

Neste contexto, os respectivos diidropirróis (6a-c) foram preparados de acordo com a metodologia de iodociclização, relatada por Brandt e colaboradores (1991). A reação para formação dos compostos $\mathbf{6 a}, \mathbf{6 b}$ e $\mathbf{6 c}$ ocorreu em um período de 12 horas, com rendimentos satisfatórios. Entretanto, os rendimentos dos compostos $\mathbf{6 b}$ e $\mathbf{6 c}$ não foram calculados, devido à necessidade de obtenção dos produtos finais $\mathbf{7 a}, \mathbf{7 b}$ e $\mathbf{7 c}$ para os ensaios biológicos. Sendo assim, os intermediários diidropirróis foram utilizados diretamente na última etapa. Esses resultados serão apresentados posteriormente. Os compostos foram identificados por espectroscopia de RMN 1H e 13C. Nos espectros 10 e $\mathbf{1 2}$ verificou-se o aparecimento de duplo dublete, representado pelos hidrogênios 4 na região de 3,00 ppm e, nessa mesma região foi possível observar a presença dos hidrogênios $\mathbf{6}$, confirmando a obtenção dos derivados diidropirróis $\mathbf{6 a}$ e 6b.

$2^{a}$ etapa: Obtenção dos derivados pirrólicos (7a-c) via iodoeliminação, utilizando como base a metodologia descrita por WOLFF e colaboradores (2006), representada no esquema 37.

\section{ESQUEMA 37}

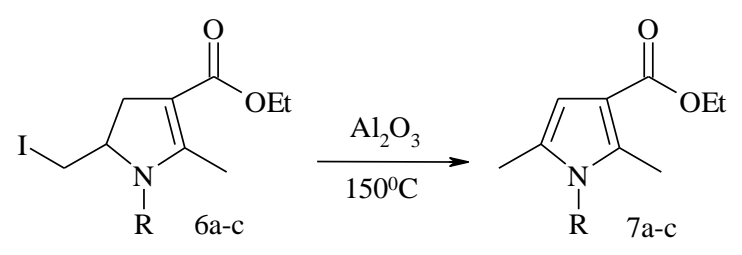

$\mathrm{R}=$ BENZILA, FENILA, $N$-HEXILA

$2^{a}$ etapa: Obtenção dos derivados pirrólicos (7a-c), via metodologia de eliminação descrita por BRANDT e colaboradores (artigo enviado para publicação). 
4.1.1.4.4. 1-benzil-2,5-dimetil-1H-pirrol-3-carboxilato de elila (7a)

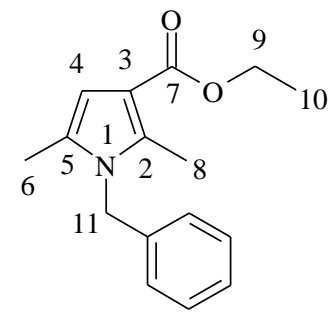

$\mathrm{C}_{16} \mathrm{H}_{19} \mathrm{NO}_{2}$; PM: 257,33 g/mol; Aspecto: líquido escuro viscoso; Rendimento: 85\% CLog P: 3,18 ;

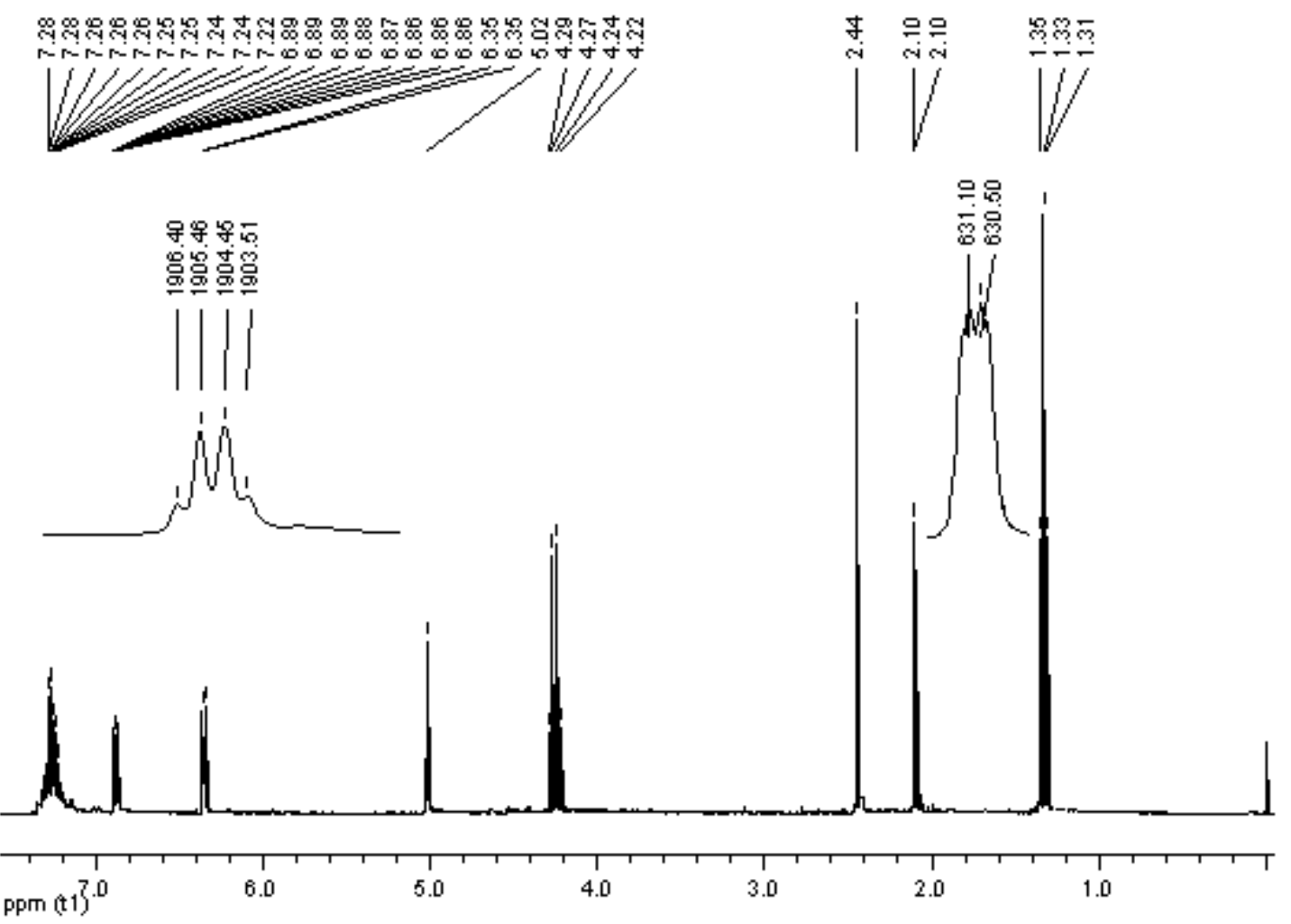

Espectro 12: Espectro de $\mathrm{RMN}{ }^{1} \mathrm{H}$ do 1-benzil-2,5-dimetil-1H-pirrol-3-carboxilato de etila (7a).

Tabela XXV: Dados de RMN ${ }^{1} \mathrm{H}$ do 1-benzil-2,5-dimetil-1H-pirrol-3-carboxilato de etila (7a).

RMN ${ }^{1} \mathrm{H}:\left(\mathrm{CDCl}_{3}-300 \mathrm{MHz}-\delta=\mathrm{ppm}\right)$

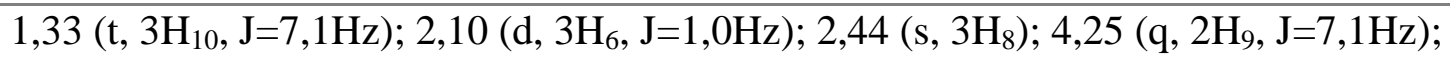

$5,02\left(\mathrm{~s}, 2 \mathrm{H}_{11}\right) ; 6,35\left(\mathrm{q}, 1 \mathrm{H}_{4}, \mathrm{~J}=1,0 \mathrm{~Hz}\right) ; 6,86\left(\mathrm{~d}, 2 \mathrm{H}_{\text {orto }}, \mathrm{J}=7,3 \mathrm{~Hz}\right) ; 7,24-7,28\left(\mathrm{~m}, 2 \mathrm{H}_{\text {meta }}\right.$,

$\left.1 \mathrm{H}_{\text {para }}\right)$. 


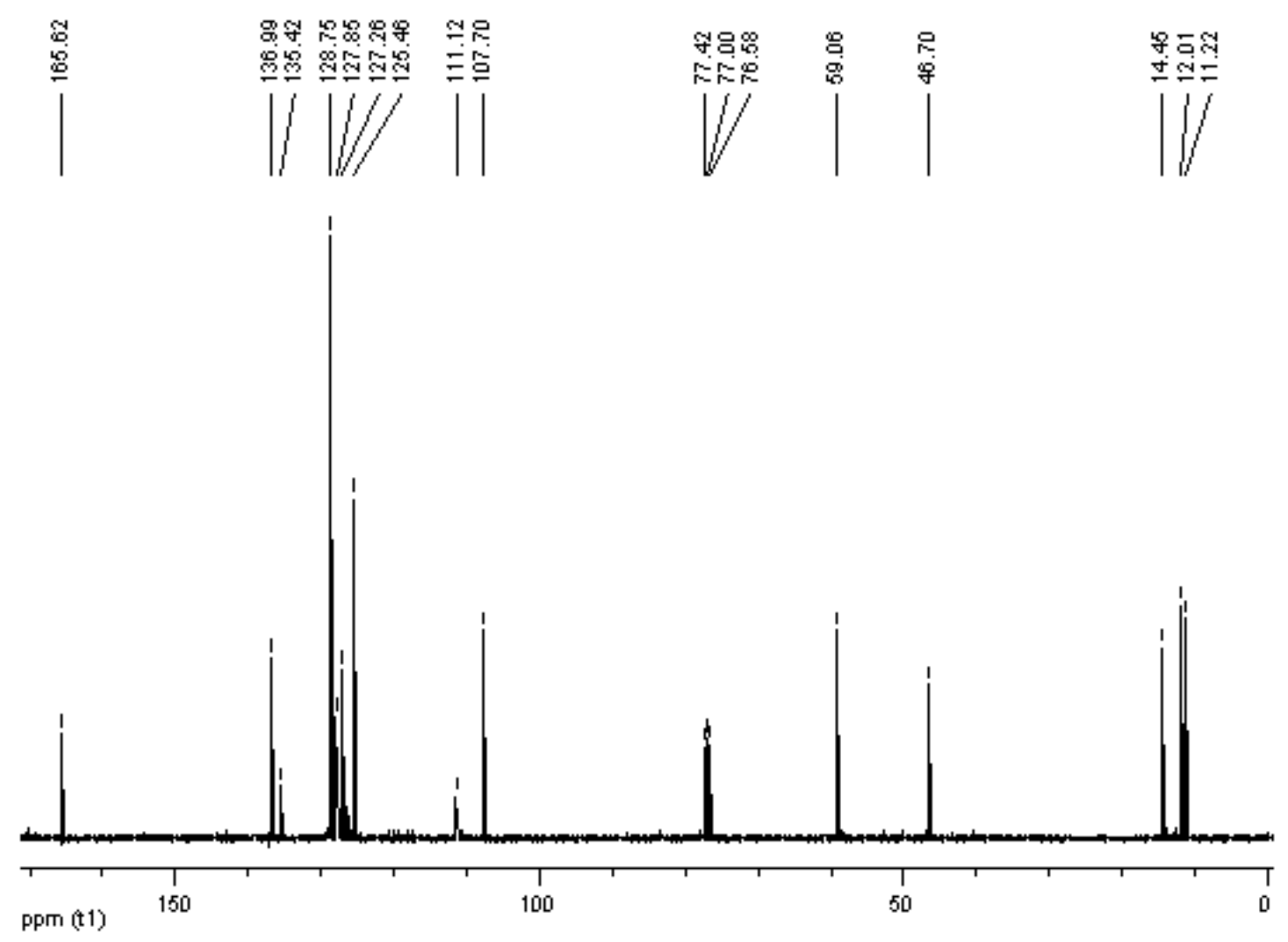

Espectro 22: Espectro de RMN ${ }^{13} \mathrm{C}$ do 1-benzil-2,5-dimetil-1H-pirrol-3-carboxilato de etila (7a).

Tabela XXVI: Dados de RMN ${ }^{13} \mathrm{C}$ do 1-benzil-2,5-dimetil-1H-pirrol-3-carboxilato de etila (7a).

\section{RMN ${ }^{13} \mathrm{C}\left(\mathrm{CDCl}_{3}-75 \mathrm{MHz}-\delta=\right.$ ppm $)$}

$11,2 *\left(\mathrm{C}_{6}\right) ; 12,0 *\left(\mathrm{C}_{8}\right) ; 14,5\left(\mathrm{C}_{10}\right) ; 46,7\left(\mathrm{C}_{11}\right) ; 59,1\left(\mathrm{C}_{9}\right) ; 107,7\left(\mathrm{C}_{4}\right) ; 111,1\left(\mathrm{C}_{3}\right) ; 126,5$

$\left(\mathrm{C}_{\text {orto }}\right) ; 127,3 * *\left(\mathrm{C}_{\text {para }}\right) ; 127,8 * *\left(\mathrm{C}_{5}\right) ; 128,7\left(\mathrm{C}_{\text {meta }}\right) ; 135,4\left(\mathrm{C}_{2}\right) ; 137,0\left(\mathrm{C}_{\text {ipso }}\right) ; 165,62$

$\left(\mathrm{C}_{7}\right)$.

* Os sinais do $\mathrm{C}_{6} \mathrm{e}_{8}$ podem estar trocados.

** Os sinais do $\mathrm{C}_{\text {para }}$ e $\mathrm{C}_{5}$ podem estar trocados. 


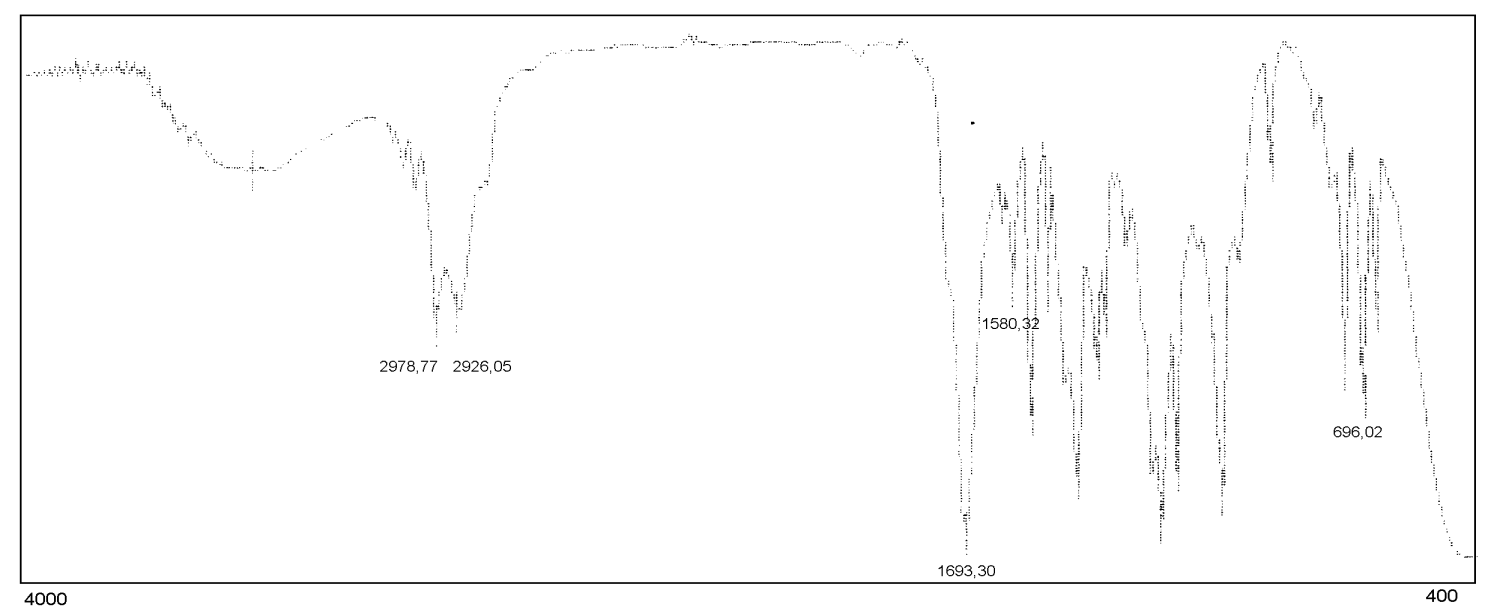

Espectro 23: Espectro de IV do 1-benzil-2,5-dimetil-1H-pirrol-3-carboxilato de etila (7a)

Tabela XXVII: Dados de IV do 1-benzil-2,5-dimetil-1H-pirrol-3-carboxilato de etila (7a) IV-v max. $\left(\mathrm{cm}^{-1}\right)$

696,02 ( $\delta$ C-H $\left.\mathrm{H}_{\text {arom. }}\right) ; 1580,32(\delta \mathrm{C}=\mathrm{C}) ; 1693,30(\sqrt{ } \mathrm{CO}) ; 2926,05\left(\sqrt{ } \mathrm{C}-\mathrm{H}_{\text {alif. }}\right) ; 2978,77(\sqrt{ }$ C-H $\mathrm{H}_{\text {arom.). }}$. 


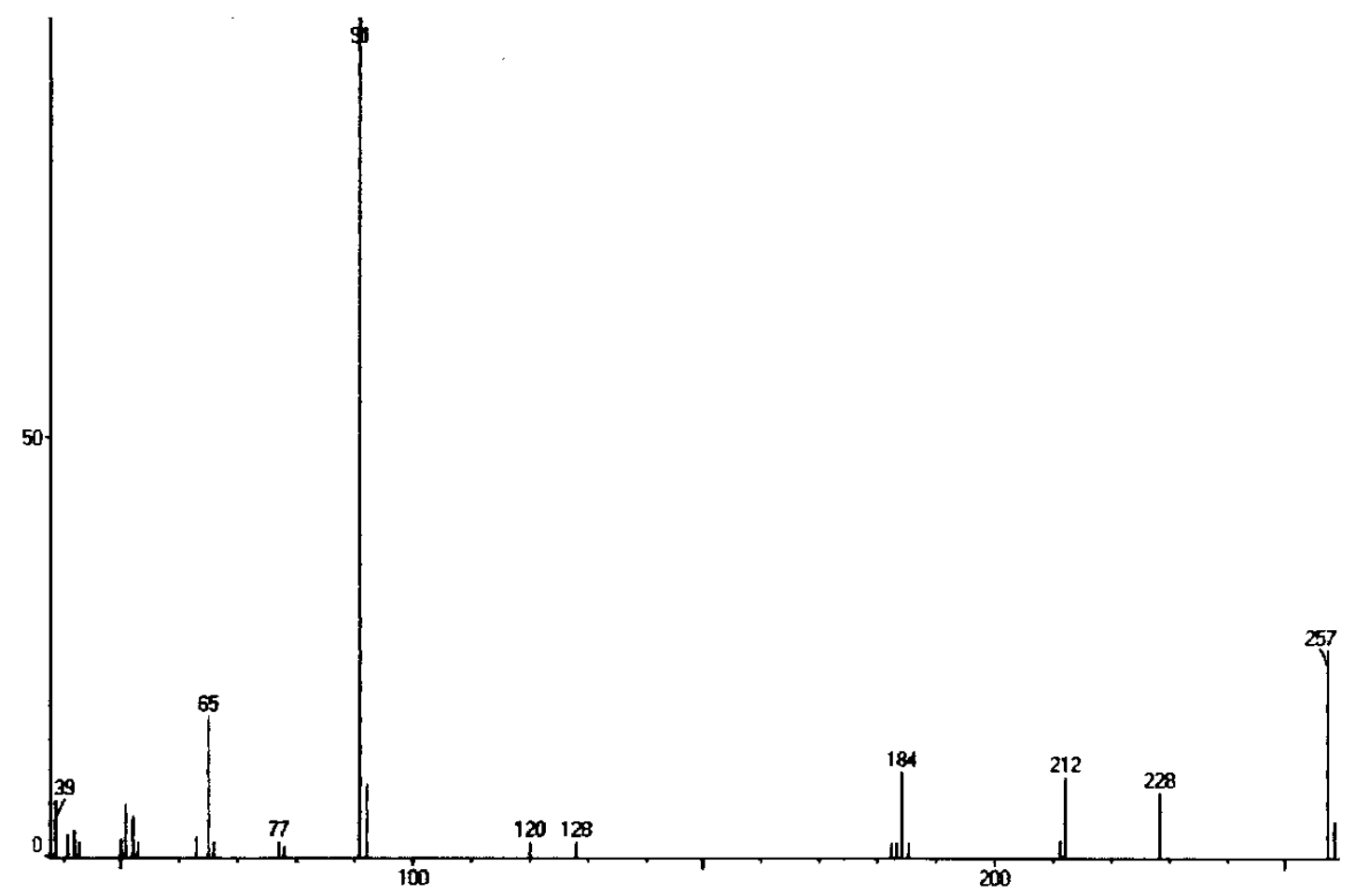

Espectro 24: Espectro de massas do 1-benzil-2,5-dimetil-1H-pirrol-3-carboxilato de etila (7a).

Tabela XXVIII: Dados do espectro de massas do 1-benzil-2,5-dimetil-1H-pirrol-3-carboxilato de etila (7a).

CG / MS - razão massa / carga $(\mathrm{m} / \mathrm{z})$ : intensidade relativa (\%)

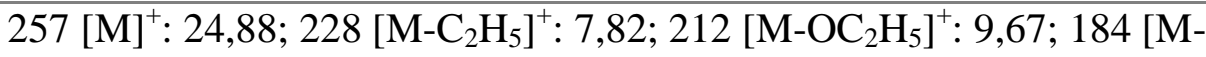
$\left.\mathrm{CO}_{2} \mathrm{C}_{2} \mathrm{H}_{5}\right]^{+}: 10,29 ; 91\left[\mathrm{C}_{6} \mathrm{H}_{5} \mathrm{CH}_{2}\right]^{+}: 100 ; 65\left[\mathrm{C}_{6} \mathrm{H}_{5}\right]^{+}: 16,74$. 
4.1.1.4.5. 1-fenil-2,5-dimetil-1H-pirrol-3-carboxilato de elila (7b)

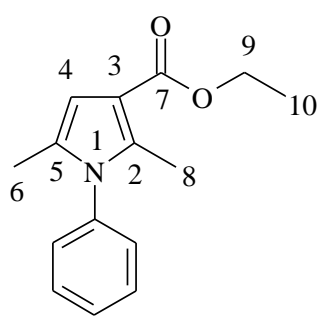

$\mathrm{C}_{15} \mathrm{H}_{17} \mathrm{NO}_{2}$; PM: 243,30 g/mol; Aspecto: líquido escuro viscoso; Rendimento: 80\%; CLogP: 3,08

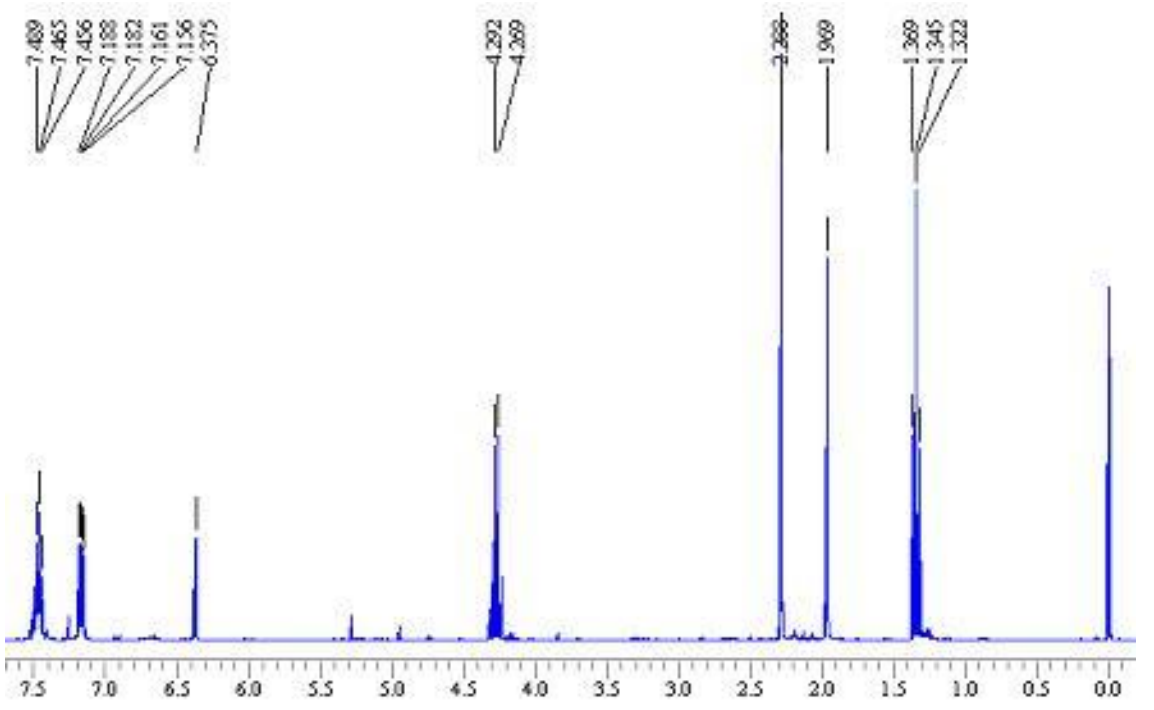

Espectro 25: Espectro de $\mathrm{RMN}{ }^{1} \mathrm{H}$ do 2,5 dimetil-1-fenil-1H-pirrol-3-carboxilato de etila (7b)

Tabela XXIX: Dados de RMN ${ }^{1} \mathrm{H}$ do 2,5 dimetil-1-fenil-1H-pirrol-3-carboxilato de etila (7b)

RMN ${ }^{1} \mathrm{H}:\left(\mathrm{CDCl}_{3}-300 \mathrm{MHz}-\boldsymbol{\delta}=\mathrm{ppm}\right)$

1,34 (t, 3H10, J=7,1Hz); 1.97 (s, 3H8); 2,30 (s, 3H 6 ); 4,29 (q, 2H9, J=7,1Hz); 6,37(s, $\left.1 \mathrm{H}_{4}\right) 7,18$ (d, 2Ho, J=7,2Hz); 7,45-7,50(m, 2Hm e1Hp). 


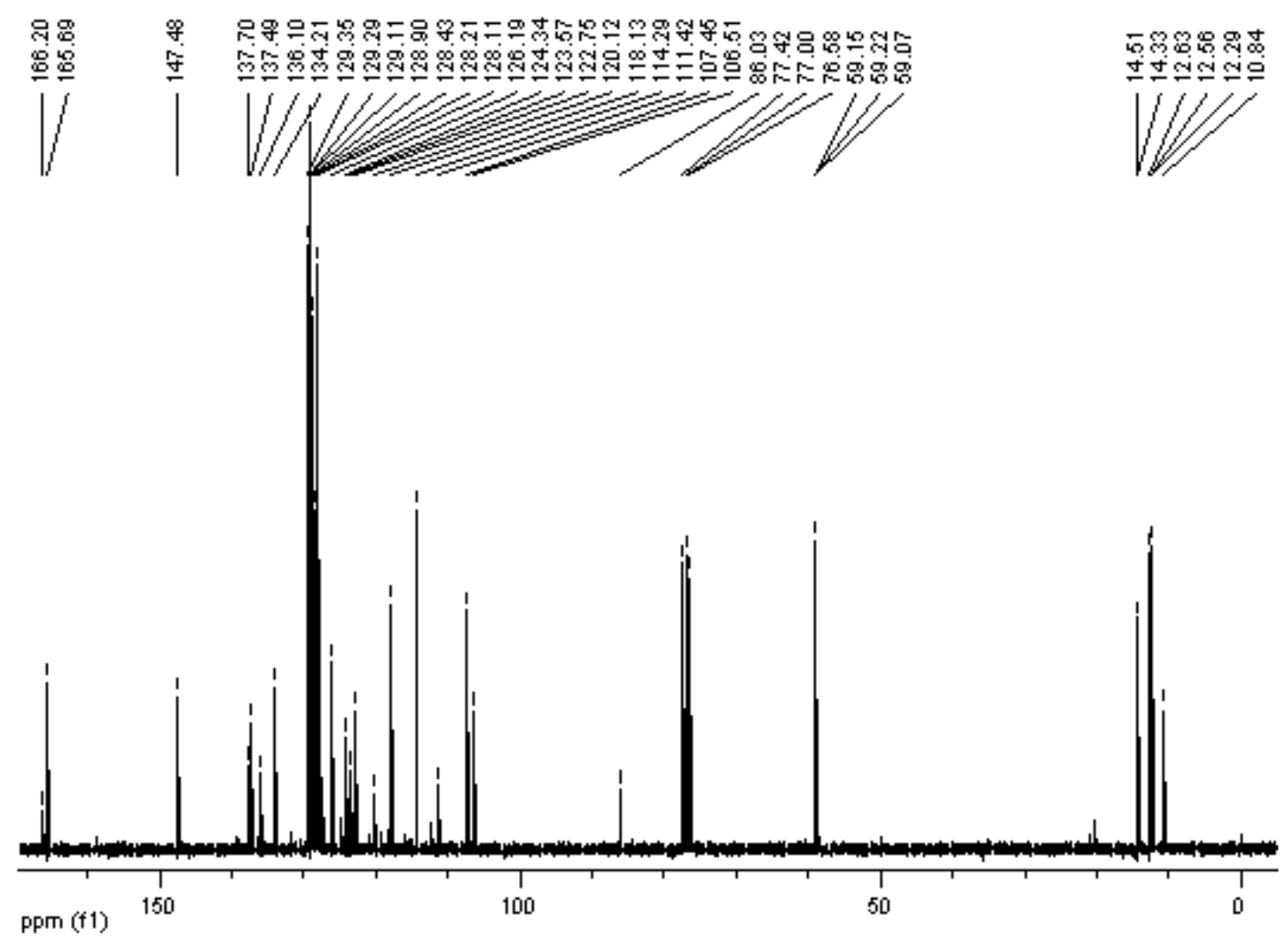

Espectro 26: Espectro de $\mathrm{RMN}{ }^{13} \mathrm{C}$ do 2,5 dimetil-1-fenil-1 $H$-pirrol-3-carboxilato de etila (7b)

Tabela XXX: Dados de RMN ${ }^{13} \mathrm{C}$ do 2,5 dimetil-1-fenil-1H-pirrol-3-carboxilato de etila (7b)

$\mathrm{RMN}^{13} \mathrm{C}\left(\mathrm{CDCl}_{3}-75 \mathrm{MHz}-\delta=\mathrm{ppm}\right)$

$10,9\left(\mathrm{C}_{6}\right)^{*} ; 12,4\left(\mathrm{C}_{8}\right)^{*} ; 14,6\left(\mathrm{C}_{10}\right) ; 59,2\left(\mathrm{C}_{9}\right) ; 107,5\left(\mathrm{C}_{4}\right) ; 111,5\left(\mathrm{C}_{3}\right) ; 120,0-129,4(3$

$\left.\mathrm{C}_{\text {orto, meta, para }} \mathrm{e}_{5}\right) ; 134,3\left(\mathrm{C}_{2}\right) ; 136,2\left(\mathrm{C}_{i p s o}\right) ; 165,8\left(\mathrm{C}_{7}\right)$.

* Os sinais do $\mathrm{C}_{6}$ e $\mathrm{C}_{8}$ podem estar trocados. 
4.1.1.4.6. 1-hexil-2,5-dimetil-1 $H$-pirrol-3-carboxilato de elila (7c)

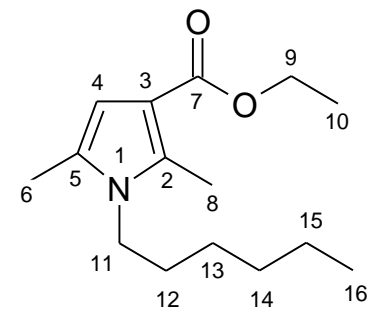

$\mathrm{C}_{15} \mathrm{H}_{25} \mathrm{NO}_{2}$; PM: 251,37 g/mol; Aspecto: líquido amarelo escuro viscoso; Rendimento: 80\%; CLogP: 3,66
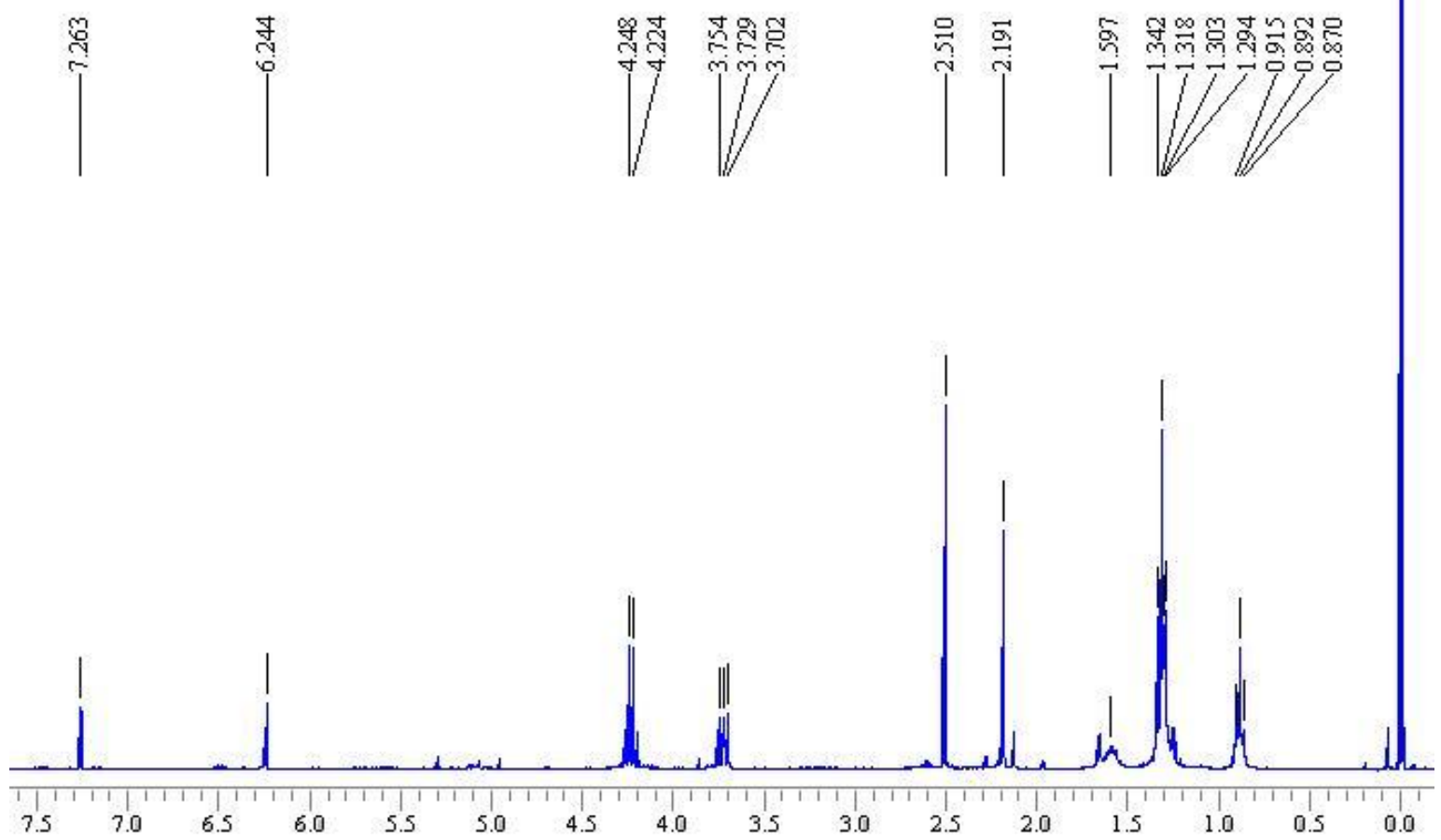

Espectro 27: Espectro de RMN ${ }^{1} \mathrm{H}$ do 1-hexil-2,5-dimetil-1H-pirrol-3-carboxilato de elila (7c)

Tabela XXXI: Dados de RMN ${ }^{1} \mathrm{H}$ do 1-hexil-2,5-dimetil-1 $H$-pirrol-3-carboxilato de elila (7c)

$\mathrm{RMN}^{1} \mathrm{H}:\left(\mathrm{CDCl}_{\mathbf{3}}-300 \mathrm{MHz}-\boldsymbol{\delta}=\mathbf{p p m}\right)$

$0,88\left(\mathrm{t}, 3 \mathrm{H}_{16}, \mathrm{~J}=6,9 \mathrm{~Hz}\right) ; 1,29-1,34\left(\mathrm{~m}, 6 \mathrm{H}_{13,14,15}\right) ; 1,31\left(\mathrm{t}, 3 \mathrm{H}_{10}, \mathrm{~J}=7,1 \mathrm{~Hz}\right) ; 1,59\left(\mathrm{~m}, 2 \mathrm{H}_{12}\right)$,

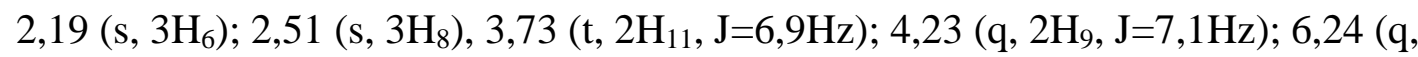

$\left.1 \mathrm{H}_{4}, \mathrm{~J}=0,9 \mathrm{~Hz}\right)$.

A desidro-halogenação ou, mais especificamente, a eliminação do iodo foi, inicialmente realizada por meio de reação térmica, sob refluxo com tolueno e DBU como base e tempo de 24 
horas (BRANDT et al., 1991). No entanto o DBU é um reagente de alto custo, além de render produtos de difícil purificação. Sendo assim optou-se por tentar outras metodologias para reação de eliminação do iodo que não utilizasse esta base.

A partir de vasta pesquisa de diferentes metodologias para eliminação do iodo, uma delas pareceu bastante interessante. Esta foi descrita por WOLFF e colaboradores (2006) e utilizava alumina neutra $\left(\mathrm{Al}_{2} \mathrm{O}_{3}\right)$ e diclorometano como solvente, levando a obtenção dos produtos eliminados em bons rendimentos. Tal metodologia foi finalmente adaptada e otimizada em nosso laboratório, alcançando com êxito rendimentos de aproximadamente 80\%. O mecanismo de ação representado no esquema 38 sugere que a abstração do próton pelo átomo de oxigênio da alumina (A), resulta na formação do intermediário exometileno (B), que, por sua vez é convertido no produto aromático C. BRANDT e colaboradores (artigo enviado para publicação). Essa nova metodologia foi bastante eficiente, devido ao fato de não utilizar DBU como base, que resulta em economia significativa de reagente. Não foi necessária a purificação do iodeto de partida, proporcionando assim economia de solvente e tempo, fato que a torna promissora, já que atende aos requisitos da Química Verde.

\section{ESQUEMA 38}

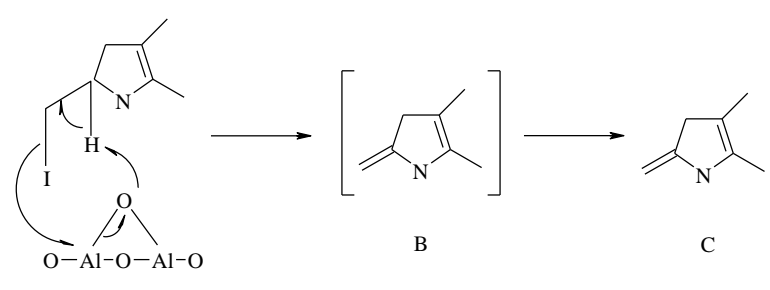




\subsubsection{Parte Experimental Biológica}

Os ensaios de avaliação biológica foram realizados no Instituto Butantan, Laboratório de Farmacologia, Unidade de Inflamação coordenada pela Dra. Catarina de Fátima Pereira Teixeira, sob orientação da Dra. Vanessa Moreira.

\subsubsection{Ensaios "in vitro": determinação do efeito citotóxico dos compostos 5a e 5b}

O efeito dos compostos 1-benzil-2-metil-5-fenil-1 $\mathrm{H}$-pirrol-3-carboxilato de etila (5a) e 1hexil-2-metil-5fenil-1Hpirrol-3-carboxilato de etila (5b) foram avaliados sobre a atividade metabólica de macrófagos peritoneais isolados em cultura, pelo ensaio de redução do MTT. Estas células foram incubadas em concentrações crescentes destes compostos por períodos de 8 (gráfico 1) e 24 horas (gráfico 2).

Os gráficos 1 e 2 mostram que as monocamadas controles, incubadas apenas com RPMI, apresentaram-se metabolicamente ativas nos períodos de tempo de 8 e 24 horas de incubação, com valor médio de absorbância de $0.45 \pm 0.02463$ e $0.410 \pm 0.031$, respectivamente, medido em $540 \mathrm{~nm}$, que foi tomado como $100 \%$ de atividade metabólica.

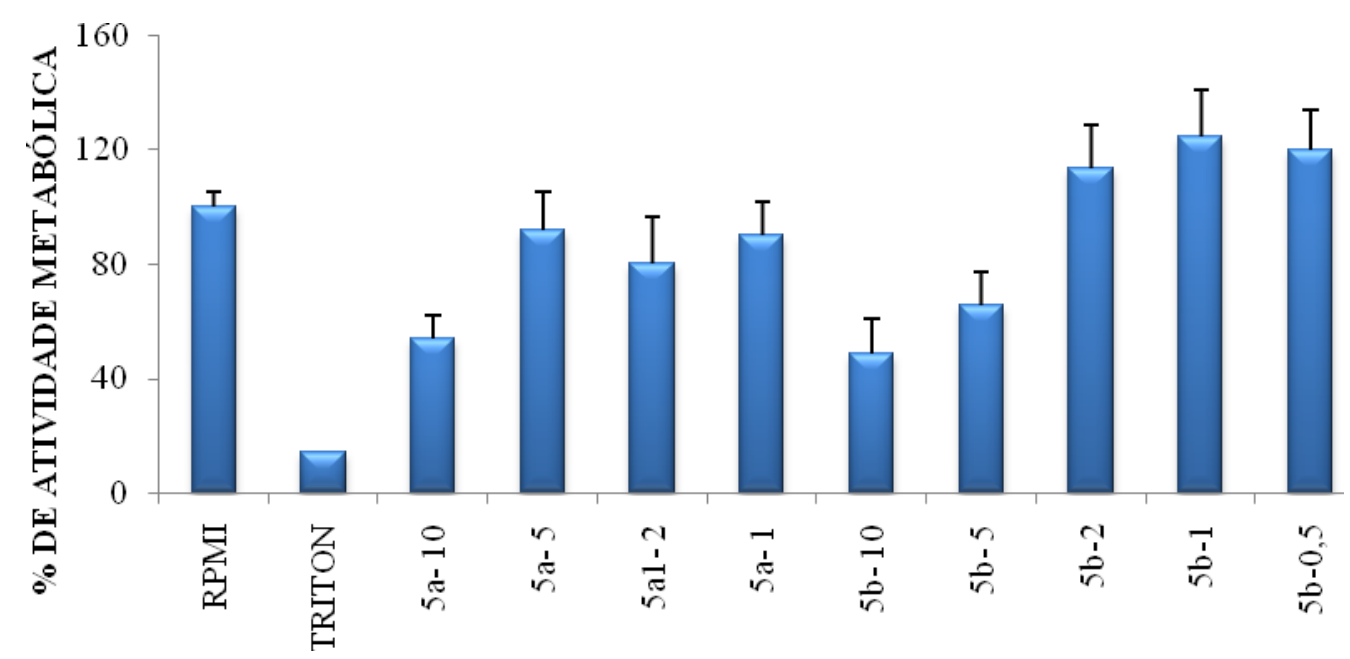

Gráfico 1: Efeito dos compostos 5a e 5b na atividade metabólica de macrófagos residentes em cultura. $2 \times 10{ }^{5}$ macrófagos residentes peritoneais foram incubados por 8 horas, a $37^{0} \mathrm{C}$ e $5 \%$ de $\mathrm{CO}_{2}$ com os

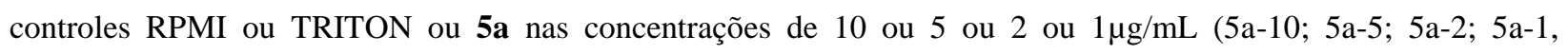
respectivamente) ou $\mathbf{5 b}$ nas concentrações de 10 ou 5 ou 2 ou 1 e $0,5 \mu \mathrm{g} / \mathrm{mL}(5 \mathrm{~b}-10 ; 5 b-5 ; 5 b-2 ; 5 b-1 ; 5 b-0,5$, respectivamente). 


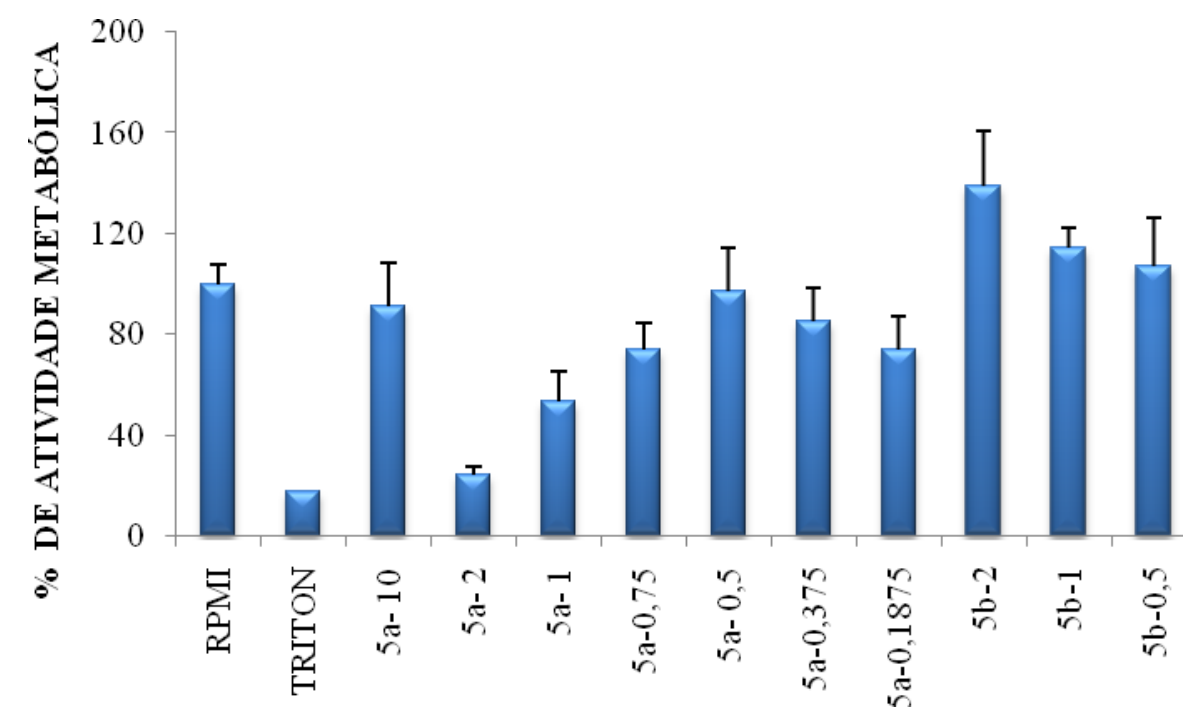

Gráfico 2: Efeito dos compostos 5a e 5b na atividade metabólica de macrófagos residentes em cultura. 2x $10^{5}$ macrófagos residentes peritoneais foram incubados por 24 horas, a $37^{\circ} \mathrm{C}$ e $5 \%$ de $\mathrm{CO}_{2}$, com os controles RPMI ou TRITON ou 5a nas concentrações de 10 ou 2 ou 1 ou 0,75 ou 0,5 ou 0,375 ou $0,1875 \mu \mathrm{g} / \mathrm{mL}$ ( $5 \mathrm{a}$ 10; 5a-2; 5a-1; 5a-0,75; 5a-0,5; 5a-0,375 e 5a-0,1875 respectivamente) ou com $5 \mathbf{b}$ nas concentrações de 2 , 1 e $0,5 \mu \mathrm{g} / \mathrm{mL}(5 \mathrm{~b}-2 ; 5 \mathrm{~b}-1 ; 5 \mathrm{~b}-0,5$, respectivamente),

O acréscimo do composto 5a ocasionou redução na atividade metabólica das células macrofágicas, principalmente em concentrações superiores a $0,75 \mu \mathrm{g} / \mathrm{mL}$, em relação ao RPMI (controle negativo), nos períodos de 8 horas e 24 horas. Vale ressaltar ainda que as concentrações de $0,75 \mu \mathrm{g} / \mathrm{mL}, 0,5 \mu \mathrm{g} / \mathrm{mL}, 0,375 \mu \mathrm{g} / \mathrm{mL}$ e $0,1875 \mu \mathrm{g} / \mathrm{mL}$ foram analisadas no período de 8 horas e não inviabilizou as células, entretanto os respectivos dados não foram demonstrados.

Sendo assim, as concentrações selecionadas do composto 5a para o ensaio de liberação $\operatorname{dePGE}_{2}$, a partir de macrófagos peritoneais isolados foram na faixa $0,75 \mu \mathrm{g} / \mathrm{mL}$ a $0,1875 \mu \mathrm{g} / \mathrm{mL}$.

A adição do composto $\mathbf{5 b}$ ao meio de cultura não causou alteração significativa na atividade metabólica destas células, em relação ao controle, nos períodos de 8 horas e 24 horas, nas concentrações de 2,1 e $0,5 \mu \mathrm{g} / \mathrm{mL}$. As concentrações de 5 e $10 \mu \mathrm{g} / \mathrm{mL}$ do composto testado reduziu significativamente a atividade metabólica celular no período de incubação de 8 horas, com percentuais de redução em torno de $64 \%$ e $47 \%$, respectivamente. Do mesmo modo, os dados não foram demonstrados no período de 24 horas para essas concentrações. Finalmente, as 
concentrações de 2 , 1 e $0,5 \mu \mathrm{g} / \mathrm{mL}$ serão utilizadas nos ensaios biológicos do composto $\mathbf{5 b}$ sobre a liberação de $\mathrm{PGE}_{2}$ induzida por LPS.

O DMSO foi utilizado para auxiliar na solubilização dos compostos, na concentração de 0,005\%, portanto não afetou a atividade metabólica dessas células (dados não demonstrados).

4.1.2.2. Efeito dos produtos $\mathbf{5} \mathbf{a}$ e $\mathbf{5 b}$ na determinação da concentração de PGE 2 através de ensaio imunoenzimático específico (EIA).

Para analisar o efeito dos compostos 5a e 5b sobre a liberação da $\mathrm{PGE}_{2}$, macrófagos peritoneais residentes isolados foram incubados por 8 a 24 horas. As concentrações dos compostos foram previamente testadas, quanto à citotoxicidade, pela análise da redução de MTT, como apresentado no item material e métodos.

O gráfico 3 mostra que em macrófagos incubados apenas com RPMI (controle), a produção média de $\mathrm{PGE}_{2}$ foi de $2274 \pm 684$ pg/mL e $3937 \pm 806$ pg/mL nos períodos de 8 e 24 horas, respectivamente. Macrófagos incubados somente com 0,75 $\mu \mathrm{g} / \mathrm{mL}$ de composto 5a, apresentou produção média de $\mathrm{PGE}_{2}$ de $3538 \pm 460 \mathrm{pg} / \mathrm{mL}$ no período de 8 horas. Os níveis de $\mathrm{PGE}_{2}$ foram significativamente aumentados após a incubação das células com LPS (8885 \pm 1413 $\mathrm{pg} / \mathrm{mL}$ e $11332 \pm 955 \mathrm{pg} / \mathrm{mL}, 8$ e 24 horas, respectivamente), quando comparados aos grupos controles (RPMI). Quando as células foram incubadas com concentrações crescentes do composto 5a, por 8 horas, não houve alteração das concentrações de PGE $_{2}$ induzidas pelo LPS. Por outro lado, no período de 24 horas, o composto 5a causou diminuição significativa da liberação de $\mathrm{PGE}_{2}$, induzida pelo LPS, em 34\%. No entanto, a incubação das células com concentrações menores de 5a $(0,387$ ou de $0,1875 \mu \mathrm{g} / \mathrm{mL})$, no período de 24 horas, não ocasionou alteração da liberação de $\mathrm{PGE}_{2}$, quando comparados ao grupo LPS. 


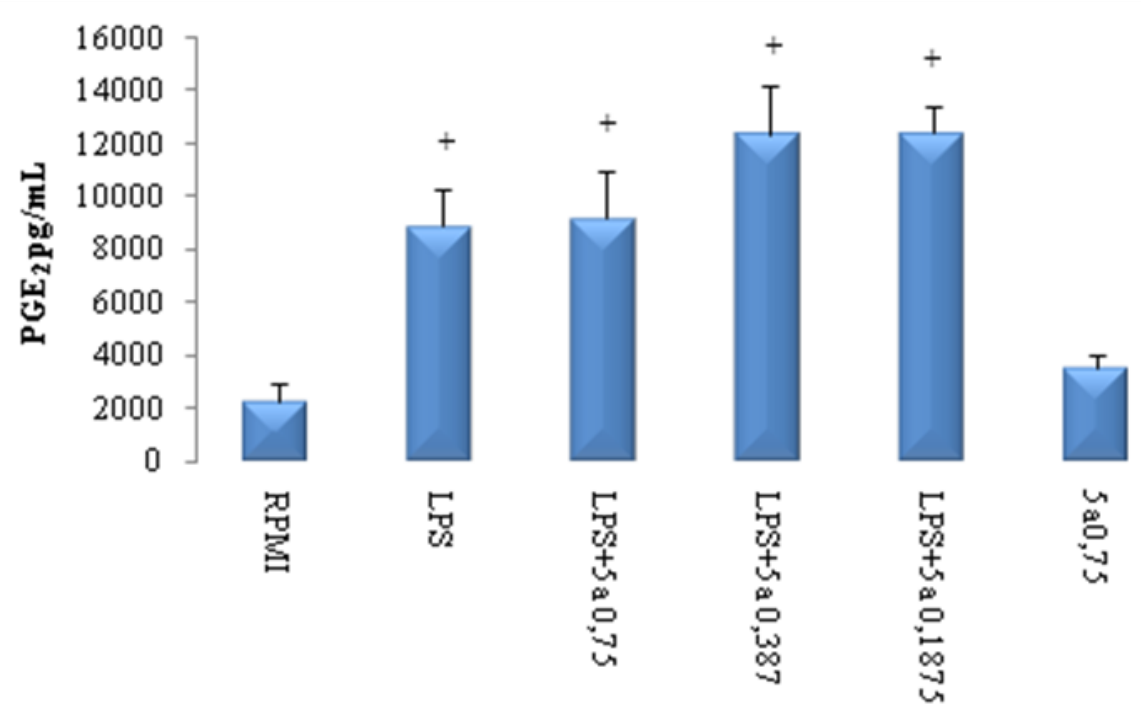

A

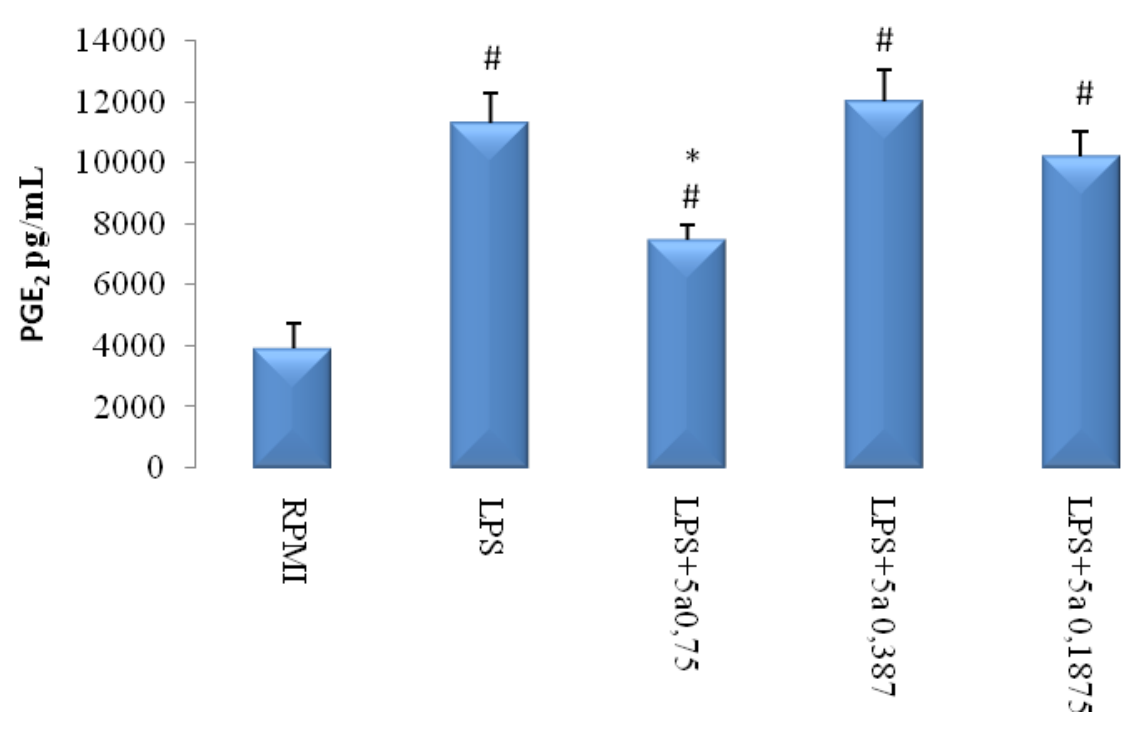

B

Gráfico 3: Efeito do composto 5a na determinação da concentração de PGE $_{2}$ induzida por LPS em macrófagos residentes em cultura nos períodos de 8 horas (A) e 24 horas (B). Macrófagos peritoneais isolados ( $2 \times 10^{5}$ células/ $1 \mathrm{~mL}$ RPMI) foram incubados, em suspensão, com RPMI (controle) ou LPS ou LPS + 5a nas concentrações de $0,75 \mu \mathrm{g} / \mathrm{mL}, \quad 0,387 \mu \mathrm{g} / \mathrm{mL}, \quad 0,1875 \mu \mathrm{g} / \mathrm{mL}$ (LPS+5a0,75, LPS+5a0,387 e LPS+5a0,1875, respectivamente) nos períodos de 8 (A) e 24 horas (B), a $37^{\circ} \mathrm{C}$ e $5 \%$ de $\mathrm{CO}_{2}$. O composto 5a na concentração de $0,75 \mu \mathrm{g} / \mathrm{mL}$ foi adicionado ao meio, na ausência de LPS $(5 \mathrm{a} 0,75)$. As concentrações de $\mathrm{PGE}_{2}$ foram avaliadas por EIA, nos sobrenadantes. Os dados representam a média \pm E.P.M de 4-5 animais. $+\mathrm{p}<0,05$ em relação ao controle em 8 horas e \#p<0,05 em relação ao controle e *p<0,05 em relação ao LPS em 24 horas (ANOVA). 
No gráfico 4 é possível observar que a produção média de $\mathrm{PGE}_{2}$ em macrófagos incubados apenas com RPMI (controle) foi de $2273 \pm 684$ pg/mL e $3937 \pm 806$ pg/mL nos períodos de 8 e 24 horas, respectivamente. Macrófagos incubados somente com 2,0 $\mu \mathrm{g} / \mathrm{mL}$ de composto 5b, apresentou produção média de $\mathrm{PGE}_{2}$ de $1954 \pm 460 \mathrm{pg} / \mathrm{mL}$ no período de 8 horas e de $2152 \pm 460$ pg/mL em 24 horas. Os níveis de $\mathrm{PGE}_{2}$ foram aumentados após a incubação das células com LPS $(10334 \pm 2883$ pg/mL e $22619 \pm 1329$ pg/mL, 8 e 24 horas, respectivamente), quando comparados aos grupos controles (RPMI). Quando as células foram incubadas com concentrações crescentes do composto $\mathbf{5 b}$, por 8 horas, não alterou a liberação de $\mathrm{PGE}_{2}$ induzida pelo LPS, exceto na dose de 2,0 $\mu \mathrm{g} / \mathrm{mL}$, que reduziu em $16 \%$ em relação. Por outro lado, no período de 24 horas, o composto $\mathbf{5 b}$ causou diminuição significativa da liberação de $\mathrm{PGE}_{2}$, induzida pelo LPS, em 40,55\% e 27,13\% nas concentrações de $1 \mu \mathrm{g} / \mathrm{mL}$ e $2 \mu \mathrm{g} / \mathrm{mL}$, respectivamente. 


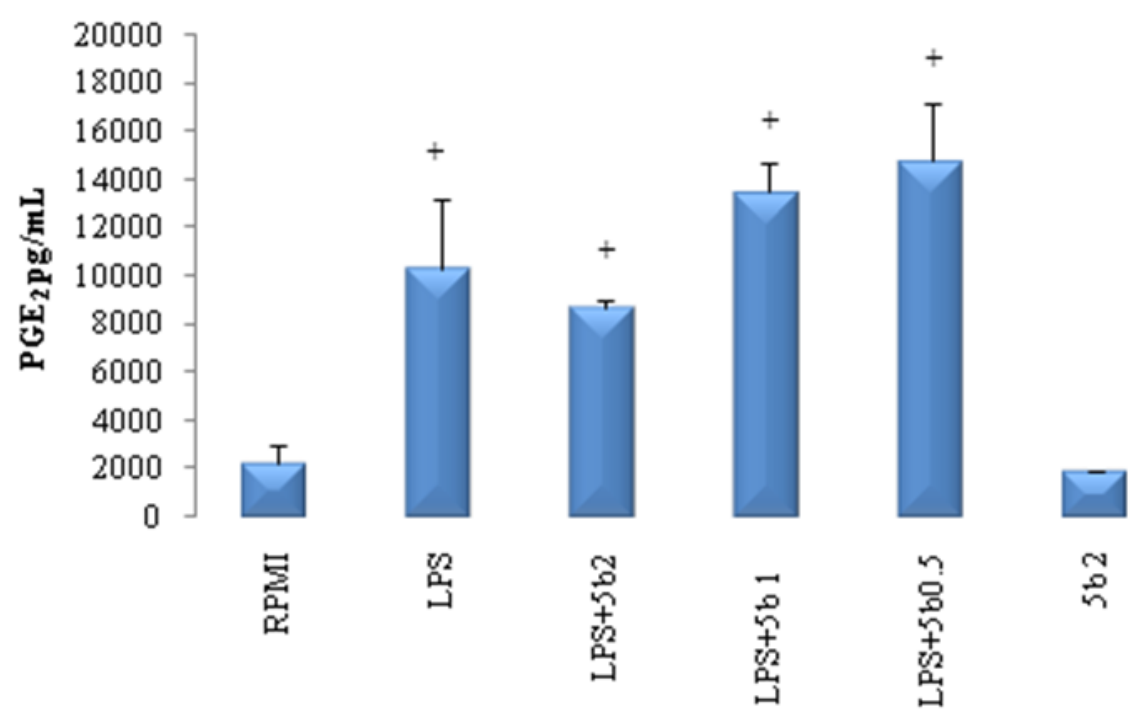

A

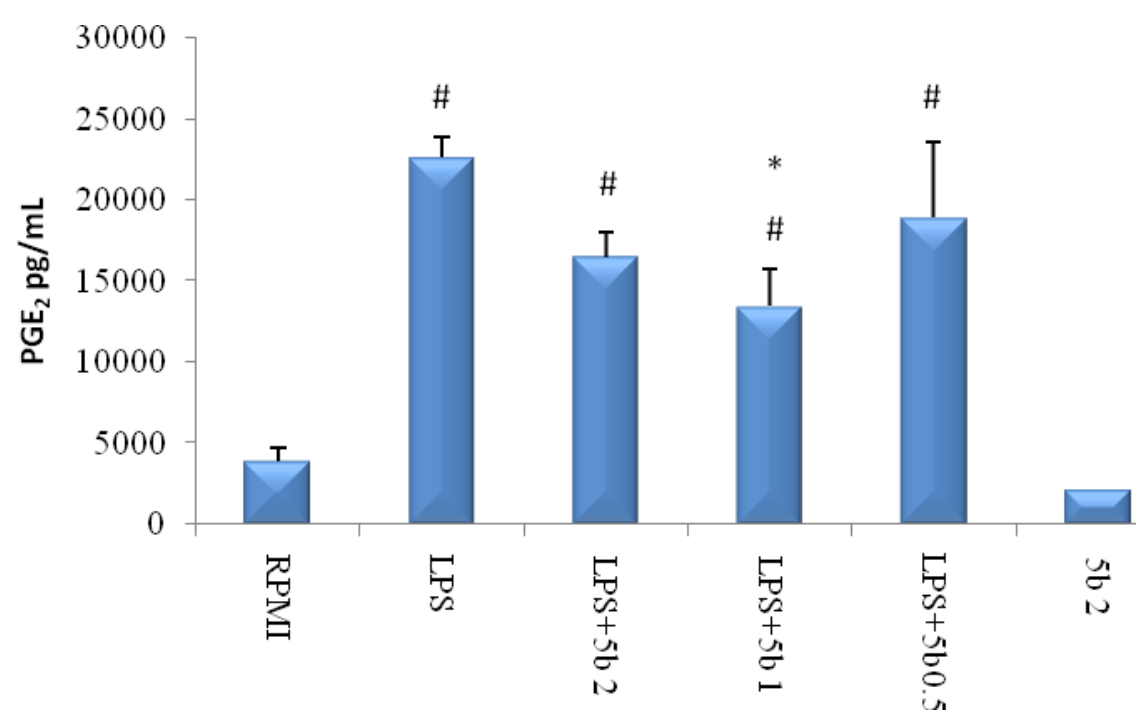

B

Gráfico 4: Efeito do composto 5b na determinação da concentração de PGE $_{2}$ induzida por LPS em macrófagos residentes em cultura nos períodos de 8 horas (A) e 24 horas (B). Macrófagos peritoneais isolados ( $2 \times 10^{5}$ células/ $1 \mathrm{~mL}$ RPMI) foram incubados, em suspensão, com RPMI (controle) ou LPS ou LPS + 5b nas

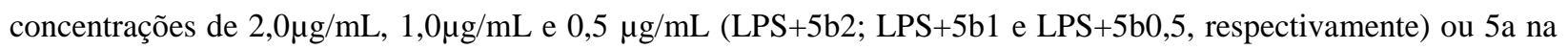
ausência de LPS (5b2), nos períodos de 8 (A) e 24 (B) horas, a $37^{\circ} \mathrm{C}$ e $5 \%$ de $\mathrm{CO}_{2}$. As concentrações de $\mathrm{PGE}_{2}$ foram avaliadas por EIA, nos sobrenadantes. Os dados representam a média \pm E.P.M de 4-5 animais. $+p<0,05$ em relação ao controle em 8 horas e \#p $<0,05$ em relação ao controle e * $\mathrm{p}<0,05$ em relação ao LPS (ANOVA). 


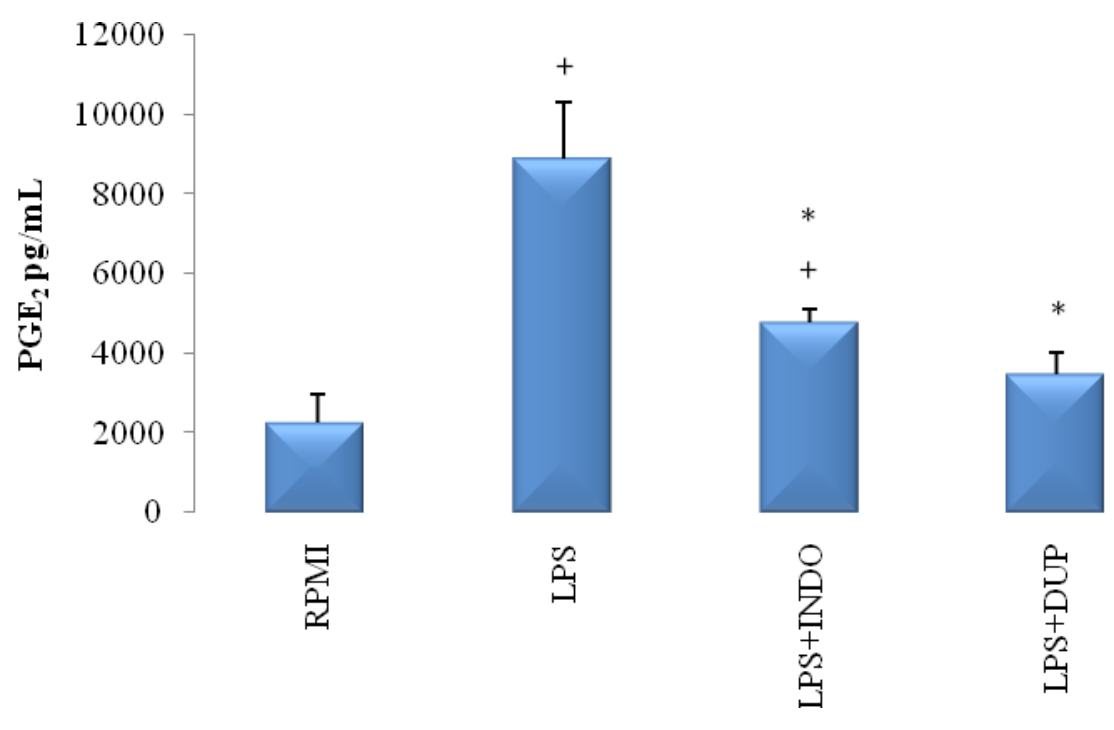

A
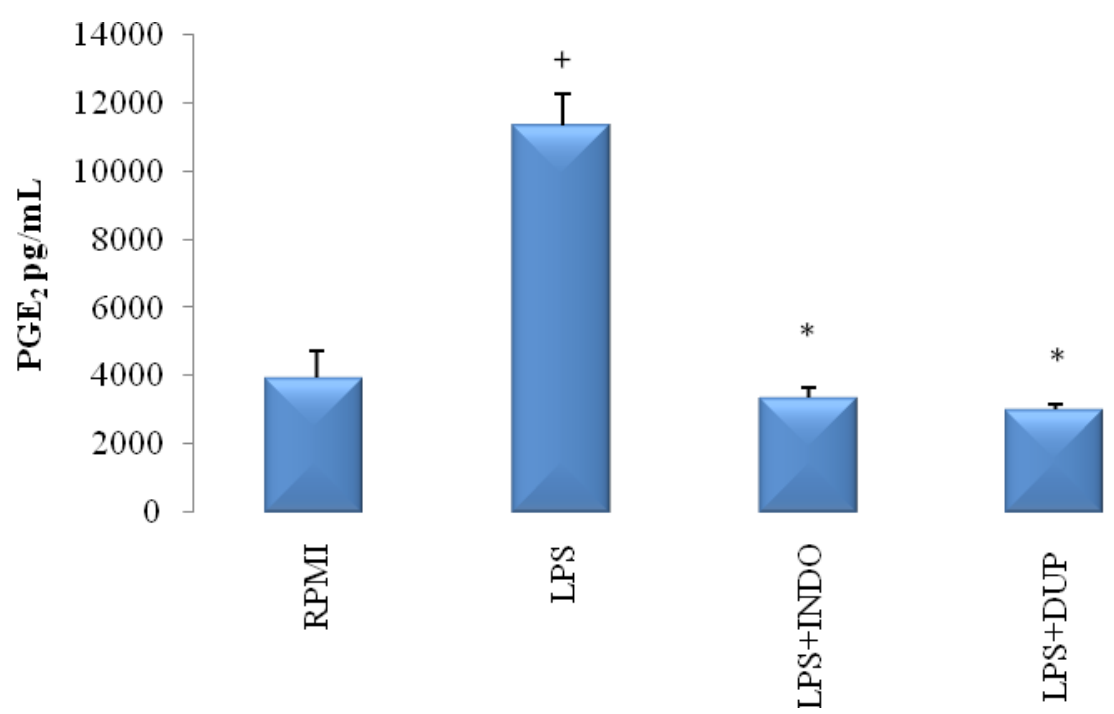

B

Gráfico 5: Efeito do composto 5b na determinação da concentração de PGE $_{2}$ induzida por LPS em macrófagos residentes em cultura nos períodos de 8 horas (A) e 24 horas (B). Macrófagos peritoneais isolados ( $2 \times 10^{5}$ células/ 1mL RPMI) foram incubados, em suspensão, com RPMI (controle) ou LPS ou LPS + indometacina

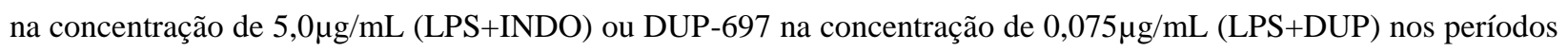
de 8 e 24 horas respectivamente, a $37^{\circ} \mathrm{C}$ e $5 \%$ de $\mathrm{CO}_{2}$. As concentrações de $\mathrm{PGE}_{2}$ foram avaliadas por EIA, nos sobrenadantes. Os dados representam a média \pm E.P.M de 4-5 animais. Para INDO $+p<0,05$ em relação ao controle e ${ }^{*} \mathrm{p}<0,05$ em relação ao LPS em 8 horas e $+\mathrm{p}<0,05$ em relação ao controle e * $\mathrm{p}<0,05$ em relação ao LPS em 24 horas. Para o DUP-697 +p<0,05 em relação ao controle e *p<0,05 em relação ao LPS em 8 horas e $+p<0,05$ em relação ao controle e * $\mathrm{p}<0,05$ em relação ao LPS em 24 horas (ANOVA). 
O gráfico 5 mostra que em macrófagos incubados apenas com RPMI (controle), a produção média de $\mathrm{PGE}_{2}$ foi de $2274 \pm 684 \mathrm{pg} / \mathrm{mL}$ e $3937 \pm 806 \mathrm{pg} / \mathrm{mL}$ nos períodos de 8 e 24 horas, respectivamente. Os níveis de $\mathrm{PGE}_{2}$ foram significativamente aumentados após a incubação das células com LPS $(8885 \pm 1413 \mathrm{pg} / \mathrm{mL}$ e $11332 \pm 955 \mathrm{pg} / \mathrm{mL}, 8$ e 24 horas, respectivamente), quando comparados aos grupos controles (RPMI). A células incubadas com 5,0 $\mu \mathrm{g} / \mathrm{mL}$ de indometacina (INDO) apresentaram redução na liberação de $\mathrm{PGE}_{2}$ em 46,22\% (média de $4777 \pm 342 \mathrm{pg} / \mathrm{mL}$ ) e $70,44 \%$ (média de $3350 \pm 321 \mathrm{pg} / \mathrm{mL}$ ) em 8 e 24 horas respectivamente, em relação ao LPS.

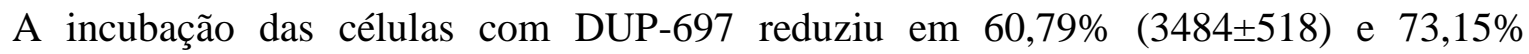

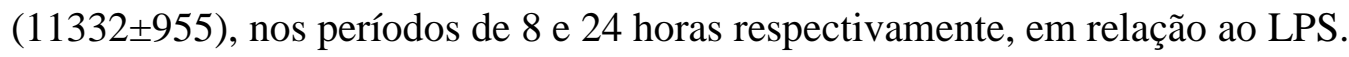

Segundo BEZUGLA e colaboradores (2006), a maior expressão de COX-2 é dada em períodos superiores há 24 horas, assim como a produção de $\mathrm{PGE}_{2}$. Esse fato foi observado com o fármaco DUP-697 (gráfico 5), que inibiu a produção de $\mathrm{PGE}_{2} \mathrm{em}$ maior proporção no período de 24horas $(73,15 \%)$ do que em 8 horas $(60,79 \%)$. Nesse contexto e sabendo-se que 5a e 5b promoveram maior inibição da liberação de $\mathrm{PGE}_{2}$ no período de 24 horas, levantou-se a hipótese de que esses compostos testados podem apresentar maior capacidade de inibição na COX-2 à COX-1, tornando-os dessa forma compostos promissores para candidatos a novos fármacos potencialmente antiinflamatórios.

4.2.2. Efeito dos derivados pirróis sobre a atividade antiinflamatória utilizando o método de Edema de pata induzido por carragenina (WINTER, 1962).

O composto 1-benzil-2-metil-5-fenil-1H-pirrol-3-carboxilato de etila (5a), denominado $\boldsymbol{p}$ benzil nesse ensaio, demonstrou efeito antiedematogênico sutil, conforme apresentado no gráfico 6, no ensaio realizado inicialmente no ICB. Somente na sexta hora observou-se pequena diferença da atividade antiedematogênica do composto $\mathbf{5 a}$ (p-benzil), em relação à carragenina e à indometacina, embora não estatisticamente significante.

Houve dificuldade na solubilização do composto, com DMSO : CMC (0,5\%). Essa concentração foi alterada posteriormente, como relatada mais adiante. 


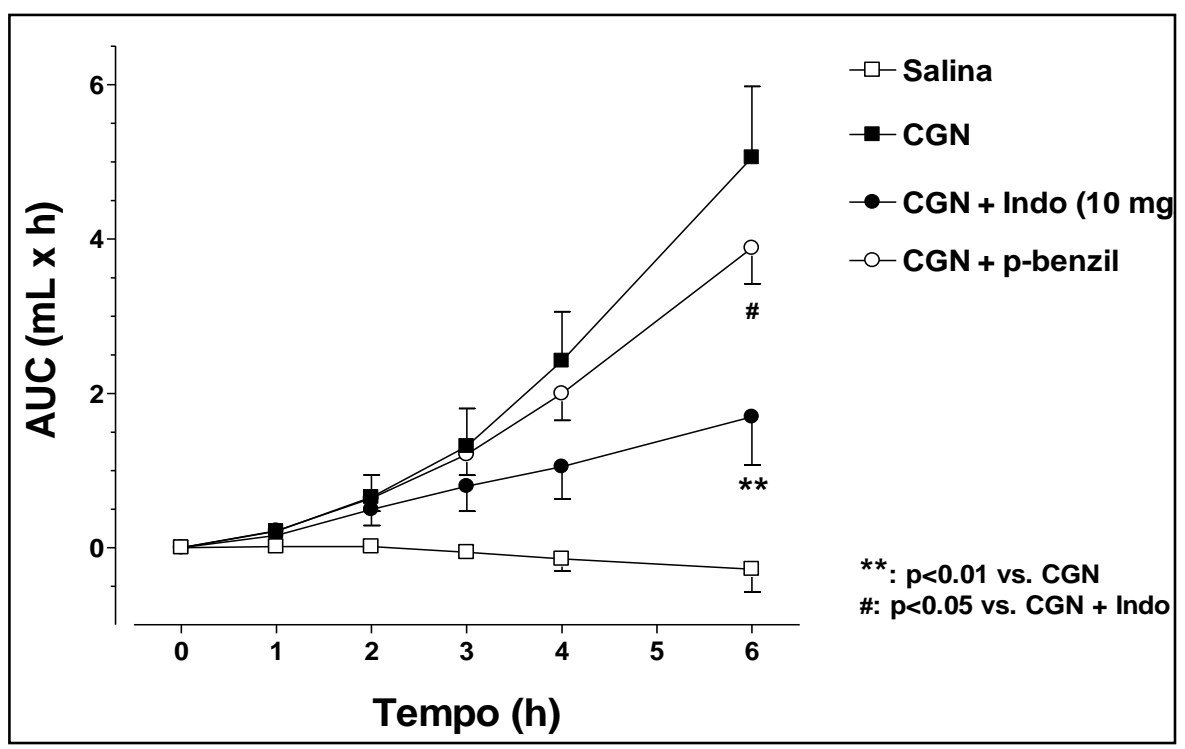

Gráfico 6: Efeito do derivado 1-benzil-2-metil-5-fenil-1H-pirrol-3-carboxilato de etila (5a-p-benzil) na dose de $10 \mathrm{mg} / \mathrm{Kg}$ I.P. sobre edema de pata induzido por carragenina. 
CAPÍTULO 5

CONCLUSÕES

$\overline{=}$




\subsection{CONCLUSÕES}

- Os $\beta$-enaminoésteres são intermediários importantes na síntese de pirróis. A nova metodologia desenvolvida em nosso laboratório apresentou ótimos resultados, visto que os produtos intermediários obtidos (3a, 3b, $\mathbf{4 a}, \mathbf{4 b}$ e $\mathbf{4 c}$ ) foram próximo ao quantitativo, em pouco tempo de reação. Exceto o composto $\mathbf{4 b}$, foi obtido em menor rendimento e maior período de tempo, visto que a anilina é menos reativa que as outras aminas utilizadas (BRANDT et al., 2004).

- Os produtos 5a e 5b foram obtidos via adaptação da metodologia de Hantzsch (ROOMI e MAcDONALD, 1970) em rendimentos satisfatórios. Entretanto a proporção da quantidade de $\beta$-enaminoéster (3a e 3b) e bromoacetofenona utilizado foi 2:1 a fim de consumir o $\mathrm{HBr}$ liberado e conseqüentemente aumentar o rendimento dos produtos. Vale ressaltar que o fato de necessitar de maior quantidade de $\beta$-enaminoéster (3a e 3b) na síntese não foi considerado desvantagem, uma vez que estes intermediários são facilmente obtidos a partir do acetoacetato de etila não alquilado (1).

- A obtenção dos produtos eliminados 7a, 7b e 7c, obtidos via metodologia desenvolvida em nosso Laboratório finalizou os estudos da reação de eliminação do iodo, atingindo excelentes resultados BRANDT e colaboradores (artigo enviado para publicação). Estes produtos, por sua vez, foram obtidos por meio de procedimento experimental significativamente simples e alcançaram rendimentos superiores a $80 \%$. Não foi necessário utilizar excesso de $\beta$-enaminoéster (4a, 3b e 4c), fato bastante vantajoso, uma vez que estes são obtidos a partir do intermediário alquilado do acetoacetato de etila (2). Outra vantagem da metodologia de ciclofuncionalizaçãoeliminação é o fato dos intermediários de síntese não necessitarem ser isolados e purificados.

- A avaliação "in vitro" do efeito dos produtos $\mathbf{5 a}$ e $\mathbf{5 b}$ sobre a atividade metabólica de macrófagos isolados em cultura forneceu dados importantes sobre as concentrações das substâncias a serem testadas na determinação da concentração de $\mathrm{PGE}_{2}$ por ensaio imunoenzimático específico (EIA). Os resultados foram promissores, uma vez que ambos compostos testados reduziram a produção de $\mathrm{PGE}_{2}$, mais especificamente no período de 24 
horas. Nesse contexto, levantou-se a hipótese de esses derivados apresentam mais especificidade pela COX-2 à COX-1, de acordo com trabalho realizado por BEZUGLA e colaboradores (2006). Como perspectiva, pretende-se realizar os ensaios com os demais derivados pirrólicos sintetizados, assim como utilizar doses idênticas dos produtos e dos respectivos controles indometacina e DUP-697, a fim de compará-los em relação à potência;.

- O ensaio realizado anteriormente no ICB manteve as perspectivas de efeito antiedematogênico dos produtos sintetizados, de acordo com gráfico 6 Pretende-se dar continuidade aos ensaios "in vivo", utilizando condições adequadas, visando padronizar o método de avaliação e conseqüentemente obter resultados satisfatórios. Pretende-se ainda modificar a via de administração dos compostos nos ensaios biológicos "in vivo” para via oral, permitindo assim avaliar o perfil farmacocinético dos mesmos.

- Como perspectiva pretende-se ainda avaliar a atividade antiinflamatória dos intermediários $\beta$-enaminoésteres, de acordo com dados presentes na literatura (UDDIN et al., 2004; ZHAO et al., 2005).

- Os estudos de QSAR estão sendo conduzidos. Alguns descritores foram previamente calculados considerando a estrutura otimizada com método Hartree-Fock 631G* (dados não demonstrados). 
CAPÍTULO 6 


\subsection{REFERÊNCIAS BIBLIOGRÁFICAS}

ALLINGER, N. L. Conformational analysis 130: MM2. A hydrocarbon force field utilizing $\mathrm{V}_{1}$ e $\mathrm{V}_{2}$ torcional terms. $J$. Am. Chem. Soc., v. 99, p. 8127-8134, 1977.

ANTONIOLETTI, R., BONADIES, F., ORELli, L. R., SCETTRI, A. Selective C-alkylation of 1,3-dicarbonyl compounds. Gazzeta Chimica Italiana, v. 122, p. 237-238, 1992.

ANVISA. Agência Nacional de Vigilância Sanitária. Disponível em: http://www.anvisa.gov.br. Acesso em: 15 de julho de 2008.

ATTANASI, O. A., FAVI, G., FILIPPONE, P., GIORGI, G., MANTELlini, F., MOSCATELli, G., SPINELLI, D. Flexible Protocol for the Chemo- and Regioselective Building of Pyrroles and Pyrazoles by Reactions of Danishefsky`s Dienes with 1,2-Diaza-1,3-butadienes. Organic Letters, v. 10, n. 10, p. 1983-1986, 2008.

BALDWIN, J. E. Rules for ring closure. J. Chem. Soc., Chem. Comm., v. 18, p. 734-736, 1976.

BARALDI, P. G., SIMONI, D., MANFREDINI, S. An improved preparation of enaminones from 1,3-diketones and ammonium acetate or amine acetates. Synth. Commun., p. 902-903, 1983.

BARREIRO, E. J., FRAGA, C. A. M. Química Medicinal. As bases moleculares da ação dos fármacos. 1ed. Porto Alegre: Artmed, 2001.

BARReiro, E. J., FRAGA, C. A. M., MiRAndA, A. L. P., RODRIGUES, C. R. A química medicinal de Nacilidrazonas: novos compostos-protótipos de fármacos analgésicos, antiinflamatórios e anti-trombóticos. Química Nova, v. 25, n. 1, p. 129-148, 2002.

BEZUGLA, Y., KOLADA, A., KAMIONKA, S., BERNARD, B., SCHEIBE, R., DIETER, P. COX-1 and COX-2 contribute differentially to the LPS-induced release of $\mathrm{PGE}_{2}$ and $\mathrm{TXA}_{2}$ in liver macrophages. Prostaglandins \& other Lipid mediators, v. 79, p. 93-100, 2006.

BHATTACHARYYA, D. K., LECOMTE, M., CAROLINE, J. R., GARAVITO, R. M., SMITH, W. L. Involvement of arginine 120, glutamate 524, and tyrosine 355 in the binding of arachidonate and 2-phenylpropionic acid inhibitors to the cyclooxigenase active site of ovine prostaglandin endoperoxide $H$-synthase-1. The Journal of Biological Chemistry, USA, v. 271, n. 4, p. 2179-2184, 1996.

Biava, M., PORRETTA, G. C., CAPPElli, A., VOMERO, S., MANETTI, F., BOtTA, M., SAUTEBin, L., ROSSI, A., MAKOVEC, F., ANZINI, M. 1,5-Diarylpyrrole-3-acetic acids and esters as novel classes of potent and highly selective cyclooxigenase-2 inhibitors. J. Med. Chem. v. 48, p. 3428-3432, 2005.

BIAVA. M., PORRETTA, G. C., POCE, G., SUPINO, S., FORLI, S., ROVINI, M., CAPPELli, A., MANETTI, F., Botta, M., SAutebin, L., ROSSi, A., Pergola, C., GHElardini, C., Vivoli, E., MaKoveC, S., ANZELlOTTI, P., PATRIGNANI, P., ANZINI, M. Cyclooxygenase-2 Inhibitors. 1,5-Diarylpyrrol-3-acetic Esters with Enhanced Inhibitory Activity toward Cyclooxygenase-2 and Improved Cyclooxygenase-2/Cyclooxygenase-1 Selectivity. J. Med. Chem., v. 50, p. 5403-5411, 2007.

BIAVA, M., PORRETTA, G. C., POCE, G., SUPINO, S., MANETTI, F., FORLI, S., BOTTA, M., SAUTEBIN, L., ROSSI, A., PERGOLA, C., GHELARDINI, C., NORCINI, M., MAKOVEC, S., GIORDANI, A., ANZELLOTTI, P., CIRILli, R., FERRETTI, R., GALlinElla, B., La TORRE, F., ANZINI, M., PARIGNANI, P. Synthesis, in 
vitro biological evaluation and molecular docking simulations of chiral alcohol and ether derivatives of the 1,5diarylpyrrole scaffold as novel anti-inflammatory and analgesic agents. Bioorganic \& Medicinal Chemistry, v. 16, . 8072-8081, 2008.

BlaCk, W. C., BAYly, C., Belley, M., Chan, C. C., Charleson, S., DENiS, D., GAUThIER, J. Y., GORDON, R., GUAY, D., KARGMAN, S., LAU, C. K., LEBlANC, Y., MANCINI, J., OUELlET, M., PERCIVAL, D., ROY, P., SKOREY, K., TAGARI, P., VICKERS, P., WONG, E., XU, L. From indomethacin to a selective COX-2 inhibitor: development of indolalkanoic acids as potent and selective cyclooxygenase-2 inhibitors. Bioorg. Med. Chem. Letters, v. 6, p. 725-730, 1996.

BODOR, N., GABANYI, Z., WONG, C. A new method for the estimation of partition-coefficient. J. Am. Chem. Soc., v. 111, p. 3783, 1989.

BOMBARDiER, C., LAINE, L., REICIN, A., SHAPIRO, D., BURGOS-VARGAS, R., DAVIS, D., DAY, R., FERRAZ, M. B., HAWKEY, C. J., HOCHBERG, M. C., KVIEN, T. K., SCHNITZER, T. J. Comparison of upper gastrointestinal toxicity of rofecoxib and naproxen in patients with rheumatoid arthrits. The New England Journal of Medicine, v. 343, n. 21, p. 1520-1528, 2000.

BORNE, R. F., LEVI, M., WILSON, N. Nonsteroid Anti-inflammatory Drugs. In: FOYE, W. O., LEMKE, T. L. Principles of Medicinal Chemistry. USA: Lippincott Willians \& Wilkins, 2008. 6ed., p. 954-1003.

BOTTING, R. COX-1 and COX-3 inhibitors. Thrombosis Research, v. 110, p. 269-272, 2003.

BRAIBANTE, M. E. F., BRAIBANTE, H. T. S., SALVATORE, S. J. S. A. Síntese de enamino compostos utilizando suportes sólidos. Química Nova, São Paulo, v. 13, p.67-68, 1990.

BRANDT, C. A., COMASSETO, J. V., FERRAZ, H. M. C. Ciclofuncionalizações envolvendo reagentes de enxofre, selênio e telúrio. Química Nova, v. 14, p. 165-174, 1991.

BRANDT, C. A., DA SILVA; A. C. M. P., PANCOTE, C. G., BRITO, C. L., DA SILVEIRA, M. A. B. Efficient synthetic method of beta-enamino esters using ultrasound. Synthesis, n.10, p. 1557, 2004.

Bratton, L. D., AUERBACh, B., ChOI, C., Dillon, L., HANSElman, J. C., LARSEN, S. D., LU, G., OlSEN, K., PFEFFERKORN, J. A., ROBERTSON, A., SEKERKE, C., TRIVEDI, B. K., UnANGST, P. C. Discovery of Pyrrole-Based Hepatoselective Ligands as Potent Inhibitors of HMG-CoA reductase. Bioorganic \& Medicinal Chemistry, v. 15, p. 5576-5589, 2007.

BURKE, A., SMYTH, E., FITZGERALD, G. A. Analgésicos-Antipiréticos; Farmacoterapia da Gota. In: BRUTON, L. L., LAZO, J. S., PARKER, K. L. Goodman \& Gilman: As Bases Farmacológicas da Terapêutica. Rio de Janeiro: McGraw-Hill, 2006. 11 ed. Cap. 26, p. 601-638.

BUSCARIOLO, I. A. Analgésicos, antipiréticos e antiinflamatórios. In: DE LUCIA, R., OLIVEIRA-FILHO, R. M. Farmacologia integrada. 2ed. Rio de janeiro: Revinter Ltda, 2004, p. 334-341.

CARSON, J. R., McKINSTRY, D. N., WONG, S. 5-benzoyl-1-methylpyrrole-2-acetic acids as antiinflammatory agents. Journal of Medicinal Chemistry, v. 14, n. 7, p. 646-647, 1971.

CARVALHO, I., PUPO, M. T., BORGES, A. D. L., BERNARDES, L. S. C. Introdução a modelagem molecular de fármacos no curso experimental de química farmacêutica. Quim. Nova, v. 26, n. 3, p. 428-438, 2003. 
CATCH, J. R., ELLIOTT, D. H. HEY, JONES, R. H. Halogeneted ketones. Part I. The bromination of acetone and methyl ethyl ketone. Journal of Chemical Society, p. 272-275, 1948.

ChADRASEKHARAN, N. V., DAI, H., ROOS, K. L. T., EVANSON, N. K., TOMSIK, J., EltON, T. S., SIMMONS, D. L. Cox-3, a cyclooxygenase-1 variant inhibited by acetaminophen and other analgesic / antipyretic drugs: cloning, structure, and expression. Proceedings of the National academy of sciences of the United States of America, v. 99, n. 21, p. 13926-13931, 2002.

CHANG, H. W., JAHNG, Y. Selective cyclooxygenase-2 inhibitors as anti-inflammatory agents. J. Med. Chem., v. 8, p. 48-79, 1998.

CLIVE, D. L. J., CHITTATTU, G., CURTIS, N., KIEL, W. A., WONG, C. K. Cyclofuntionalisation of ortho-alkenyl phenols: a new method for introducing the benzeneseleno-group. J. Chem. Soc., Chem. Commun., p. 725-727, 1977.

CRUCIANI, G., CAROSATI, E., CLEMENTI, S. Three-dimensional quantitative structure-property relationships. In: WERMUTH, C. G. The Practice of Medicinal Chemistry. 2ed. San Diego: Academic Press, 2003, p.405-516.

CURINI, M., MONTANARI, F., ROSATI, O., LIOY, E., MARGARITA, R. Layred zirconium phosphate and phosphonate as heterogeneous catalyst in the preparation of pyrroles. Tetrahedron Letters, v. 44, p. 3923-3925, 2003.

DA SILVA, F. M., LACERDA, P. S. B., JUNIOR, J. J. Desenvolvimento Sustentável e Química Verde. Química Nova, v. 28, n. 1, p. 103-110, 2005.

DAVIS, F. A., BOWEN, K. A., XU, H., VELVADAPU, V. Synthesis of Polysubstituted Pyrroles from Sulfinimines (N-sulfinil imines). Tetrahedron, v. 64, p. 4174-4182, 2008.

DEMIR, A. S., AKHMEDOV, I. M., SESENOGLU, O. Synthesis of 1,2,3,5-tetrasubstituted pyrrole derivatives from 2-(2-bromoallyl)-1,3-dicarbonyl compounds. Tetrahedron, v. 58, p. 9793-9799, 2002.

DEMIR, A.S., EMRULLAHOGLU, M. An effective new synthesis of 2-aminopyrrole-4-carboxylates. Tetrahedron, v. 61, p. 10482-10489, 2005.

DEWAR, M. J. S. E., ZOEBISCH, G., HEALY, E. F., STEWART, J. J. P. AM1: a new general purpose quantum mechanical molecular model. J. Am. Chem. Soc., v. 107, p. 3902-3909, 1985.

E-SCIENCE. Laboratório de Leishmaniose. Macrófagos e células dendríticas. Disponível em: WWW.escience.unincamp.br/lableish/informativos/novidades_completo.php?id_novidade=3.

ELSAS, P. X., QUETO, T., MENDONÇA-SALES, S. C., ELSAS, M. G. I., KANAOKA, Y., LAM, B. K. Cysteinil Leukotrienes Mediate the Enhancing Effects of Indomethacin and Aspirin on Eosinophil Procuction in Murine Bone Marrow Cultures. British Journal of Pharmacology, v. 153, p. 528-535, 2008.

ESCOLA DE QUÍMICA VERDE. Disponível em: http://quimicaverde.iq.usp.br. Acesso em: 16 de junho de 2008.

ETtOrRe, A., BIAVA, M., FIORAVANTI, R., PORRETA, G. C. The antifungal agent 1-[2-(4-cholorobenzylamino)benzyl]1-H-imidazole. Acta Crystallogr. Sect. C. Cryst. Struct. Commun., v. 53, p. 761, 1997.

FAN, H., PENG, J., HAMANN, M. T., HU, J. F. Lamellarins and Related Pyrrole-Derived Alkaloids from Marine Organisms. Chem. Rev., v. 108, p. 264-287, 2008. 
FERREIRA, D. T. Sínteses e semi-sínteses de fármacos. In: ANDREI, C. C., FERREIRA, D. T., FACCIONE, M., FARIA, T. J. Da química medicinal à química combinatória e modelagem molecular. 1 ed. São Paulo: Manole, 2003. Cap. 3, p.49-63.

FITZGERALD, G. A. Cox-2 and beyond: approaches to prostaglandin inhibition in human disease. Nature rev. drug. discov., v. 2, p. 879-890, 2003.

GAUDIO, A. C., ZANDONADE, E. Proposição, validação e análise dos modelos que correlacionam estrutura química e atividade biológica. Química Nova, v. 24, n. 5, p. 658-671, 2001.

GAUSSIAN® 03W for Windows, version 6.0; Gaussian Inc.: Pittsburgh, PA, 1995-2003.

GEORGE, R. J., STURMOSKI, M. A., ANANT, S., HOUCHEN, C. W. EP4 Mediates PGE 2 Dependent Cell Survival Through the PI3 Kinase/AKT Pathway. Prostaglandins Other Lipid Mediat., v. 83, p. 112-120, 2007.

GERALD, G. A. F. Cox-2 and beyond: approaches to prostaglandin inhibition in human disease. Nature Reviews, v. 2 , p. 879-890, 2003.

GORDON, S. The macrophage: Past, present and future. European Journal of Immunology, v. 37, p. 9-17, 2007.

GREENHILL, J. V. The reactions with aldehydes of enaminones derived from dimedone. J. Chem. Soc. C, p. 2699, 1971.

GUAN, Y., ZHANG, Y., WU, J., QI, Z., YANG, G., DOU, D., GAO, Y., CHEN, L., ZHANG, X., DAVIS, L. S., WEI, M., FAN, X., CARMOSINO, M., HAO, C., IMIG, J. D., BREYER, R. M., BREYER, M. D. Anthihypertensive Effects of Selective Prostaglandin $\mathrm{E}_{2}$ Receptor Subtype 1 Targeting. The Journal of Clinical Investigation, v. 117, $\mathrm{n}$. 9, p. 2496-2505, 2007.

HALl, A., ATKINSON, S., BROWN, S. H., CHESSELl, I. P., CHOWDHURY, A., CLAYON, N. M., COLEMAN, T., GIBLIN, G. M. P., GLEAVE, R. J., HAMMOND, B., HEALY, M. P., JOHNSON, M. R., MICHEL, A. D., NAYLOR, A., NOVELLI, R., SPALDING, D. J., TANG, S. P. Structure-activity relationships of 1,5-biaryl pyrroles as $\mathrm{EP}_{1}$ receptor antagonists. Bioorganic \& Medicinal Chemistry, v. 16, p. 3657-3662, 2006.

HARRAK, Y., ROSELL, G., DAIDONE, G., PLESCIA, S., SCHILlACI, D., PUJOL, M. D. Synthesis and Biological Activity of New Anti-inflammatory Compounds Containing the 1,4-benzodioxine and/or Pyrrole System. Bioorganic \& Medicinal Chemistry, v. 15, p. 4876-4890, 2007.

HILÁRIO, M. O. E., TERRERI, M. T., LEN, C.A. Antiinflamatórios não-hormonais: inibidores da ciclooxigenase 2. Jornal de Pediatria. v. 82, n. 5 (Supl), 2006.

HYPERCHEM $^{\mathrm{TM}}$ release 7.5 for Windows; Hypercube Inc.: Gainesville, FL, 2002.

IVANOVA, N.A., VALIULLINA, Z.R., SHITIKOVA, O.V., MIFTAKHOV, M.S. Unexpected transformation of methyl 3,6-anhydro-2,7-dideoxy-7-iodo-4,5-O-isopropylidene-D-allo-heptonate in the dehydroiodination reaction with 1,8-diazabicyclo[5.4.0]undec-7-ene. Russian Chemical, v. 54, p. 2698-2701, 2005.

KAlgutKar, A. S., MARnetT, A. B., CREWS, B. C., REMMEL, R. P., MARNETT, L. J. Ester and amide derivatives of the nonsteroidal antiinflammatory drug, indomethacin, as selective cyclooxygenase-2 inhibitors. Journal of Medicinal Chemistry, v. 43, n. 15, p. 2860-2870, 2000.

KASCHERES, C. M. The chemistry of enaminones, diazocarbonyls and small rings: our contribution. J. Braz. Chem. Soc., v. 14, n. 6, p. 945-969, 2003. 
KHAN, K. N. M., PAULSON, S. K., LEFKOWITH, J., VERBURG, K., MAZIASZ, T. Fetal and neonatal renal aspects of cyclooxygenase (COX) inhibition - Reply. Kidney International, v. 62, n. 4, p. 1477-1478, 2002.

KIRMSE, W. 100 years of the Wolff rearrangement. Eur. J. Org. Chem., p. 2193-2256, 2002.

KNORR, L. Einwirkung des Diacetbernsteinsäureesters auf Ammoniak und primäre Aminbasen. Berichte der deutschen chemischen Gesellschaft, v.18, n. 1, p. 299-311, 1885.

KOROLKOVAS, A. Essentials of Medicinal Chemistry. 2ed. New York: Wiley, 1988.

KRÖTZ, F., SCHIELE, T. M., KLAUSS, V., SOHIN, H. Y. Selective COX-2 inhibitors and risk of myocardial infarction. Journal of vascular research, v.42, p.312-324, 2005.

KURUMBAIL, R. G., STEVEnS, A. M., GIERSE, J. K., McDONALD, J. J., STEGEMAN, R. A., PAK, J. Y., GILDEHAUS, D., MIYASHIRO, J. M., PENNING, T. D., SEIBERT, K., ISAKSON, P. C., STALLINGS, W. C. Structural basis for selective inhibition of cyclooxygenase-2 by anti-inflammatory agents. Nature, v. 384, p. 644648, 1996.

LAGES, A. S., ROMEIRO, N. C., FRAGA, C. A. L., BARREIRO, E. J. Inibidores seletivos de prostaglandina endoperóxido sintase-2 (PGHS-2): nova estratégia para o tratamento da inflamação. Química Nova, v. 21, n. 6, p. 761-770, 1998.

LEHUÉDÉ, J., FAUCONNEAU, B., BARRIER, L., OURAKOW, M., PIRIOU, A., VIERFOND, J. M. Synthesis and antioxidant activity of new tetraarylpyrroles. European Journal Medicinal Chemistry, v. 34, n. 11, p. 991-996, 1999.

LEVENE, P. A. Bromoacetone. Organic Syntheses Collective, v. 2, p. 88-89, 1943.

LINSTEAD, R. P., MAY, C. J. The quantitative estimation of mixtures of isomeric unsaturated compounds. Part II. Iodometric methods. J. Chem. Soc., p. 2565-2579, 1927.

LÚCIO, M., BRINGEZU, F., REIS, S., LIMA, J. L. F. C., BREZESINSKI, G. Binding of Nonsteroidal Antiinflammatory Drugs to DPPC: Structure and Thermodynamic Aspects. Langmuir, v. 24, p. 4132-4139, 2008.

MARCH, J., Advanced Organic Chemistry. 4ed. New York: Wiley-Interscience Publication, 1992, p. 896-898.

MARTIC, M., TATIC, I., MARKOVIC, S., KUJUNDZIC, N., KOSTRUN, S. Synthesis, biological activity and molecular modeling studies of novel COX-1 inhibitors. European Journal of Medicinal Chemistry, v. 39, p. 141151, 2004.

MARNETT, L. J., KALGUTKAR, A. S. Design of selective inhibitors of cyclooxygenase-2 as nonulcerogenic antiinflammatory agents. Current Opinion in Chemical Biology, USA, v. 2, p. 482-490, 1998.

MARTINES, M. A., U., DAVOLOS, M. R., JAFELICCI, M. J. O efeito do ultra-som em reações químicas. Química Nova, v. 23, n. 2, 2000.

MARVEL, C. S.; HAGER, F. D. Ethyl n-butylacetoacetate. Org. Synth. Coll., New York, v. 1, p. 248-250, 1941.

MASON, T. J. Sonochemistry and environment - providing a "green"link between chemistry, physics and engineering. Ultrasonics Sonochemistry, v. 14, p. 476-483, 2007.

MERCK index. 12.ed. Withehouse Station, 1996.

MILLER, K. J. J. Am. Chem. Soc., v. 112, p. 8533, 1990.

MINETTO, G., LUCA, F. R., MAURIZIO, T. Microwave - assisted Paal - Knorr reaction. A rapid approach to substituted pyrroles and furans. Organic Latters, v. 6, n. 3, p. 389-392, 2004. 
MOSMANN, T. Rapid colorimetric assay for cellular growth and survival: application to profiration and citotoxicity assays. J. Immunol. Meth. v. 65, p. 55-63, 1983.

NARASAKA, K., SOAI, K., MUKAYAMA, C. The New Michael Reaction. Chemistry Letters, p. 1223-1224, 1974.

ÖLGEN, S., NEBIOGLU, D. Synthesis and biological evaluation of N-substituted indole esters as inhibitors of cyclooxygenase-2 (COX-2). Il Farmaco, v. 57, p. 677-683, 2002.

PAAL, C. Synthese von Thiophen- und Pyrrolderivaten. Berichte der deutschen chemischen Gesellschaft, v. 18, n. 1, p.367-371, 1885.

PANCOTE, C.G. Síntese de pirróis. Protótipos de agentes antiinflamatórios, São Paulo. Tese de mestrado, Faculdade de Ciências Farmacêuticas - Universidade de São Paulo, 2004.

PERRIN D. D., ARMAREGO, W. L. F., PERRIN, D. R. Purification of laboratory chemicals. 2ed. Oxford: Pergamon Press, 1980.

PDB. Protein Data Bank. Crystal structure of arachidonic acid bound in the cyclooxygenase active site of Pghs-1. Disponível em: http://w.w.w.rcsb.org/pdb/. Acesso em: 26 novembro 2003.

PDB. Protein Data Bank. Crystal structure of arachidonic acid bound to the cyclooxygenase active site of Cox-2. Disponível em: http://w.w.w.rcsb.org/pdb/. Acesso em: 26 novembro 2003.

PFEFFERKORN, J. A., CHOI, C., SONG, Y., TRIVEDI, B. K., LARSEN, S. D., ASKEW, V., DILlON, L., HANSElmAN, J. C., LIN, Z., LU, G., ROBERTSON, A., SEKERKE, C., AUERBACH, B., PAVlOVSKY, A., HARRIS, M. S., BAINBRIDGE, G., CASPERS, N. Design and Synthesis of Novel, Conformationally Restricted HMG-CoA reductase Inhibitors. Bioorganic \& Medicinal Chemistry Letters, v. 17, p. 4531-4537, 2007.

PORTH, C. M. Inflammation, Tissue Repair and Fever. In:___. Essencials of Pathophysiology: concepts of altered health states. USA: Lippincott Willians \& Wilkins, 2007. 2ed., p. 269-292.

POTEMKIN, V., GRISHINA, M. Principles for 3D/4D QSAR classification of drugs. Drug discovery today, v. 13, n. 21-22, p. 952-959.

PRADO, A. G. S. Química verde, os desafios da química do novo milênio. Química Nova, v. 26, n. 5, p. 738-744, 2003.

TALAWAR, M. B., SIVABALAN, R., MUKUNDAN, T., MUTHURAJAN, H., SIKDER, A. K., GANDHE, B. R., SUBHANANDA RAO, A. Environmentally compatible next generation green energetic materials (GEMs). Journal of Hazardous Materials, v. 161, p. 589-607, 2009.

RAIMAN, M. V, PUKIN, A. V., TYVORSKII, V. I., DE KIMPE, N., KULINKOVICH, O. G. A convenient approach to the synthesis of 2-(2-aminoethyl) pyrroles and their heterocyclization into hydrogenated pyrrolopyridines and related pyrroloindolizines. Tetrahedron, v. 59, p. 5265-5272, 2003.

RAMSAY, R. G., CIZNADIJA, D., VANEVSKI, M., MANTAMADIOTIS, T. Transcriptional regulation of cyclooxygenase: Three pillars of control. International Journal of Immunopathology and Pharmacology, Austrália, v. 16, n.2: 59-67 suppl., 2003.

RANU, B. C., DEY, S. S. An efficient synthesis of pyrroles by a one-pot, three-component condensation of a carbonyl compound, an amine and a nitroalkene in a molten ammonium salt. Tetrahedron Letters, v. 44, p. 2865-2868, 2003. 
RECHSTEINER, B., TEXIERBOULLET, F., HAMELIN, J. Synthesis in dry coupled with microwave irradiation: application to the preparation of enaminoketones. Tetrahedron Letters, v. 34, n. 32, p. 5071-5074, 1993.

REDDY, D. S., RAJALE, T. V., SHIVAKUMAR, K., IQBAL, J. A mild and efficient method for the synthesis of vinylogous carbamates from alkyl azides. Tetrahedron Letters, v. 46, p. 979-982, 2005.

ROOMI, M. W., MAcDONALD, S. F. The Hantzsch pyrrole synthesis. Canadian Journal of Chemistry, v. 48, p. 1689, 1970.

SADICOFF, B. L., AMORIM, M. C. V., MATTOS, M. C. S. Uma demonstração simples e visual do efeito do aquecimento com microondas em reações de poliadição. Química Nova, v.23, n.4, p.557-559, 2000.

SALTER, E. A., WIERZBICKI, A., SPERL, G., THOMPSON, W. J. Molecular modeling study of COX-2 inhibition by diarylheterocycles and sulindac sulfide. Journal of Molecular Structure (Theochem), v. 549, p. 111-121, 2001.

SANCHEZ, I., PUJOL, M. D. A Convenient Synthesis of Pyrrolo [2,1-c] [1,4] benzoxazines. Tetrahedron, v. 55, p. 5593-5598, 1999.

SANT'ANNA, C. M. R. Glossário de termos usados no planejamento de fármacos (recomendações da IUPAC para 1997). Química Nova, v. 25, n. 3, p. 505-512, 2002).

SCHIMMER, B. P., PARKER, K. L. Adrenocorticotropic hormone; adrenocortical steroids and their synthetic analogs; inhibitors of the synthesis and actions of adrenocortical hormones. In: HARDMAN, J. G., LIMBIRD, L. E., GUILMAN, A. G. The pharmacoclogical basis of therapeutics. 10 ed. USA. McGraw-Hill Companies, 2001. Cap. 60, p. 1649-1678.

SCHWAB, J. M., SCHLUESENER, H. J., MEYERMANN, R., SERMAN, C. N. Cox-3 the enzyme and the concept: steps towards higly specialized pathways and precision therapeutics? Prostaglandins Leukotrienes and Essential Fatty Acids, Alemanha, v. 69, n. 5, p. 339-343, 2003.

SCWAB, J. M., SCHLUESENER, H. J., MEYERMANN, R., SERMAN, C. N. Cox-3 the enzyme and the concept: steps towards higly specialized pathways and precision therapeutics? Prostaglandins Leukotrienes and Essential Fatty Acids, Alemanha, v. 69, n. 5, p. 339-343, 2003.

SERHAN, C. N. CHIANG, N., DYKE, T. E. V. Resolving Inflammation: Dual Anti-inflammatory and Pro-resolution Lipid Mediators. Nature Reviews, v. 8, p. 349-361, 2008.

SHIN, S. S., BYUN, Y., LIM, K. M., CHOI, J. K., LEE, K, MOH, J. H., KIM, J. K., JEONG, Y. S., KIM, J. Y., CHOI, Y. H., KOH, H., PARK, Y., OH, Y. I., NOH, M., CHUNG, S. In vitro structure-activity relationship and in vivo studies for a novel class of cyclooxygenase-2 inhibitors: 5-aryl-2,2-dialkyl-4-phenyl-3(2H)furanone derivatives. $J$. Med. Chem., v. 47, p. 792-804, 2004.

SIMMONS, D. L. Variants of ciclooxygenase-1 and their roles in medicine. Thrombosis Research, USA, v. 110, p. 265-268, 2003.

SIMON, L. S. Role and regulation of cyclooxygenase-2 during inflammation. Am. J. Med., Massachusetts, v. 106, n. 5B, p. 37S-42S, 1999.

SMITH, S. E. Historical Survey of Definitions and Concepts of Inflamation. In: J. R. VANE; S. H. FERREIRA. Handbook of Experimental Pharmacology, v. 50 / I. New York: Springer-Velog Berlin Heidelberg, 1978. p. 6-12. 
SMITH, S. E. Historical Survey of Definitions and Concepts of Inflamation. In: J. R. VANE; S. H. FERREIRA. Handbook of Experimental Pharmacology, v. 50 / I. New York: Springer-Velog Berlin Heidelberg, 1978. p. 6-12.

SOMVANSHI, R. K., KUMAR, A., KANT, S., GUPTA, D., SINGH, S. B., DAS, U., SRINIVASAN, A., SINGH, T. P., DEY, S. Surface Plasmon Resonance Studies and Biochemical Evaluation of a Potent Peptide Inhibitor Against Cyclooxygenase-2 as an Anti-inflammatory Agent. Biochemical and Biophysical Research Communications, v. 361, p. 37-42, 2007.

SHU-JUNG HU, S., BRADSHAW, H. B., CHEN, JS-C, TAN, B., WALKER, J. M. Prostaglandin E 2 Glycerol Ester, an Endogenous COX-2 Metabolite of 2-arachidonoylglycerol, Induces Hyperalgesia and Modulates NFkB Activity. British Journal of Pharmacology, v. 153, p. 1538-1549, 2008.

SUSLICK, K. S. The chemical effects of ultrasound. Scientific American, v. 2, p. 80-86, 1989.

TANIURA, S., KAMITANI, H., WATANABE, T., ELING, T. E. Transcriptional regulation of cyclooxygenase-1 by histone deacetylase inhibitors in normal human astrocyte cells. J. Biol. Chem., Japão, v. 277, n. 19, p. 16823-16830, 2002.

TAVARES, L. C. QSAR: a abordagem de Hansch. Química Nova, v. 27, n. 4, p. 631-639, 2004.

TERFLOTH, L., GASTEIGER, J. Electronic screening: lead finding from database mining. In: WERMUTH, C. G. The Practice of Medicinal Chemistry. 2ed. San Diego: Academic Press, 2003, p.131-145.

TRAUTWEIN, A. W., SÜßMUTH, R. D., JUNG, G. Hantzsch pyrrole synthesis on solid support. Bioorganic \& Medicinal Chemistry Letters, v. 8, p. 2381-2384, 1998.

UDDIN, M. J., PRAVEEN, P. N., KNAUS, R., KNAUS, E.E. Design of triaryl olefins: a new class of potent and selective cyclooxigenase-2 (COX-2) inhibitors. Bioorganic \& Medicinal Chemistry Letters, v. 14, p. 1953-1956, 2004.

VALDUGA, C. J., BRAIBANTE, H. S., BRAIBANTE, E. F. Reactivity of $p$-phenyl substituted beta-enamino compounds using K-10/ultrasond. I Synthesis of pyrazoles and pyrazolinones. J. Heterocyclic Chem., v. 35, n. 1, p. 189-192, 1998.

VANE, J. R. Inhibition of prostaglandin synthesis as a mechanism of action for the aspirin-like drugs. Nat. New Biol., v.231, p. 232, 1971.

VANE, J. R., BAKHLE, Y. S. BOTTING, Y. M. Cyclooxygenase 1 and 2. Ann. Rev. Pharmacol. Toxicol., v. 38, p. 97 120, 1998.

VARMA, R. S., DAHIYA, R., KUMAR, S. Clay catalyzed of imines and enamines under solvent-free conditions using microwave irradiation. Tetrahedron Letters, v. 38, n. 12, p. 2039-2042, 1997.

VISWANADHAN, V.N., GHOSE, A. K., REVANKAR, G. N., ROBINS, R. K. J. Chem. Inf. Comput. Sci., v. 29,p. $163,1989$.

WEY, S. J., AUGUSTYNIAK, M. E., COCHRAN, E. D., ElLIS, J. L., FANG, X., GARVEY, D. S., JANERO, D. R., LETTS, L. G., MARTINO, A. M., MELIM, T. L., MURTY, M. G., RICHARDSON, S. K., SCHROEDER, J. D. SELIG, W. M., TROCHA, A. M., WEXLER, R. S., YOUNG, D. V., ZEMTSEVA, I. S., ZIFCAK, B. M. StructureBased Design, Synthesis, and Biological Evaluation of Indomethacin Derivatives as Cyclooxygenase-2 Inhibiting Nitric Oxide Donors. J. Med. Chem., v. 50, p. 6367-6382, 2007. 
WERMUTH, C. G. Designing prodrugs and bioprecursors. In: WERMUTH, C. G. The Practice of Medicinal Chemistry. 2ed. San Diego: Academic Press, 2003a, p.561-585.

WERMUTH, C. G. Molecular variations in homologous series: vinylogues and benzologues. In: WERMUTH, C. G. The Practice of Medicinal Chemistry. 2ed. San Diego: Academic Press, 2003b, p.175-188.

WERMUTH, C. G. Ring transformations. In: WERMUTH, C. G. The Practice of Medicinal Chemistry. 2ed. San Diego: Academic Press, 2003c, p.215-231.

WERMUTH, C. G. Strategies in the search for new leads compounds or original working hypothesis. In: WERMUTH, C. G. The Practice of Medicinal Chemistry. 2ed. San Diego: Academic Press, 2003d, p.69-89.

WINTER, C. A., RISLEY, E. A. NUSS, G. W. Carragenin-induced edema in hind paw of rat as an assay for antiinflammatory drugs. Proc. Soc. Exp. Biol. Med., v. 111, n. 3, p.544-547, 1962.

WOLFF, R.R., BASAVA, V., GIULIANO, R.M., BOYKO, W.J., SCHAUBLE. Iodosulfonation of alkenes with benzenesulfinic acid- $N$-iodosuccinimide - Facile preparation of $\alpha, \beta$-unsaturated sulfones. Can. J. Chem., v. 84, p. 667-675, 2006.

YAQUB, S., HENJUM, K., MAHIC, M., JANSEN, F. L., AANDAHL, E. M., BJORNBETH, B. A., TASKÉN, K. Regulatory T Cells in Colorectal Cancer Patients Suppress Anti-tumor Immune Activity in a COX-2 Dependent Manner. Cancer Immunol. Immunother., v. 57, p. 813-821, 2008.

YOUNG, D., MARTIN, T., VENKATAPATHY, R., HARTEN, P. Are the chemical structures in your QSAR correct? QSAR \& Combinatorial Science, v. 27, n. 11-12, p. 1337-1345, 2008.

ZHAO, Y., ZHAO, J., ZHOU, Y., LEI, Z., LI, L., ZHANG, H. Efficient synthesis of $\beta$-amino- $\alpha, \beta$-unsaturated carbonyl compounds. New J. Chem., v. 29, p. 769-772, 2005.

ZHANG, Z.H., HU, J.H. Cobalt(II) chloride-mediated synthesis of $\beta$-enamino compounds under solvent-free conditions. J. Braz. Chem. Soc., v. 17, n. 7, p. 1447-1451, 2006.

ZHANG, Z.H., MA, Z.C., MO, L.P. Enamination of 1,3-dicarbonyl compounds catalyzed by tin tetrachloride. Indian Journal of Chemistry, v. 46B, p. 535-539, 2007.

ZHANG, Z.H., YIN, L., WANG, Y.M. A general and efficient method for the preparation of $\beta$-enamino ketones and esters catalyzed by indium tribromide. Adv. Synth. Catal., v. 348, p. 184-190, 2006. 